\title{
Hierarchical-Coassembly-Enabled 3D-Printing of Homogeneous and Heterogeneous Covalent Organic Frameworks
}

Mingshi Zhang, ${ }^{\dagger} \star{ }^{\star}$ Longyu Li $,{ }^{\dagger}, \star$ Qianming Lin, ${ }^{\dagger}$ Miao Tang, ${ }^{\dagger}$ Yuyang $\mathrm{Wu},{ }^{\S}$ and Chenfeng $\mathrm{Ke}^{\dagger, *}$

${ }^{\dagger}$ Department of Chemistry, Dartmouth College, 41 College Street, Hanover, NH 03755

$\S$ IMSERC, Northwestern University, 2145 Sheridan Road, Evanston, IL 60208

Email: Chenfeng.ke@dartmouth.edu

\section{Contents}

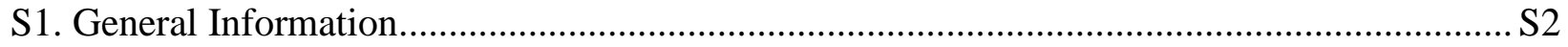

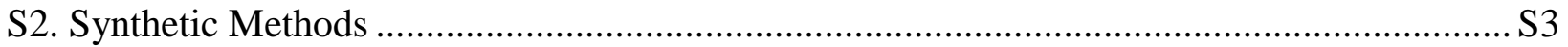

S3. Structural modeling and Powder X-ray diffraction analysis .............................................. S13

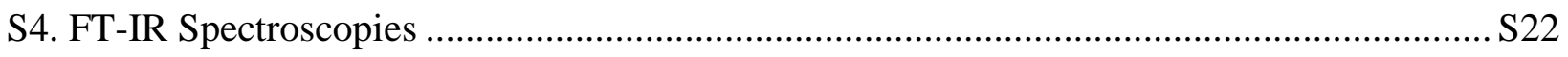

S5. Rheological Studies and 3D Printing ......................................................................... S25

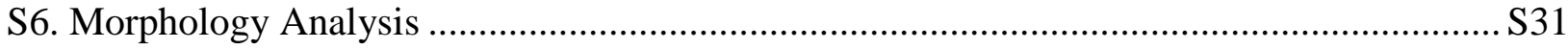

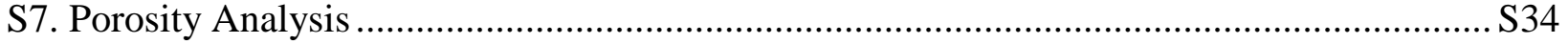

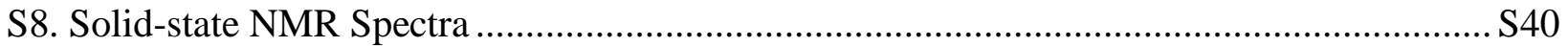

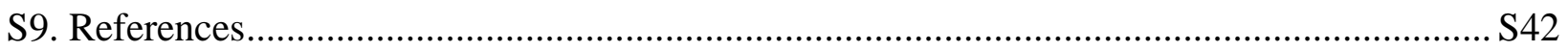




\section{S1. General Information}

All reagents and solvents were purchased from commercial companies including Fisher Scientific, Sigma-Aldrich, Acros Organics, Alfa Aesar, and VWR, and used without further purification, which include anhydrous phloroglucinol (99+\%), trifluoroacetic acid (99\%), anhydrous sodium sulfate (Certified ACS), aniline (99+\%), glacial acetic acid (Certified ACS), $p$-phenylenediamine $(99+\%)$, o-tolidine (98\%), terephthalaldehyde $(98+\%), p$-toluenesulfonic acid monohydrate (99\%), 1,4-dioxane (Certified ACS), acetone (Certified ACS), N,N-dimethylformamide (Certified ACS), tetrahydrofuran (Optima ${ }^{\mathrm{TM}}$ for HPLC), methylene chloride (Stabilized/Certified ACS), hydrochloric acid (32 - 35\%), absolute ethanol (200 proof), hexamethylenetetramine (ACS reagent, $\geq 99.0 \%$ ), Pluronic ${ }^{\circ} \mathrm{F}-127$ powder (BioReagent), and mesitylene (98\%).

NMR spectra were recorded on either a Bruker AVIII $500 \mathrm{MHz}$ spectrometer or a Bruker AVIII $600 \mathrm{MHz}$ Spectrometer and referenced to residual solvent peaks. The working frequencies are 500 or $600 \mathrm{MHz}$ for ${ }^{1} \mathrm{H}$ and 125 or $150 \mathrm{MHz}$ for ${ }^{13} \mathrm{C}$. Solid state ${ }^{13} \mathrm{C}$-cross-polarization at magic-angle spinning (CPMAS) nuclear magnetic resonance measurements were performed on a Varian $400 \mathrm{MHz}$ VNMRS system. Elemental analysis was performed by Intertek Pharmaceutical Services (Whitehouse, NJ). Fourier transform infrared (FT-IR) spectra were collected on a Jasco 6200. The IR spectra of the samples were collected with a universal Zn-Se ATR (attenuated total reflection) in the $600-4000 \mathrm{~cm}^{-1}$ region. Powder X-ray Diffraction (PXRD) data were collected on a Rigaku MiniFlex powder X-ray diffractometer $\left(\mathrm{Cu}, \mathrm{K}_{\alpha 1}=1.54059, \mathrm{~K}_{\alpha 2}=1.54439\right.$, from $2^{\circ}$ or $3^{\circ}$ to $35^{\circ}$, step size $=0.02^{\circ}$ ). UV-Vis spectra were recorded on a Shimadzu UV-1800 UV-Vis spectrophotometer. Gel permeation chromatography (GPC) was performed on a Waters Alliance GPC system using dimethyl sulfoxide (DMSO) containing $0.1 \% \mathrm{LiBr}$ as the eluent at $50{ }^{\circ} \mathrm{C}$. Scanning electron microscopy (SEM) data were acquired on an FEI dual beam Scios Low Vacuum SEM/FIB. Optical microscope white-light images are recorded by an AmScope SM-1TSW2 stereomicroscope. Supercritical $\mathrm{CO}_{2}$ activation was performed by a Samdri 795 Critical Point Dryer (inlet pressure ca. $1350 \mathrm{psi}$, temperature at $45^{\circ} \mathrm{C}$ ). The samples were activated in a porous capsule in the drying chamber and fulfilled by $\mathrm{CO}_{2}$. The $\mathrm{CO}_{2}$ was kept inputting for another 10 min to purge the chamber. Next, the chamber was sealed, and the temperature was raised to $40{ }^{\circ} \mathrm{C}$ (i.e., above the $\mathrm{CO}_{2}$ critical temperature) overnight to afford the activated samples. Low-pressure gas sorption measurements were performed on a Micrometritics FLEX 3.0 surface area analyzer. Samples were first activated at Samdri 795 Critical Point Dryer for $24 \mathrm{~h}$ and then degassed under 
dynamic vacuum for $24 \mathrm{~h}$ at $100{ }^{\circ} \mathrm{C}$ prior to each measurement. $\mathrm{N}_{2}$ sorption isotherms were measured using a liquid nitrogen bath $(77 \mathrm{~K})$.

\section{S2. Synthetic Methods}<smiles>O=Cc1c(O)c(CO)c(CO)c(O)c1C=O</smiles>

1,3,5-triformylphloroglucinol (Tp) was synthesized according to a previously reported method. ${ }^{\mathrm{S} 1}$ In an ice bath, phloroglucinol (anhydrous, $6.0 \mathrm{~g}, 47.6 \mathrm{mmol})$ and hexamethylenetetramine $(15.1 \mathrm{~g}$, $107.9 \mathrm{mmol})$ were added to a three-necked round bottom flask $(250 \mathrm{~mL})$ before trifluoroacetic acid $(90 \mathrm{~mL})$ was added. The reaction was degassed thoroughly by three freeze-pump-thaw cycles. Under a nitrogen atmosphere, the reaction was refluxed (oil bath temperature $100{ }^{\circ} \mathrm{C}$ ) vigorously for $2.5 \mathrm{~h}$. The reaction mixture gradually changed from a yellow suspension to a clear, dark red solution. A $3 \mathrm{M} \mathrm{HCl}(150 \mathrm{~mL})$ aqueous solution was added to the reaction dropwise using a constant pressure drop addition funnel. After complete addition of $\mathrm{HCl}$, the reaction mixture was refluxed (oil bath temperature $100^{\circ} \mathrm{C}$ ) for an additional hour. The reaction mixture was then allowed to cool to room temperature, insoluble residues were removed by filtration, and the filtrate was extracted with $\mathrm{CH}_{2} \mathrm{Cl}_{2}(100 \mathrm{~mL} \times 5)$. The organic phases were combined and dried over anhydrous $\mathrm{Na}_{2} \mathrm{SO}_{4}$. The desired product was obtained after removing the solvent under reduced pressure, followed by recrystallization of the crude product $(2.0 \mathrm{~g})$ in ethanol $(300 \mathrm{~mL})$ at $78{ }^{\circ} \mathrm{C}$, yielding $1.9 \mathrm{~g}$ of a white powder (yield $=19 \%)$. ${ }^{1} \mathrm{H} \mathrm{NMR}\left(500 \mathrm{MHz}, \mathrm{CDCl}_{3}\right) \delta=10.15(\mathrm{~s}, \mathrm{CHO})$, $14.12(\mathrm{~s}, \mathrm{OH})$.

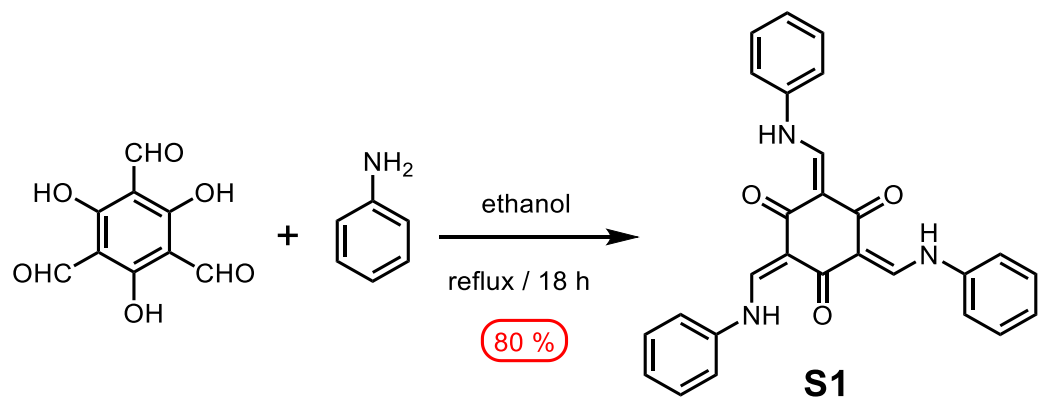

S1. Compound S1 was synthesized according to a previously reported method. ${ }^{\mathrm{S}}$ In a $100 \mathrm{~mL}$ round bottom flask, Tp (100 mg, $0.48 \mathrm{mmol}$ ) and aniline (443 mg, $4.8 \mathrm{mmol}$ ) were dissolved in 
ethanol (30 mL). The reaction was refluxed overnight and then cooled to room temperature. The orange precipitate was collected by filtration, washed with cold ethanol, and dried under the reduced pressure to afford the product as a yellow solid $\left(160 \mathrm{mg}, 0.38 \mathrm{mmol}, 80 \%\right.$ yield). ${ }^{1} \mathrm{H}$ NMR (500 MHz, $\left.\mathrm{CDCl}_{3}\right) \delta=13.0-13.4(\mathrm{~m}, N H, 3 \mathrm{H}), 8.94-8.69$ (m, HC-N, 3H), 7.43 (m, Ph, $6 \mathrm{H}), 7.32(\mathrm{~m}, P h, 6 \mathrm{H}), 7.22(\mathrm{~m}, P h, 3 \mathrm{H})$.

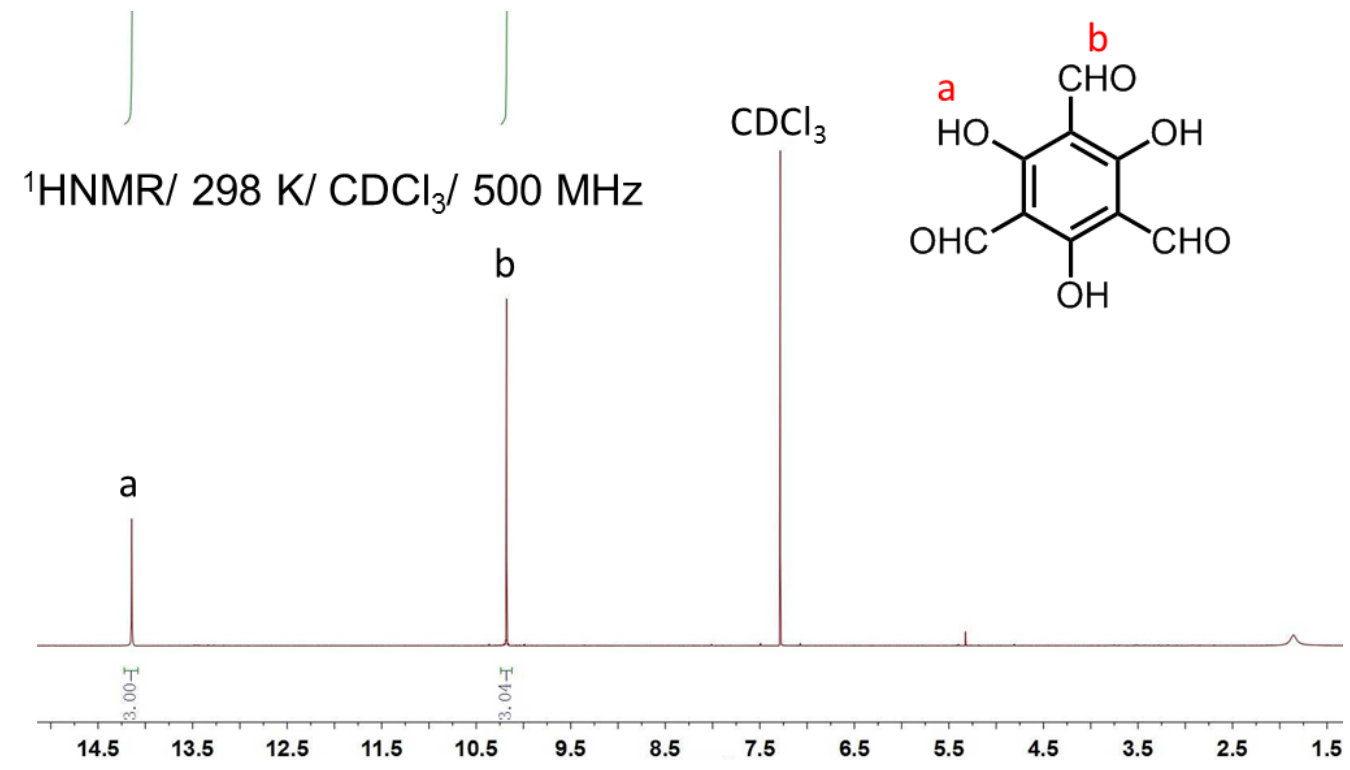

Figure S1. ${ }^{1} \mathrm{H}$ NMR spectrum $\left(500 \mathrm{MHz}, \mathrm{CDCl}_{3}\right)$ of $\mathbf{T p}$ at $298 \mathrm{~K}$

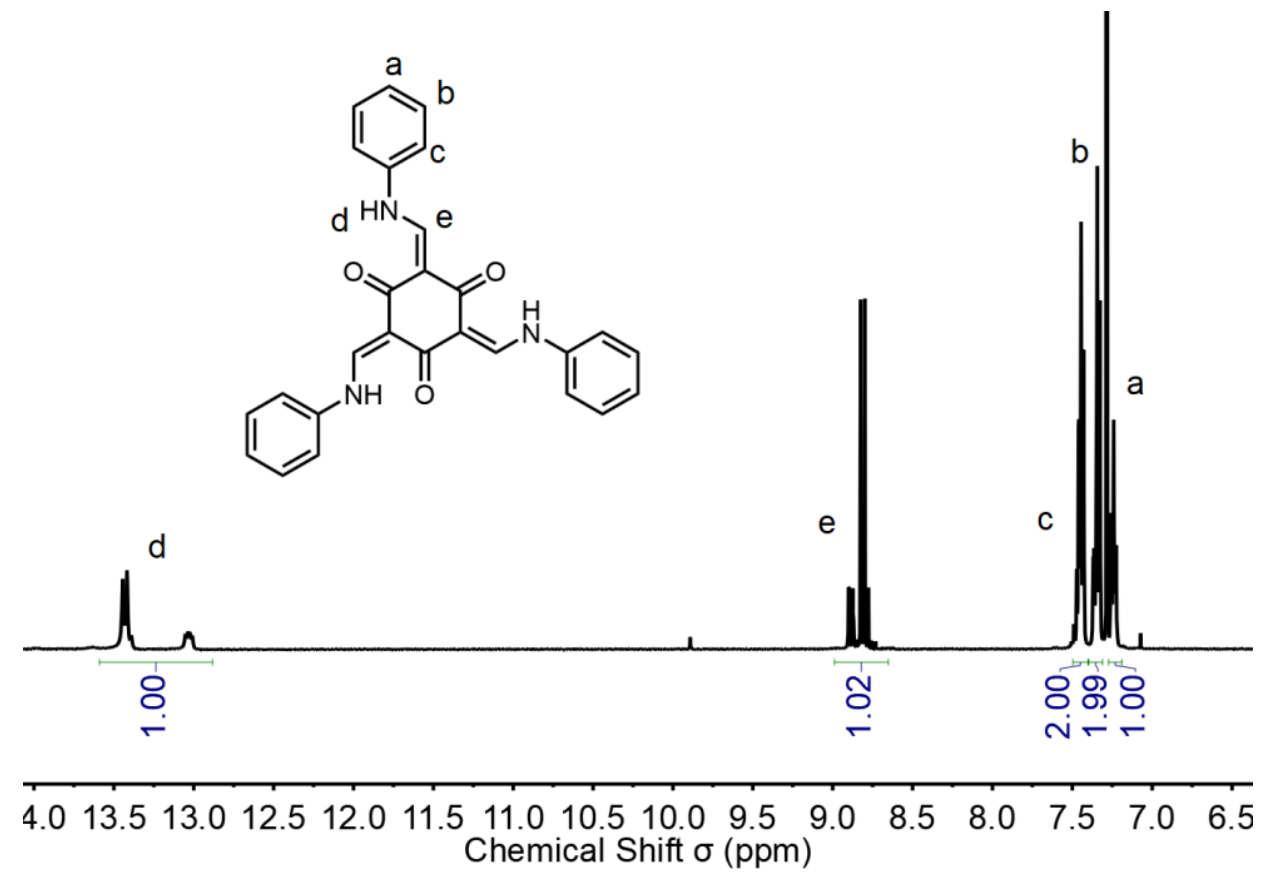

Figure S2. ${ }^{1} \mathrm{H}$ NMR spectrum $\left(500 \mathrm{MHz}, \mathrm{CDCl}_{3}\right)$ of $\mathbf{S 1}$ at $298 \mathrm{~K}$ 


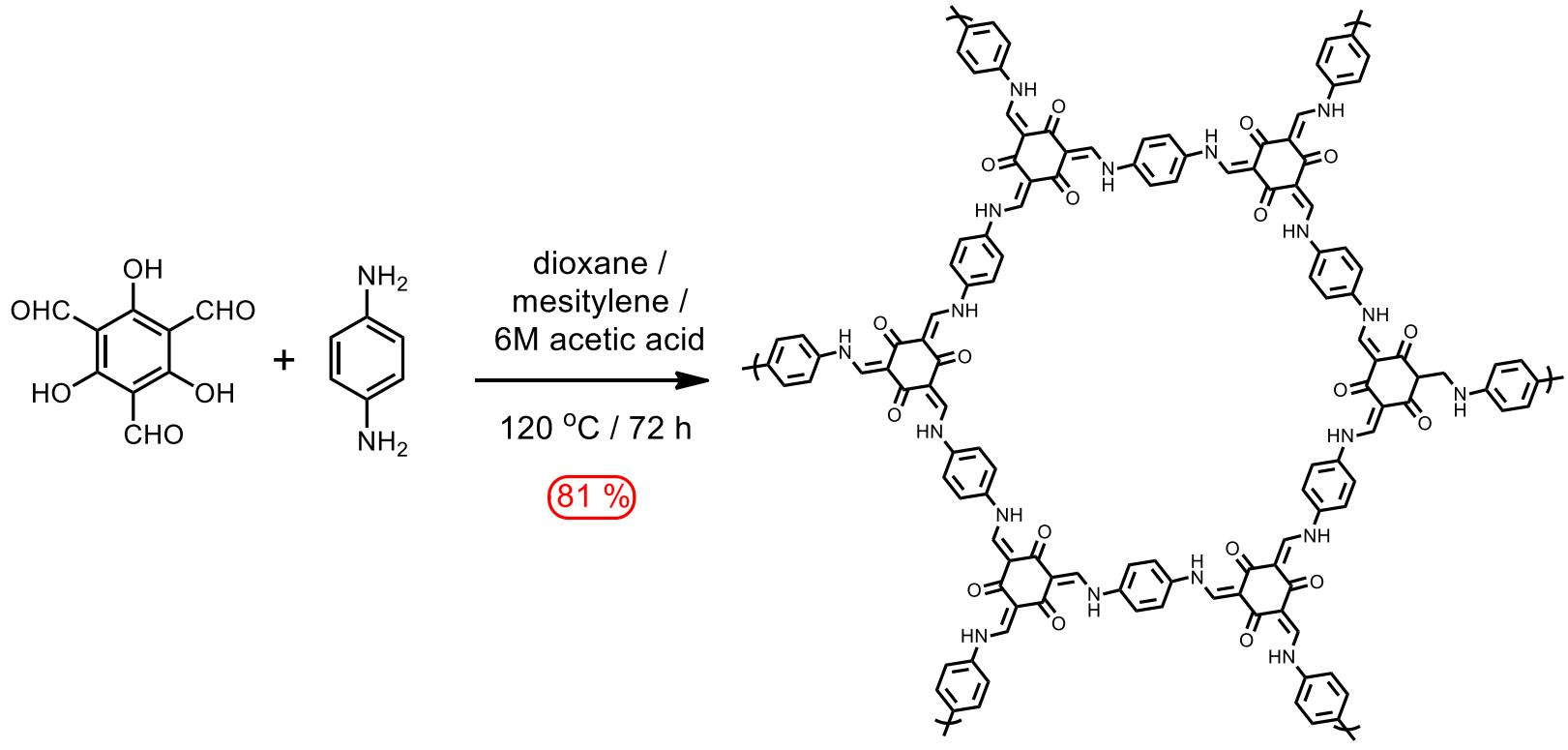

$s$-TpPa-1. s-TpPa-1 was synthesized according to a previously reported method. ${ }^{\mathrm{S} 1}$ In a sealed Schlenk flask (25 mL), Tp (126 mg, $0.6 \mathrm{mmol})$ and paraphenylenediamine (Pa, $96 \mathrm{mg}, 0.9 \mathrm{mmol})$ in a mixture of dioxane $(3 \mathrm{~mL})$, mesitylene $(3 \mathrm{~mL})$ and $6 \mathrm{M}$ acetic acid $(1 \mathrm{~mL})$ were degassed thoroughly by three freeze-pump-thaw cycles. The mixture was sonicated for $30 \mathrm{~min}$ at room temperature and then heated to $120^{\circ} \mathrm{C}$ for $72 \mathrm{~h}$. A red precipitate was generated during this period, which was collected by filtration subsequently. The collected powder was washed extensively using a large excess of DMF (3 times) and acetone (3 times). The sample was then activated using supercritical $\mathrm{CO}_{2}$ and high vacuum at $180^{\circ} \mathrm{C}$ for $24 \mathrm{~h}$, yielding a red powder $(180 \mathrm{mg}$, yield = 81\%). FT-IR (powder, $\mathrm{cm}^{1}$ ): 1580 (s), 1517 (m), 1451 (m), 1285(s), $1254(\mathrm{~s}), 1127(\mathrm{w}), 1087(\mathrm{w})$, 991 (m), 825 (s). Elemental analysis: $\mathrm{C}_{36} \mathrm{H}_{24} \mathrm{~N}_{6} \mathrm{O}_{6} \cdot 1.9 \mathrm{H}_{2} \mathrm{O}$, calculated: $\mathrm{C} 64.5 \%, \mathrm{H} 4.2 \%, \mathrm{~N}$ $12.5 \%$; found: C $65.1 \%$, H $3.9 \%$, N $11.9 \%$. 


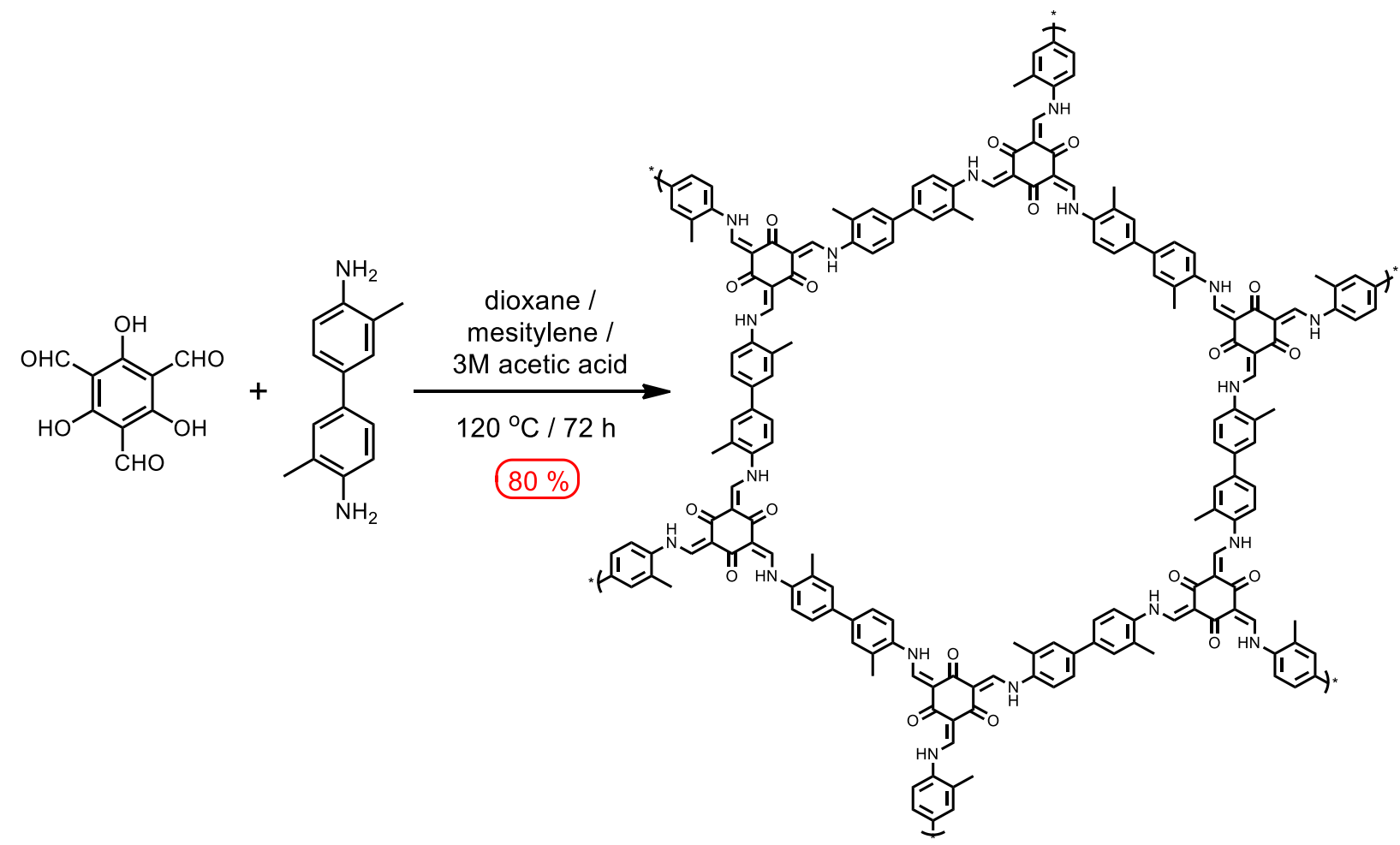

$s$-TpBD-Me2. $s$-TpBD-Me2 was synthesized according to a previously reported method. ${ }^{\mathrm{S} 3}$ In a sealed Schlenk flask (25 mL), Tp (126 mg, $0.6 \mathrm{mmol})$ and $o$-tolidine $(191 \mathrm{mg}, 0.9 \mathrm{mmol})$ in a mixture of dioxane $(3 \mathrm{~mL})$, mesitylene $(3 \mathrm{~mL})$ and $3 \mathrm{M}$ acetic acid $(1 \mathrm{~mL})$ were degassed thoroughly by three freeze-pump-thaw cycles. The mixture was sonicated for $30 \mathrm{~min}$ at room temperature and then heated to $120{ }^{\circ} \mathrm{C}$ for $72 \mathrm{~h}$. An orange precipitate was generated during this period, which was collected by filtration. The solid sample was washed extensively using a large excess of DMF (3 times) and acetone (3 times). The sample was activated using supercritical $\mathrm{CO}_{2}$ and high vacuum at $100{ }^{\circ} \mathrm{C}$ under vacuum for $24 \mathrm{~h}$, yielding an orange powder $(254 \mathrm{mg}$, yield $=$ $80 \%$ ). FT-IR (powder, $\mathrm{cm}^{-1}$ ): 1573 (s), 1501 (w), $1438(\mathrm{~m}), 1273$ (s), 1252 (s),1121 (w), 996 (w), $871(\mathrm{~m}), 804(\mathrm{~m})$. Elemental analysis: $\mathrm{C}_{60} \mathrm{H}_{48} \mathrm{O}_{6} \mathrm{~N}_{6} \cdot 0.3 \mathrm{DMF} \cdot 1.3 \mathrm{H}_{2} \mathrm{O}$, calculated C $73.6 \%$, H $5.3 \%$, N $8.9 \%$; found: C $73.4 \%, \mathrm{H} 5.2 \%, \mathrm{~N} 8.7 \%$. 


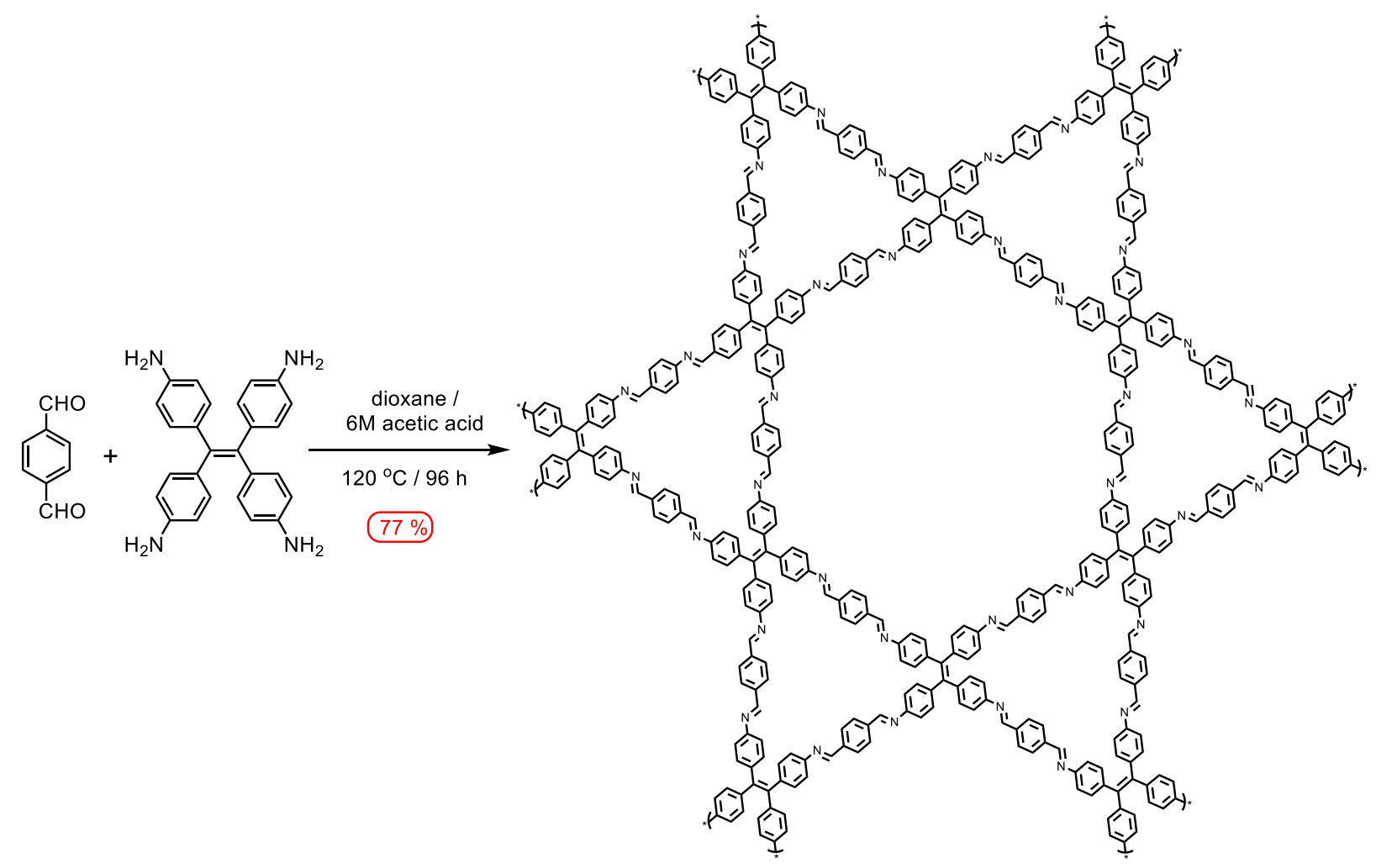

$\boldsymbol{s}$-TPE-COF. $\boldsymbol{s}$-TPE-COF was synthesized based on a previously reported method. ${ }^{\mathrm{S} 4}$ In a sealed Schlenk flask $(25 \mathrm{~mL})$, terephthalaldehyde $(108 \mathrm{mg}, 0.8 \mathrm{mmol})$ and tetrakis-(4-aminophenyl)ethane $(150 \mathrm{mg}, 0.4 \mathrm{mmol})$ in a mixture of dioxane $(6 \mathrm{~mL})$ and $6 \mathrm{M}$ acetic acid $(1 \mathrm{~mL})$ were degassed thoroughly by three freeze-pump-thaw cycles. The mixture was sonicated for $30 \mathrm{~min}$ at room temperature and then heated to $120^{\circ} \mathrm{C}$ for $96 \mathrm{~h}$. An orange precipitate was generated during this period, which was collected by filtration. The solid sample was washed extensively using a large excess of DMF (3 times) and acetone (3 times). The sample was activated using supercritical $\mathrm{CO}_{2}$ and high vacuum at $100{ }^{\circ} \mathrm{C}$ under vacuum for $24 \mathrm{~h}$, yielding an orange powder $(199 \mathrm{mg}$, yield = 77\%). FT-IR (powder, $\mathrm{cm}^{-1}$ ): $2874(\mathrm{w}), 1705$ (m), 1619 (s), 1595 (s), 1563 (m), 1495 (s), 1409(w), 1360 (w), 1299 (m), 1197 (s), $1164(\mathrm{~s}), 1101$ (m), 1012(m), $964(\mathrm{~m}), 881$ (m), 835 (s), 783 (m). Elemental analysis: $\mathrm{C}_{42} \mathrm{H}_{28} \mathrm{~N}_{4} \cdot 0.4 \mathrm{DMF} \cdot 0.45 \mathrm{H}_{2} \mathrm{O}$, calculated: C 82.9 \%, H $5.1 \%$, N, $9.8 \%$; found: C $82.6 \%, \mathrm{H} 4.8 \%, \mathrm{~N} 9.7 \%$. 


\section{S2.1 Synthesis of 3D-printed COF monolith}

3D-TpPa-1 hydrogel (G1). Pluronic F127 (2.0 g, $0.159 \mathrm{mmol})$ was dissolved in ice-cold water (6 $\mathrm{mL})$ before TsOH $(0-0.5 \mathrm{~g}, 0-2.6 \mathrm{mmol})$ was added. Pa $(0.7 \mathrm{~g}, 6.5 \mathrm{mmol})$ was added to the aqueous solution with stirring at $0{ }^{\circ} \mathrm{C}$, forming a purple solution. In a separate reaction vessel, $\mathbf{T p}(0.9 \mathrm{~g}$, $4.3 \mathrm{mmol}$ ) was dissolved in THF ( $25 \mathrm{~mL}$ ) and the solution was combined with the aqueous solution of $\mathrm{F} 127 / \mathrm{Pa} / \mathrm{TsOH}$ under vigorous stirring. The color of reaction mixture gradually changed from transparent orange to opaque red, and the temperature of the reaction was allowed to warm to room temperature. The reaction mixture was stirred in the open air to allow THF evaporation. After ca. $4 \mathrm{~h}$, a red-colored opaque hydrogel was obtained (9.40 g net mass), which was subjected to rheology measurements to evaluate the hydrogel's 3D printability.

GPC analysis. In order to monitor the evolution of imine condensation in the hydrogel of TpPa-1 ink, the as-prepared G1 was freeze-dried and dissolved in DMSO. Insoluble species (ca. 35-40 \% of the total mass) were removed using a syringe filter. The soluble solution was injected into the GPC, using a series of PEG of known molecular weights for comparison. As shown in Figure S3, a broad peak with a retention time of 15.6 min could be attributed to the imine polymer.

3D-TpBD-Mez hydrogel (G2). Pluronic F127 (2.0 g, 0.159 mmol) was dissolved in ice-cold water $(6 \mathrm{~mL})$ before $\mathrm{TsOH}(0.3 \mathrm{~g}, 1.6 \mathrm{mmol})$ was added. $o$-tolidine $(0.96 \mathrm{~g}, 4.5 \mathrm{mmol})$ was added to the aqueous solution with stirring at $0{ }^{\circ} \mathrm{C}$, forming a light-red solution. In a separate reaction vessel, Tp $(0.64 \mathrm{~g}, 3.0 \mathrm{mmol})$ was dissolved in THF $(20 \mathrm{~mL})$ and the THF solution was combined to the aqueous solution of F127/o-tolidine/TsOH under vigorous stirring. The color of the mixture gradually changed from transparent orange to opaque red and the temperature of the reaction was allowed to warm to room temperature after $30 \mathrm{~min}$. The reaction mixture was stirred in open air to allow THF evaporation. After ca. $4 \mathrm{~h}$, an orange-colored hydrogel was obtained (10.58 g net mass), which was subjected to rheology measurements to evaluate its 3D printability.

3D-TPE-COF hydrogel (G3). We first attempted to prepare 3D-TPE-COF hydrogel in a similar manner compared to those of 3D-TpPa-1 and 3D-TpBD-Me2. Experimentally, Pluronic F127 (2.0 $\mathrm{g}, 0.159 \mathrm{mmol})$ was dissolved in ice-cold water $(6 \mathrm{~mL})$ before TsOH $(0.15 \mathrm{~g}, 0.8 \mathrm{mmol})$ was added. Tetrakis-(4-aminophenyl)-ethene $(0.48 \mathrm{~g}, 1.2 \mathrm{mmol})$ was added to the aqueous solution with stirring at $0{ }^{\circ} \mathrm{C}$, forming a dark-red solution. In a separate reaction vessel, terephthalaldehyde $(0.32$ $\mathrm{g}, 2.4 \mathrm{mmol}$ ) was dissolved in THF (20 mL) and this THF solution was mixed with the aqueous 
solution of F127/tetrakis(4-aminophenyl)ethene/TsOH. Different from the ketoenamine-based COF hydrogels, a large amount of orange precipitate was formed immediately upon mixing, which was difficult to disperse even with vigorous stirring. After the evaporation of THF, an orange hydrogel-like substance was formed but was unsuitable for 3D printing due to severe tip clogging.

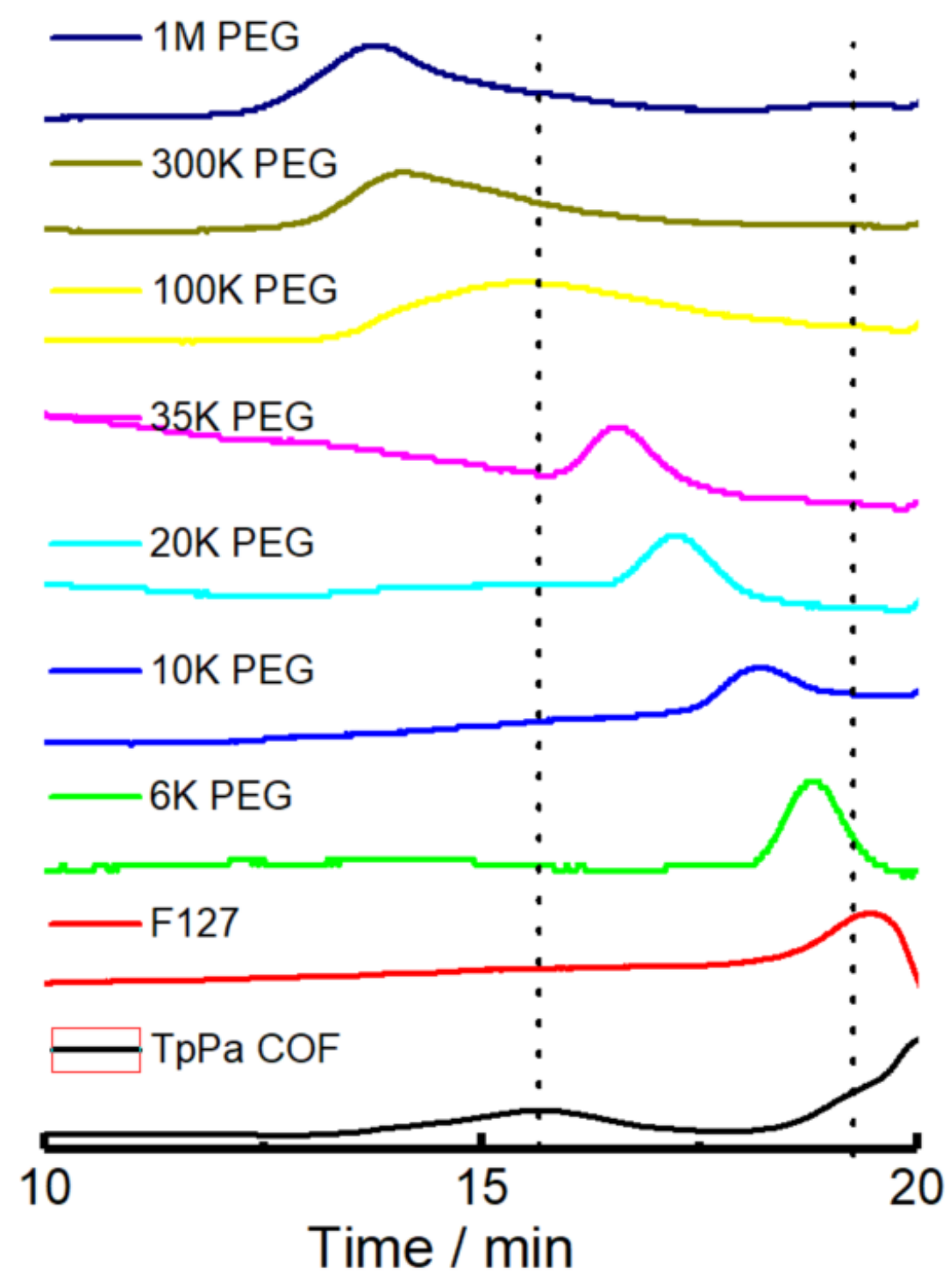

Figure S3. GPC profiles of PEG (6k-1M Da), F127 (red), and TpPa-1 ink (black) measured using DMSO (containing $0.1 \% \mathrm{LiBr}$ ) as the mobile phase with a flow rate of $1.0 \mathrm{~mL} / \mathrm{min}$ at $50{ }^{\circ} \mathrm{C}$. Polymeric species (comparable to the retention time of 100k Da PEG) in TpPa-1 ink other than F127 were recorded in the GPC profile, suggesting a limited degree of polymerization in the iminecondensation. 
Trans-imination method: Terephthalaldehyde (0.32 g, $2.4 \mathrm{mmol})$, aniline $(0.44 \mathrm{~g}, 4.8 \mathrm{mmol})$, and TsOH $(0.15 \mathrm{~g}, 0.8 \mathrm{mmol})$ were dissolved in a mixture of $30 \mathrm{~mL} \mathrm{THF}, 7 \mathrm{~mL} \mathrm{H} \mathrm{O}_{2}$ and $3 \mathrm{~mL} \mathrm{EtOH}$. The clear yellow solution was stirred overnight. Pluronic F127 (2.0 g, 0.159 mmol) was dissolved in the solution once thin layer chromatography $\left(\mathrm{SiO}_{2}\right.$, eluent: ethyl acetate/hexanes $=1: 1, \mathrm{R}_{\mathrm{f}}=$ 0.63) suggested that all terephthalaldehyde had been consumed. Tetrakis-(4-aminophenyl)-ethene $(0.48 \mathrm{~g}, 1.2 \mathrm{mmol})$ was introduced to the solution subsequently. The reaction turned red with fine yellow particles generated. The reaction mixture was stirred vigorously in open air to allow THF and ethanol evaporation. After ca. $4 \mathrm{~h}$, an orange-colored hydrogel was obtained (9.47 g net mass), which was subjected to rheology measurements.

F127 template removal. A 3D-printed TpPa-1 or TpBD-Me 2 hydrogel monolith was placed in a sealed container with saturated $\mathrm{LiCl}$ aqueous solution (relative humidity $=11 \%$ ) for $24 \mathrm{~h}$ to gradually remove water from the hydrogel. After water evaporation, the monolith was transferred to an oven and heated to $90-150{ }^{\circ} \mathrm{C}$ for 24 to $72 \mathrm{~h}$. The surface of the monolith darkened, which may be attributed to the oxidation of Pa or $o$-tolidine moieties. The monolith was then soaked in a large excess of DMF $(6 \times 30 \mathrm{~mL}$ for $24 \mathrm{~h}$ each $)$ and acetone $(6 \times 30 \mathrm{~mL}$ for $24 \mathrm{~h}$ each $)$ to remove the unreacted species, TsOH, and Pluronic F127 template. After the evaporation of acetone, the sample was broken into small pieces for porosity analysis or ground to powder for PXRD and FTIR measurements. 3D-TPE-COF monolith was placed in a sealed container with a saturated $\mathrm{LiCl}$ aqueous solution (relative humidity $=11 \%$ ) for $24 \mathrm{~h}$ to remove the water from the hydrogel. After water evaporation, the monolith was heated under $\mathrm{N}_{2}$ at $90^{\circ} \mathrm{C}$ for $36 \mathrm{~h}$ (caution: we noticed the porous polymer was oxidized if heated in open air). After heating, the printed monoliths were soaked in a large excess of DMF $(6 \times 30 \mathrm{~mL}$ for $24 \mathrm{~h}$ each $)$ and acetone $(6 \times 30 \mathrm{~mL}$ for $24 \mathrm{~h}$ each $)$ to afford 3D-TPE-COF (F127 Removal) for PXRD and FT-IR analyses.

Annealing. A 3D-printed TpPa-1 or TpBD-Me2 monolith after F127 removal was placed in a flask with a water-chilled condenser and a mixed solvent of dioxane $(3 \mathrm{~mL})$, mesitylene $(3 \mathrm{~mL})$, and $6 \mathrm{M}$ acetic acid $(1 \mathrm{~mL})$ was added. The flask was heated to $100{ }^{\circ} \mathrm{C}$ for $48 \mathrm{~h}$. Alternatively, the reaction was conducted on the same scale in a sealed container that was heated at $150{ }^{\circ} \mathrm{C}$ for $72 \mathrm{~h}$. No structural deformation or cracking was observed during this period. After cooling down, the monolith was transferred to a beaker filled with DMF $(30 \mathrm{~mL}, 4 \mathrm{~h})$ and then acetone $(30 \mathrm{~mL}, 5-6$ h) to allow solvent exchange. After that, the monolith was left in open air to allow acetone 
evaporation. After supercritical $\mathrm{CO}_{2}$ activation, the sample was sent whole for SEM, broken into small pieces for porosity analysis, or ground to powders for PXRD, FT-IR, elemental analysis, and solid-state NMR measurements.

To avoid the oxidation of imines, the heated 3D-TPE-COF monolith was directly subjected to annealing without F127 removal. The monolith was immersed in a mixed solvent of dioxane (6 $\mathrm{mL}$ ) and $6 \mathrm{M}$ acetic acid ( $1 \mathrm{~mL}$ ) and heated to $100{ }^{\circ} \mathrm{C}$ under $\mathrm{N}_{2}$ atmosphere for $48 \mathrm{~h}$. After cooling down, the monolith was transferred to a beaker and washed with DMF (30 mL, $4 \mathrm{~h}$ ) followed by acetone $(30 \mathrm{~mL}, 6 \mathrm{~h})$ for solvent exchange. After the acetone was evaporated in open air, the sample was activated using supercritical $\mathrm{CO}_{2}$. The sample was broken into small pieces for porosity analysis or ground to powders for PXRD FT-IR, elemental analysis, and solid-state NMR measurements.

3D-TpPa-1. IR: 1580 (s), 1517(m), 1451 (m), 1285(s), 1254 (s), 1127(w), 1087 (w), 991 (m), 825 (s). Elemental analysis: $\mathrm{C}_{36} \mathrm{H}_{24} \mathrm{~N}_{6} \mathrm{O}_{6} \cdot 1.95 \mathrm{H}_{2} \mathrm{O}$, calculated: $\mathrm{C} 64.4 \%, \mathrm{H} 4.2 \%, \mathrm{~N} 12.5 \%$; found: C $65.0 \%, \mathrm{H} 4.2 \%, \mathrm{~N} 11.8 \%$.

3D-TpBD-Me2: 1573 (s), 1501 (w), 1438 (m), 1273 (s), 1252 (s), 1121 (w), 996 (w), 871 (m), 804 (m). Elemental analysis: $\mathrm{C}_{60} \mathrm{H}_{48} \mathrm{O}_{6} \mathrm{~N}_{6} \cdot 4 \mathrm{H}_{2} \mathrm{O}$, calculated C $70.6 \%$, H $5.5 \%$, N $8.2 \%$; found: C $70.6 \%$, H $5.1 \%$, N $7.6 \%$.

3D-TPE-COF: 2874 (w), 1705 (m), 1619 (s), 1595 (s), 1563 (m), 1495 (s), 1409(w), 1360 (w), $1299(\mathrm{~m}), 1197$ (s), 1164 (s), 1101 (m), 1012(m), 964 (m), 881 (m), 835 (s), 783 (m). $\mathrm{C}_{42} \mathrm{H}_{28} \mathrm{~N}_{4} \cdot 0.75 \mathrm{H}_{2} \mathrm{O}$, calculated: $\mathrm{C} 83.8 \%, \mathrm{H} 4.9 \%, \mathrm{~N}, 9.3 \%$; found: C 83.6 \%, H $4.9 \%, \mathrm{~N} 9.5 \%$.

\section{S2.2 Preparation of a TpPa-1 and F127 blend gel}

Powder-formed $s$-TpPa-1 (1.0 g) was evenly dispersed in water (10 mL) with the help of ultrasonication for $1 \mathrm{~h}$. The mixture was cooled to $0{ }^{\circ} \mathrm{C}$ in an ice bath before Pluronic F127 (3.5 g, $0.278 \mathrm{mmol}$ ) was added to the mixture. The mixture was vigorously stirred for $30 \mathrm{mins}$ and then warmed to room temperature to form a blend hydrogel. The hydrogel was nearly imprintable using tips with a large inner diameter $(0.8 \mathrm{~mm})$ and the blend frequently clogged the tips with no complete 3D structure built. An incomplete structure was then air dried and soaked in EtOH or water to remove the F127. The structure collapsed to powder in a few minutes. Other samples were broken into small pieces for porosity analysis or ground to powders for PXRD analysis. 


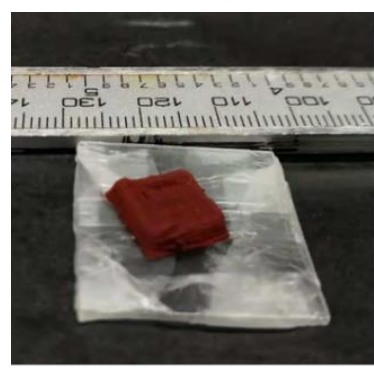

(a)

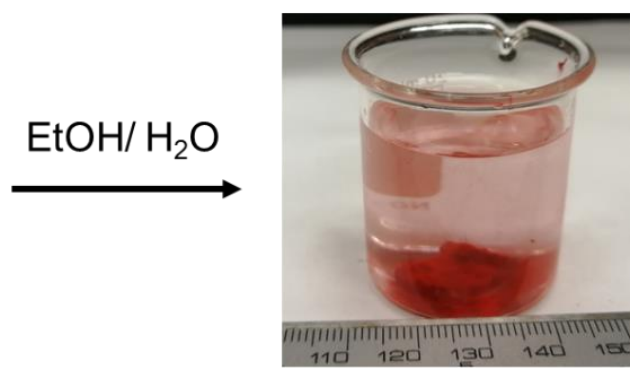

(b)

Figure S4. Images of (a) an air-dried $s$-TpPa-1 cube and (b) a collapsed monolith after 1 min of soaking in water.

\section{S2.3 Hetero-printing and post-printing treatments}

Hydrogels G1 and G2 (or G3) were loaded into two syringe barriers and used for 3D printing. G1 ink was printed to form a lattice structure at the bottom, and $\mathbf{G} 2$ or $\mathbf{G 3}$ ink was extruded on top of the lattice formed by $\mathbf{G 1}$.

[3D-TpPa-1/TpBD-Me2] monolith was placed in a sealed container with a saturated $\mathrm{NaCl}$ aqueous solution (relative humidity $=75 \%$ ) for $24 \mathrm{~h}$ and in saturated $\mathrm{LiCl}$ aqueous solution (relative humidity $=11 \%$ ) for another $24 \mathrm{~h}$ to even the solvent evaporation rate. The dried monolith was heated to $90^{\circ} \mathrm{C}$ in an oven for $48 \mathrm{~h}$. Unreacted species and F127 template were removed by soaking the monolith in a large excess of DMF $(6 \times 30 \mathrm{~mL}$ for $24 \mathrm{~h})$ and acetone $(6 \times 30 \mathrm{~mL}$ for $24 \mathrm{~h})$. After F127 removal, the monolith was annealed in a mixed solvent of dioxane (3 $\mathrm{mL})$, mesitylene $(3 \mathrm{~mL})$, and $6 \mathrm{M}$ acetic acid $(1 \mathrm{~mL})$ at $100{ }^{\circ} \mathrm{C}$ for $48 \mathrm{~h}$. The sample was ground to powder for PXRD measurements.

[3D-TpPa-1/TPE-COF] monolith was placed in a sealed container with a saturated $\mathrm{NaCl}$ aqueous solution (relative humidity $=75 \%$ ) for $24 \mathrm{~h}$ and in saturated $\mathrm{LiCl}$ aqueous solution (relative humidity $=11 \%$ ) for another $24 \mathrm{~h}$. The dried monolith was heated to $90{ }^{\circ} \mathrm{C}$ under $\mathrm{N}_{2}$ atmosphere for $48 \mathrm{~h}$ followed by annealing in a mixture of dioxane $(6 \mathrm{~mL})$ and $6 \mathrm{M}$ acetic acid $(1 \mathrm{~mL})$ under $\mathrm{N}_{2}$ atmosphere at $100{ }^{\circ} \mathrm{C}$ for $48 \mathrm{~h}$. The sample was ground to powder for PXRD measurements. 


\section{S3. Structural modeling and Powder X-ray diffraction analysis}

All COF models (hexagonal 2D frameworks) were built using the Materials Studio software package, and their space groups were selected with the maximum possible symmetry. Energy minimization was performed to optimize the geometry of the building units, employing the universal force field implemented in the Forcite module of Materials Studio. The unit cell parameters were also optimized. Pawley refinement was carried out using Reflex, a software package for crystal structure determination from PXRD pattern. The Pawley refinement was performed to optimize the lattice parameters iteratively until the Rp and Rwp values converged. The overlay of the observed PXRD profiles with those refined profiles shows good agreement.

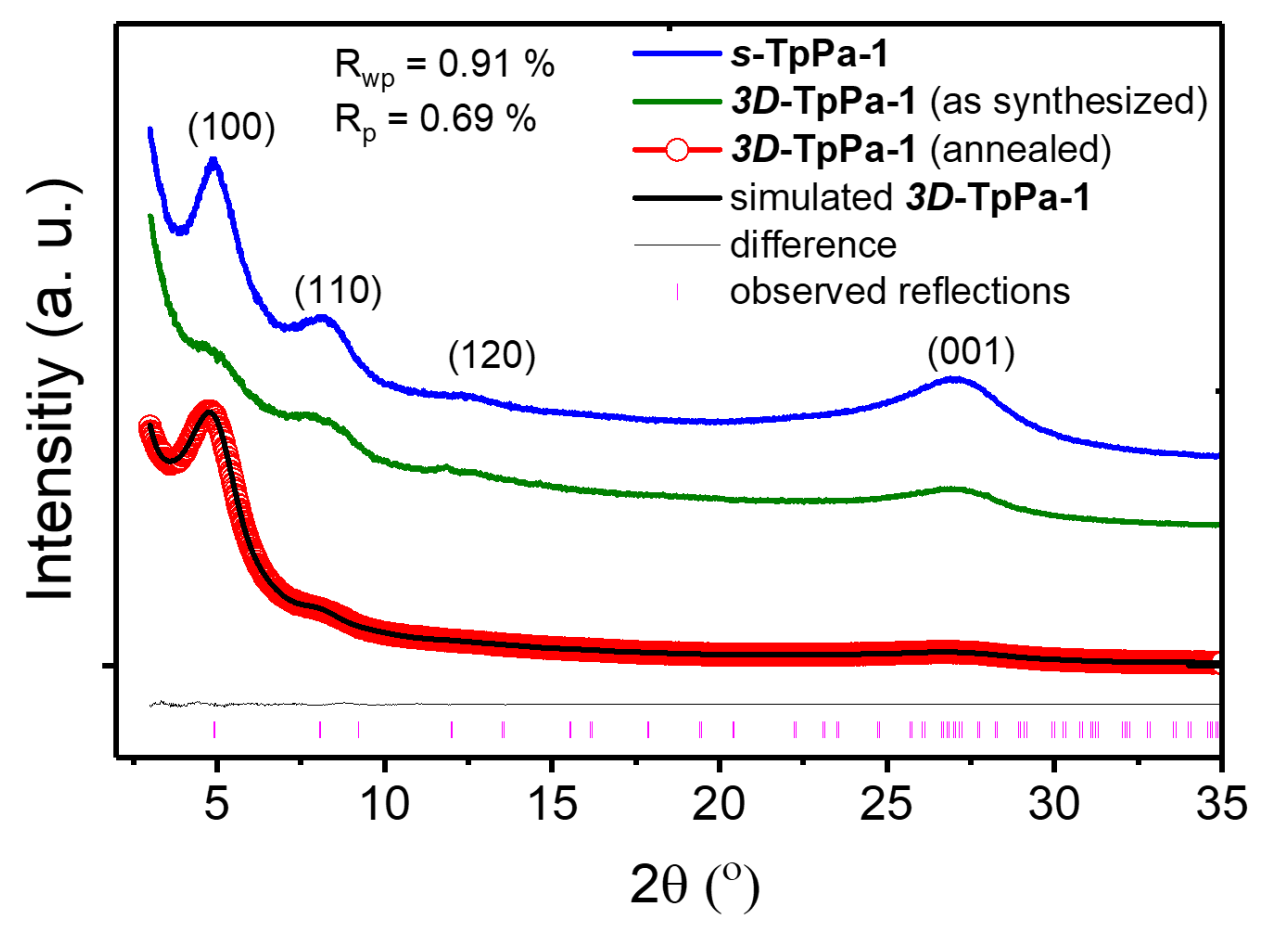

Figure S5. PXRD patterns and Pawley refinement of 3D-TpPa-1 (annealed) with the experimental profiles in black, Pawley-refined profiles in green, the differences between the experimental and refined PXRD patterns in black, and the observed reflections in pink. For comparison, PXRD profiles of $\mathbf{3 D}$-TpPa-1 (as synthesized) in red and $s-\mathbf{T p P a - 1}$ in blue were also shown in the figure.

Table S1. Refined unit cell parameters and atomic coordinates for 3D-TpPa-1

\begin{tabular}{|c|c|c|c|}
\hline \multicolumn{3}{|c|}{ TpPa-1 } \\
\hline \multicolumn{3}{|c|}{ hexagonal P-6/m, a = b =23.1997 $\AA, \mathrm{c}=3.4248 \AA$} \\
\hline O1 & 0.28081 & 0.53575 & 0.5 \\
\hline N2 & 0.40779 & 0.54779 & 0.5 \\
\hline C3 & 0.30554 & 0.59597 & 0.5 \\
\hline
\end{tabular}




\begin{tabular}{|c|c|c|c|}
\hline C4 & 0.37956 & 0.63946 & 0.5 \\
\hline C5 & 0.42377 & 0.61657 & 0.5 \\
\hline C6 & 0.45635 & 0.526 & 0.5 \\
\hline C7 & 0.43358 & 0.45738 & 0.5 \\
\hline C8 & 0.5256 & 0.57032 & 0.5 \\
\hline H9 & 0.3807 & 0.42194 & 0.5 \\
\hline H10 & 0.47574 & 0.6534 & 0.5 \\
\hline H11 & 0.54694 & 0.62355 & 0.5 \\
\hline H12 & 0.35893 & 0.50918 & 0.5 \\
\hline
\end{tabular}

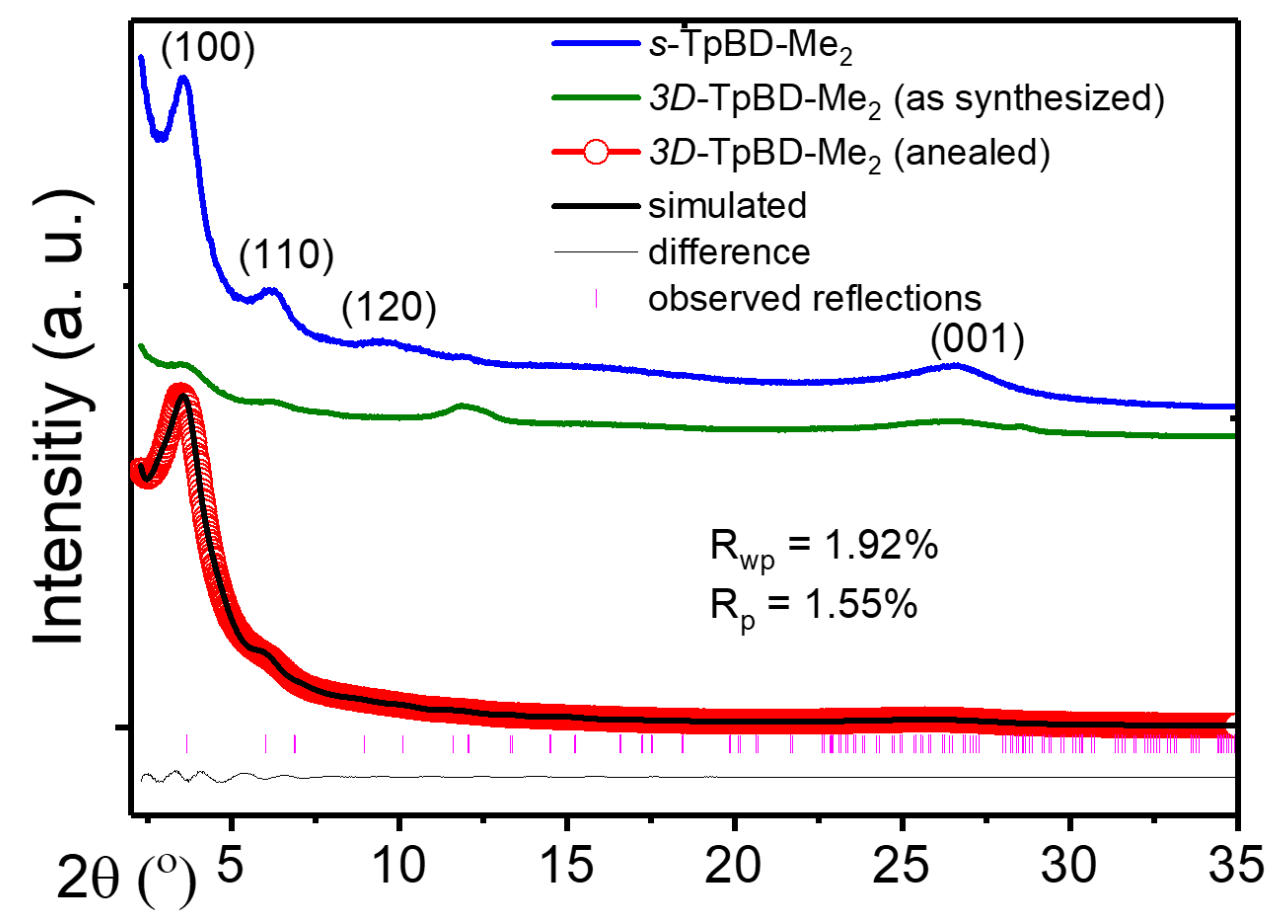

Figure S6. PXRD patterns and Pawley refinement of 3D-TpBD-Me2 (annealed) with the experimental profiles in black, Pawley-refined profiles in green, the differences between the experimental and refined PXRD patterns in black, and the observed reflections in pink. For comparison, PXRD profiles of 3D-TpBD-Me2 (as synthesized) in red and $\boldsymbol{s}$ - TpBD-Me 2 in blue were also shown in the figure.

Table S2. Refined unit cell parameters and atomic coordinates for $3 D$-TpBD-Me2

\section{TpBD-Me}

hexagonal P-6/m, a = b = 30.7779 $\mathrm{A}, \mathrm{c}=3.8927 \AA$ 


\begin{tabular}{|l|l|l|l|}
\hline H1 & 0.34529 & 0.51498 & 0.22797 \\
\hline H2 & 0.52461 & 0.64155 & 1 \\
\hline H3 & 0.55991 & 0.58871 & 1 \\
\hline H4 & 0.41078 & 0.45832 & 1 \\
\hline H5 & 0.45825 & 0.65597 & 1 \\
\hline C6 & 0.35864 & 0.50405 & 1 \\
\hline H7 & 0.34027 & 0.46249 & 0 \\
\hline O8 & 0.28633 & 0.72086 & 0 \\
\hline C9 & 0.48897 & 0.5173 & 0 \\
\hline C10 & 0.41517 & 0.5293 & 0 \\
\hline C11 & 0.37849 & 0.60561 & 0 \\
\hline N12 & 0.43019 & 0.61854 & 0 \\
\hline C13 & 0.44725 & 0.58236 & 0 \\
\hline C14 & 0.43649 & 0.49805 & 0 \\
\hline C15 & 0.51962 & 0.57 & 0 \\
\hline C16 & 0.49917 & 0.60138 & 0 \\
\hline C17 & 0.72282 & 0.35898 & 0 \\
\hline C18 & 0.69682 & 0.38883 & \\
\hline
\end{tabular}

Table S3. Refined unit cell parameters and atomic coordinates for 3D-TPE-COF

\begin{tabular}{|c|c|c|c|}
\hline \multicolumn{4}{|c|}{ TPE-COF } \\
\hline \multicolumn{5}{|c|}{ Hexagonal P6 $\mathrm{a}=\mathrm{b}=38.9845 \AA, \mathrm{c}=5.6303 \AA$} \\
\hline $\mathrm{C} 1$ & 0.44397 & 0.48203 & 0.58729 \\
\hline $\mathrm{C} 2$ & 0.41567 & 0.46291 & 0.76649 \\
\hline C3 & 0.37909 & 0.46146 & 0.75599 \\
\hline C4 & 0.37026 & 0.47897 & 0.56374 \\
\hline C5 & 0.39853 & 0.49764 & 0.38477 \\
\hline C6 & 0.43497 & 0.49911 & 0.39627 \\
\hline C7 & 0.4803 & 0.44377 & 0.60807 \\
\hline C8 & 0.46213 & 0.41581 & 0.42601 \\
\hline C9 & 0.45971 & 0.37883 & 0.4413 \\
\hline C10 & 0.47501 & 0.36927 & 0.64108 \\
\hline
\end{tabular}




\begin{tabular}{|c|c|c|c|}
\hline C11 & 0.49213 & 0.39687 & 0.82477 \\
\hline $\mathrm{C} 12$ & 0.49495 & 0.43388 & 0.80764 \\
\hline N13 & 0.33319 & 0.47824 & 0.53929 \\
\hline C14 & 0.30397 & 0.4643 & 0.68942 \\
\hline C15 & 0.26778 & 0.46604 & 0.63578 \\
\hline C16 & 0.2367 & 0.45111 & 0.80094 \\
\hline C17 & 0.26386 & 0.48263 & 0.4227 \\
\hline N18 & 0.47209 & 0.33133 & 0.66797 \\
\hline C19 & 0.47294 & 0.30978 & 0.4948 \\
\hline C20 & 0.47004 & 0.27128 & 0.54398 \\
\hline $\mathrm{C} 21$ & 0.48443 & 0.25489 & 0.37717 \\
\hline $\mathrm{C} 22$ & 0.45329 & 0.25073 & 0.7564 \\
\hline H32 & 0.42199 & 0.44927 & 0.91497 \\
\hline H33 & 0.35817 & 0.44642 & 0.89742 \\
\hline H34 & 0.39215 & 0.51095 & 0.23478 \\
\hline H35 & 0.45603 & 0.5131 & 0.25506 \\
\hline H36 & 0.44993 & 0.42269 & 0.2725 \\
\hline H37 & 0.44519 & 0.35753 & 0.30019 \\
\hline H38 & 0.50356 & 0.38972 & 0.98087 \\
\hline H39 & 0.50793 & 0.45473 & 0.95101 \\
\hline $\mathrm{H} 40$ & 0.30563 & 0.45165 & 0.85686 \\
\hline $\mathrm{H} 41$ & 0.23889 & 0.43787 & 0.96517 \\
\hline $\mathrm{H} 42$ & 0.2873 & 0.49433 & 0.29136 \\
\hline $\mathrm{H} 43$ & 0.47822 & 0.32091 & 0.31416 \\
\hline $\mathrm{H} 44$ & 0.49768 & 0.27038 & 0.2131 \\
\hline $\mathrm{H} 45$ & 0.4417 & 0.26261 & 0.88755 \\
\hline
\end{tabular}




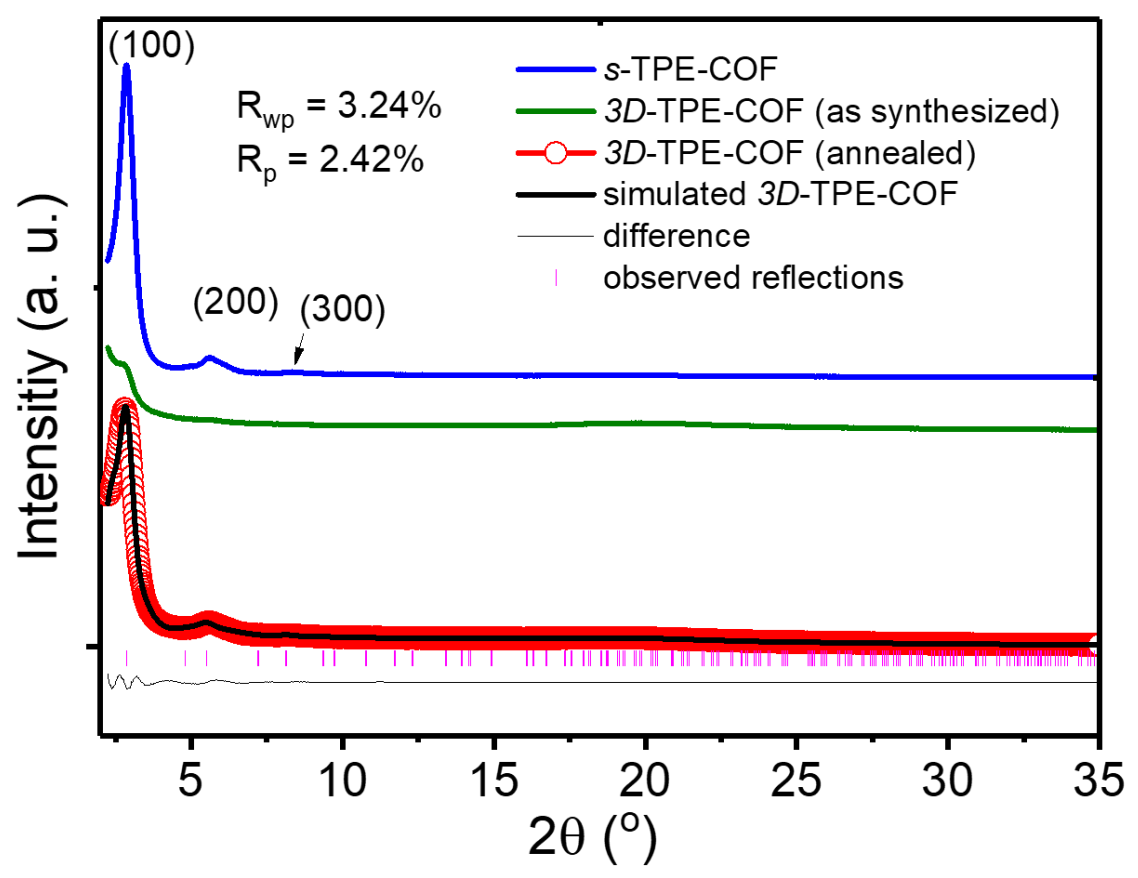

Figure S7. PXRD patterns and Pawley refinement of 3D-TPE-COF (annealed) with the experimental profiles in black, Pawley-refined profiles in green, the differences between the experimental and refined PXRD patterns in black, and the observed reflections in pink. For comparison, PXRD profiles of $\mathbf{3 D}$-TPE-COF (as synthesized) in red and $s$ - TPE-COF in blue were also shown in the figure.

(c)

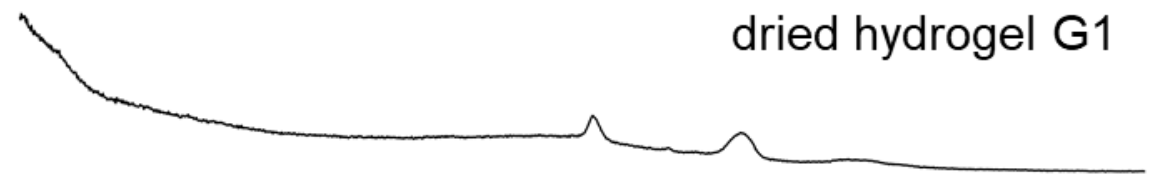

(b)

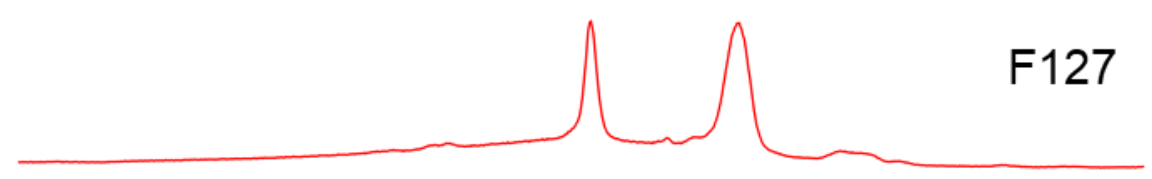

(a)

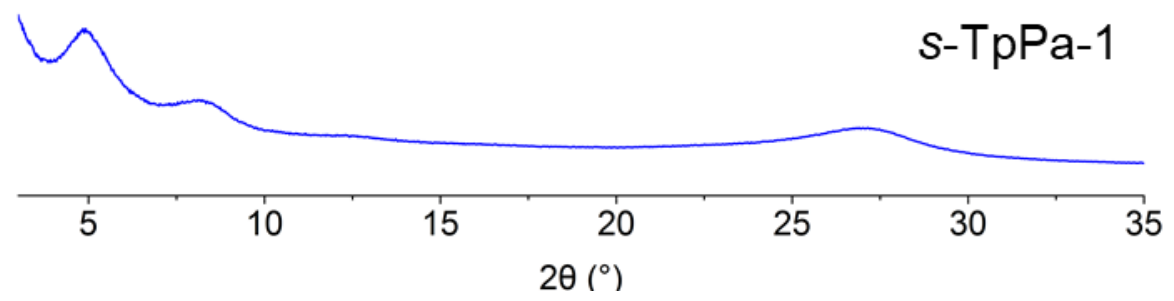

Figure S8. PXRD profiles of (a) s-TpPa-1, (b) F127 and (c) dried hydrogel G1. 
(d)

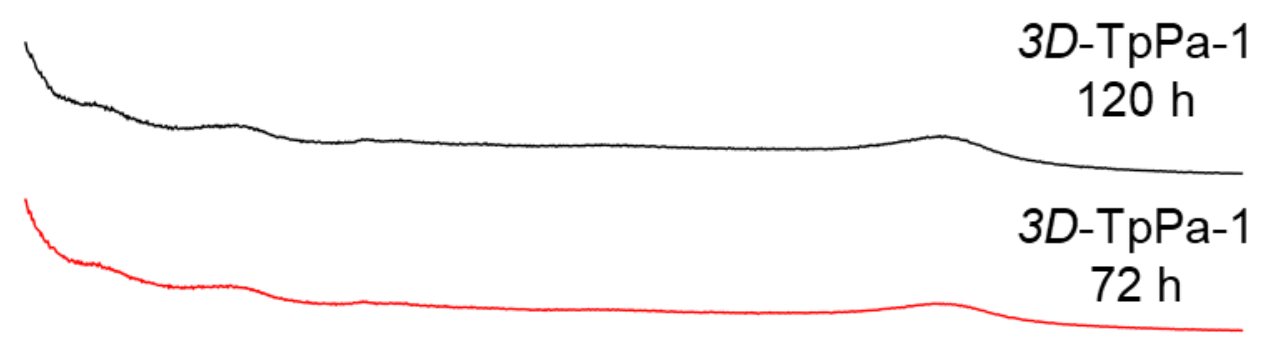

(b)

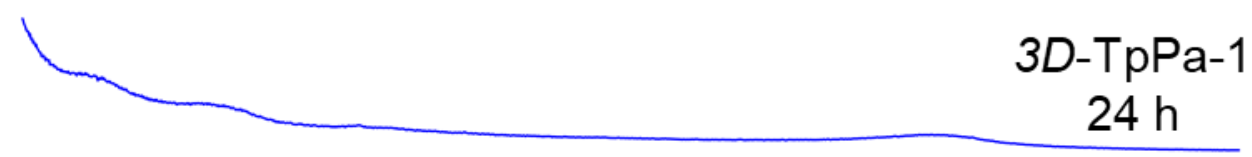

(a)

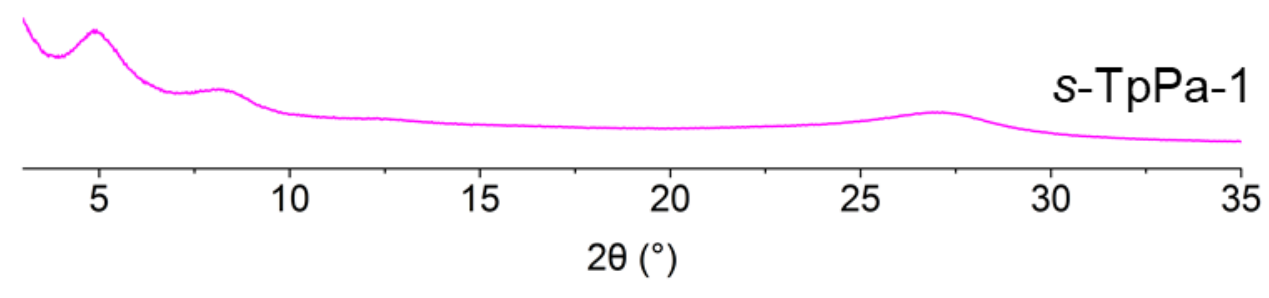

Figure S9. PXRD profiles of (a) $s$-TpPa-1 and (b-d) 3D-TpPa-1 samples after being heated at 90 ${ }^{\circ} \mathrm{C}$ for (b) $24 \mathrm{~h}$, (c) $72 \mathrm{~h}$, and (d) $120 \mathrm{~h}$ followed by F127 removal.

(d)

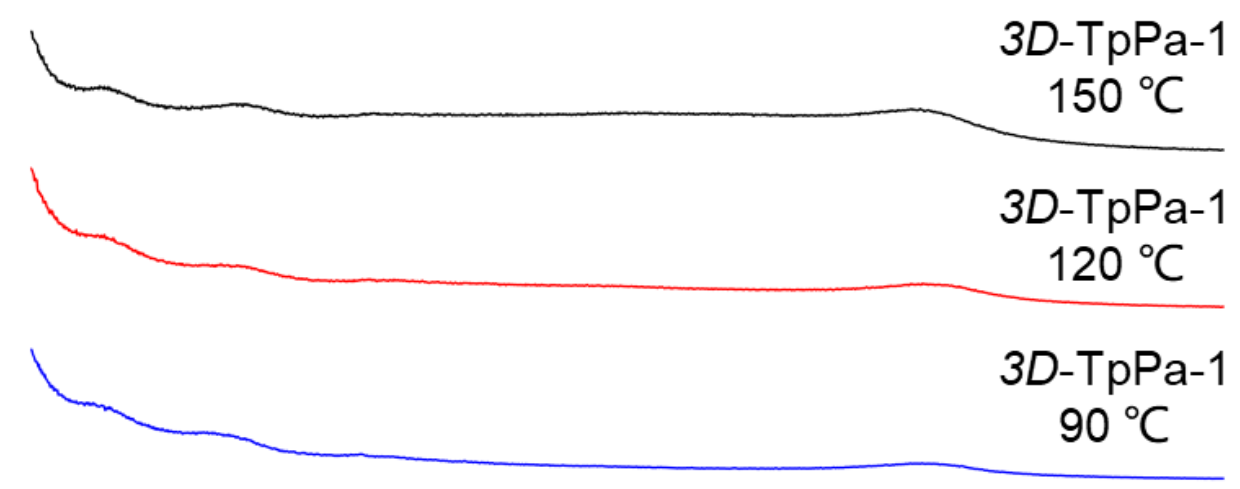

(b)

(c)

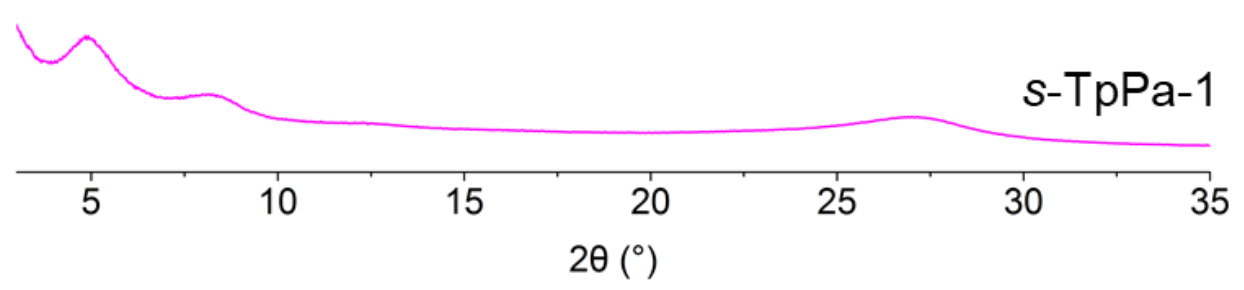

Figure S10. PXRD profiles of (a) $s$-TpPa-1 and (b-d) 3D-TpPa-1 samples after heating for $24 \mathrm{~h}$ at (b) $90{ }^{\circ} \mathrm{C}$, (c) $120^{\circ} \mathrm{C}$, and (d) $150{ }^{\circ} \mathrm{C}$ followed by $\mathrm{F} 127$ removal. 
(g)

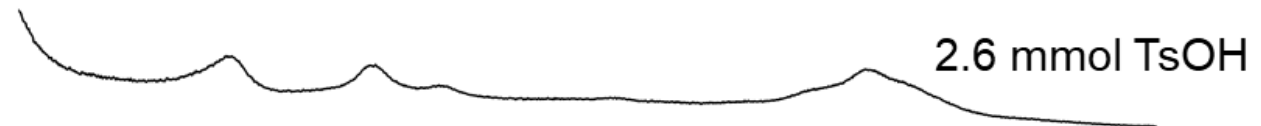

(f)

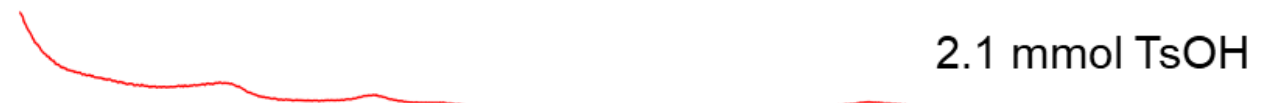

(e)

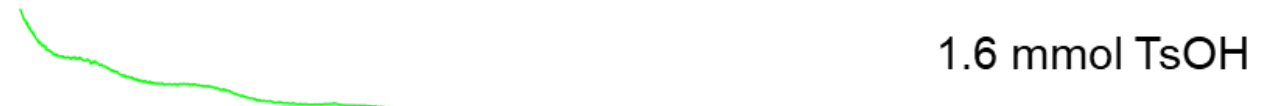

(d)

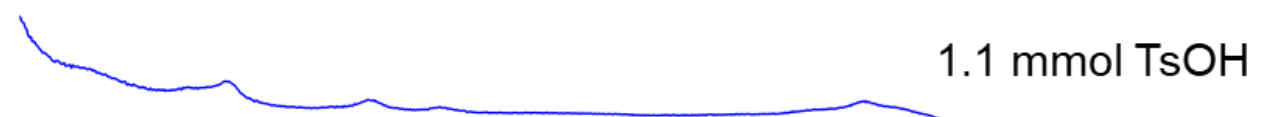

(c)

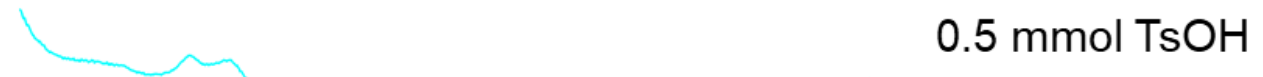

(b)

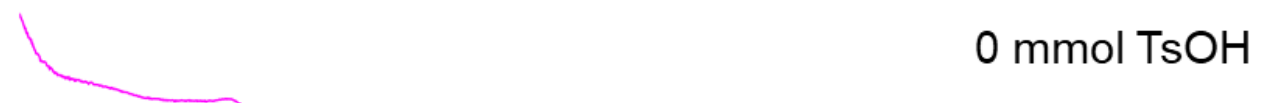

(a)

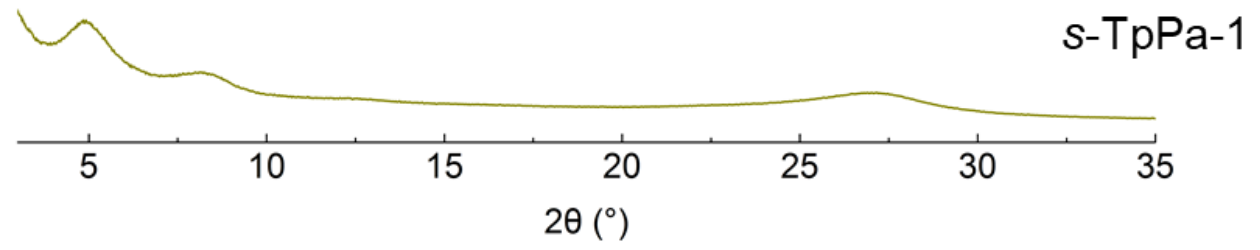

Figure S11. PXRD profiles of (a) $s$-TpPa-1, and (b-g) 3D-TpPa-1 samples that are synthesized in the presence of (b) $0 \mathrm{mmol}$, (c) $0.5 \mathrm{mmol}$, (d) $1.1 \mathrm{mmol}$, (e) $1.6 \mathrm{mmol}$, (f) $2.1 \mathrm{mmol}$ and (g) 2.6 mmol.

\section{$\mathrm{O} \mathrm{mmol} \mathrm{TsOH}$}

(c)

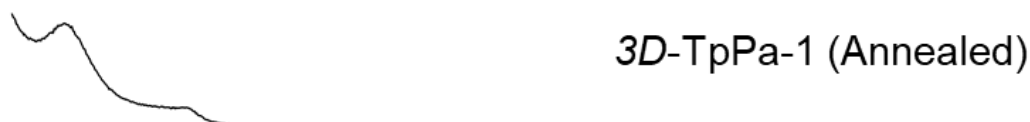

(b)

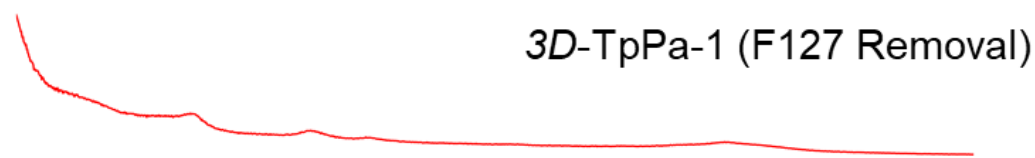

(a)

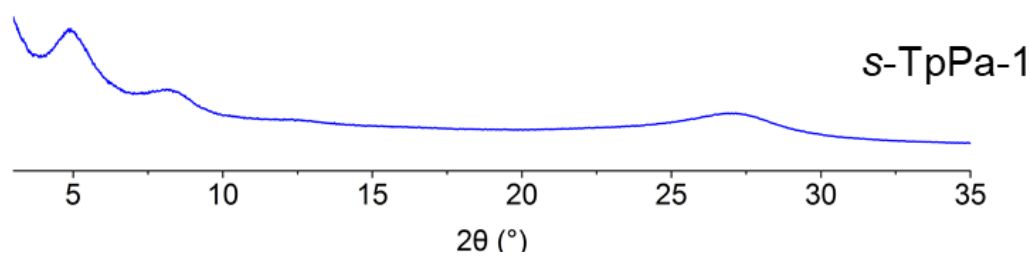

Figure S12. PXRD profiles of (a) s-TpPa-1, (b-c) as-synthesized 3D-TpPa-1 prepared in the absence of TsOH after F127 removal (b) and solvent annealing (c). 


\section{$2.1 \mathrm{mmol} \mathrm{TsOH}$}

(c)

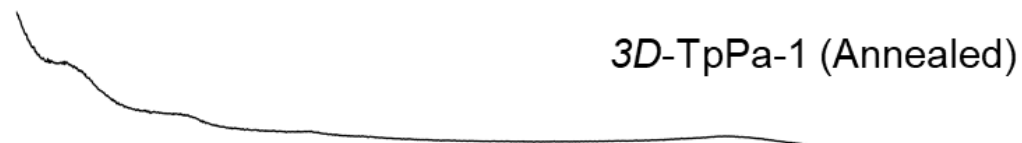

(b)

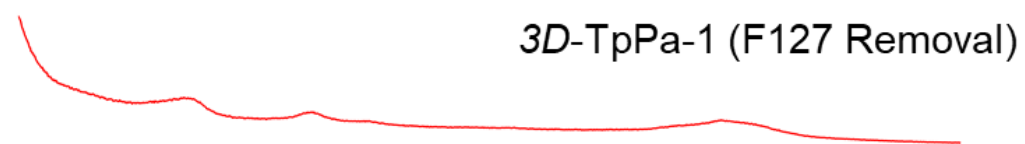

(a)

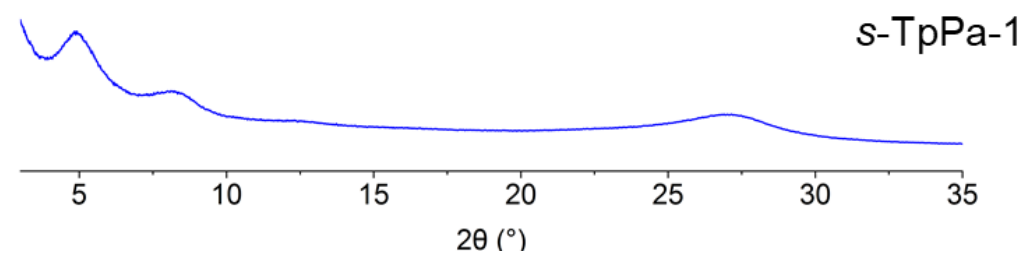

Figure S13. PXRD profiles of (a) s-TpPa-1, (b-c) as-synthesized 3D-TpPa-1 prepared in the presence of $\mathrm{TsOH}(2.1 \mathrm{mmol})$ after F127 removal (b) and solvent annealing (c).

(c)

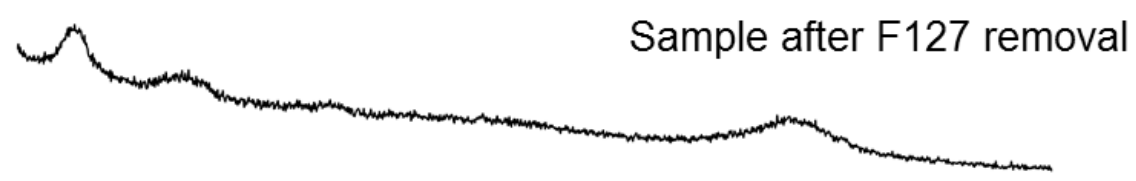

(b)

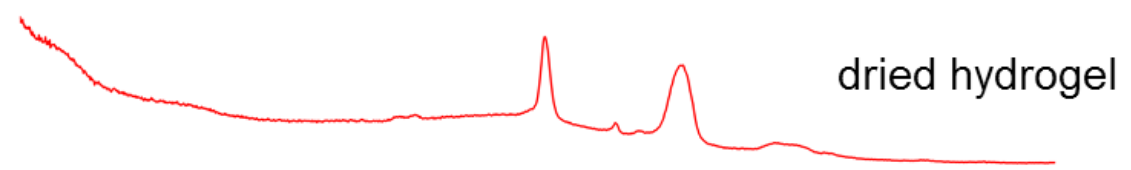

(a)

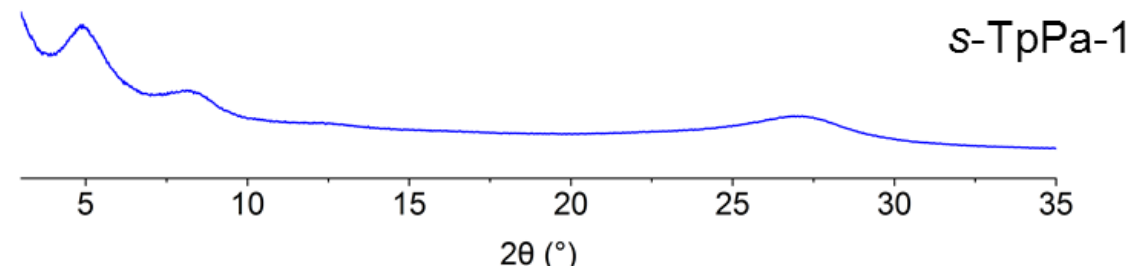

Figure S14. PXRD profiles of (a) s-TpPa-1, (b) air-dried $s$-TpPa-1/ F127 blend hydrogel and (c) sample after F127 removal. 
(c)

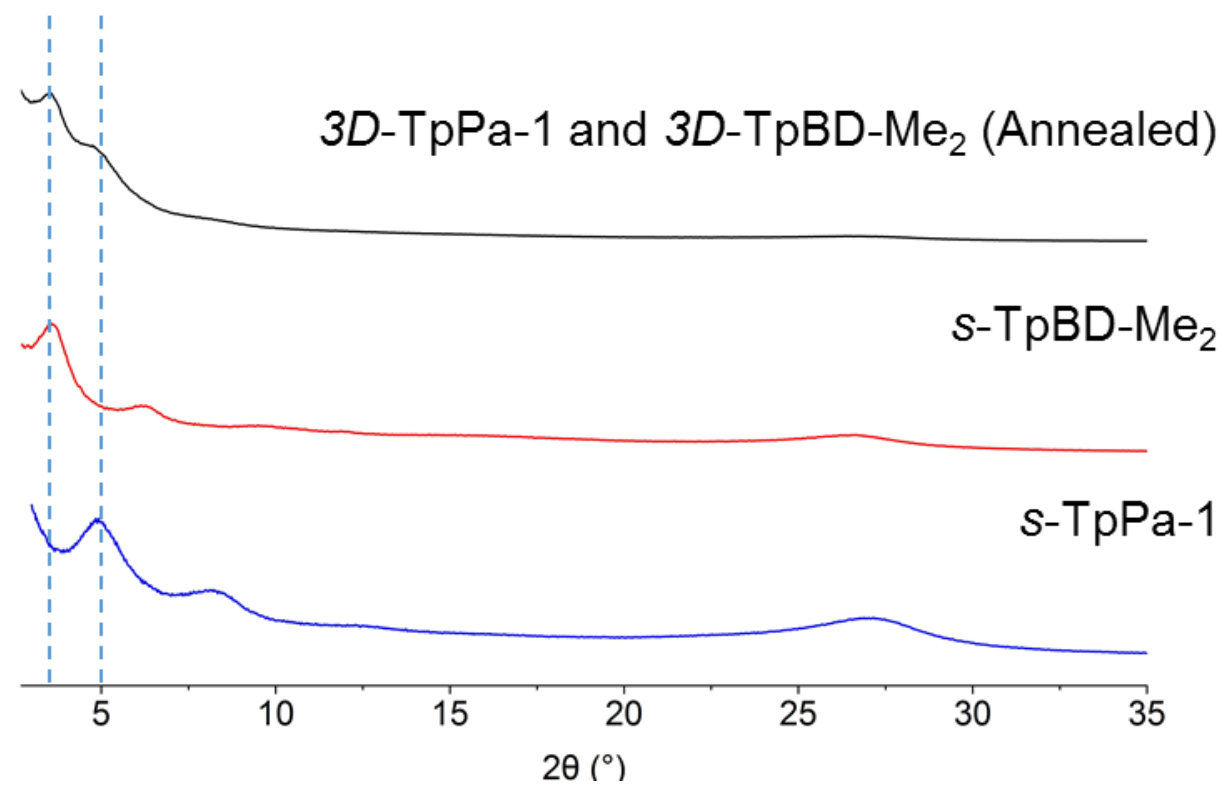

Figure S15. PXRD profiles of (a) $s$-TpPa-1, (b) $s$-TpBD-Me2, and (c) a 3D-printed [3D-TpPa1/TpBD-Me2] hetero-monolith.

(c)

(b)

(a)

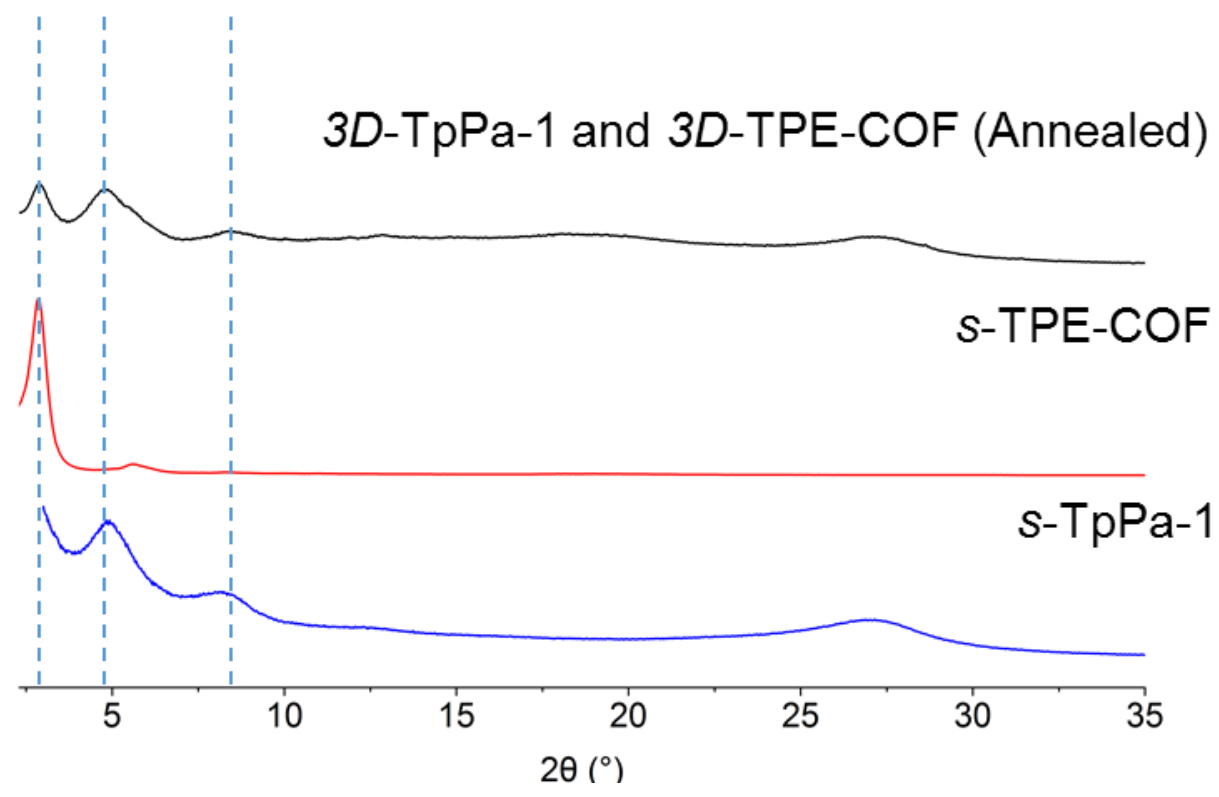

Figure S16. PXRD profiles of (a) $s$-TpPa-1, (b) $s$-TPE-COF, and (c) a 3D-printed hetero-COF monolith 3D-TpPa-1/TPE-COF. 
S4. FT-IR Spectroscopies

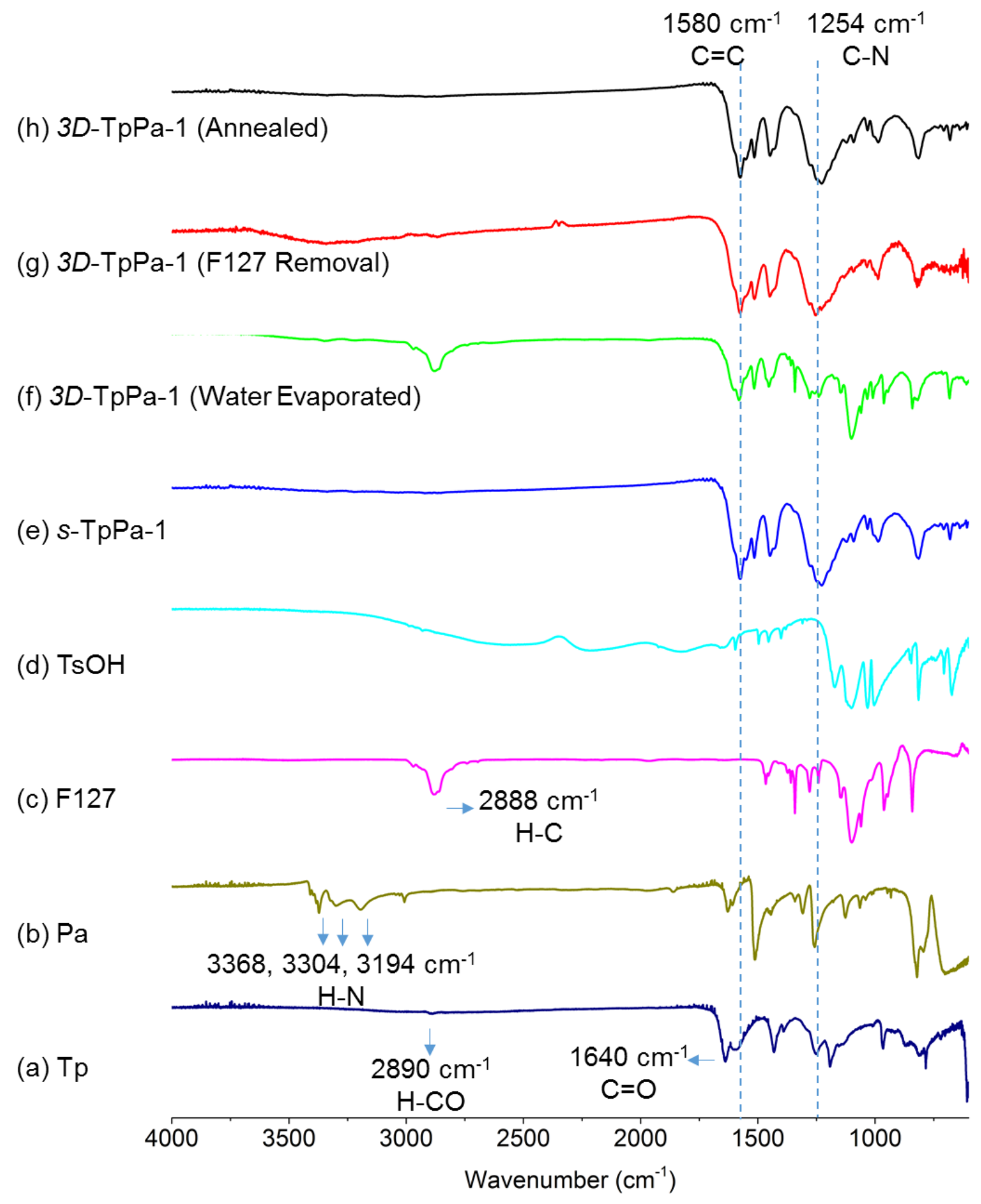

Figure S17. FT-IR of spectra of (a) Tp, (b) Pa, (c) F127, ${ }^{\mathrm{S} 5}$ (d) TsOH, (e) $\boldsymbol{s}$-TpPa-1, (f) $3 \boldsymbol{D}$-TpPa1 after water evaporation, (g) 3D-TpPa-1 after F127 removal and (h) 3D-TpPa-1 after solvent annealing. 


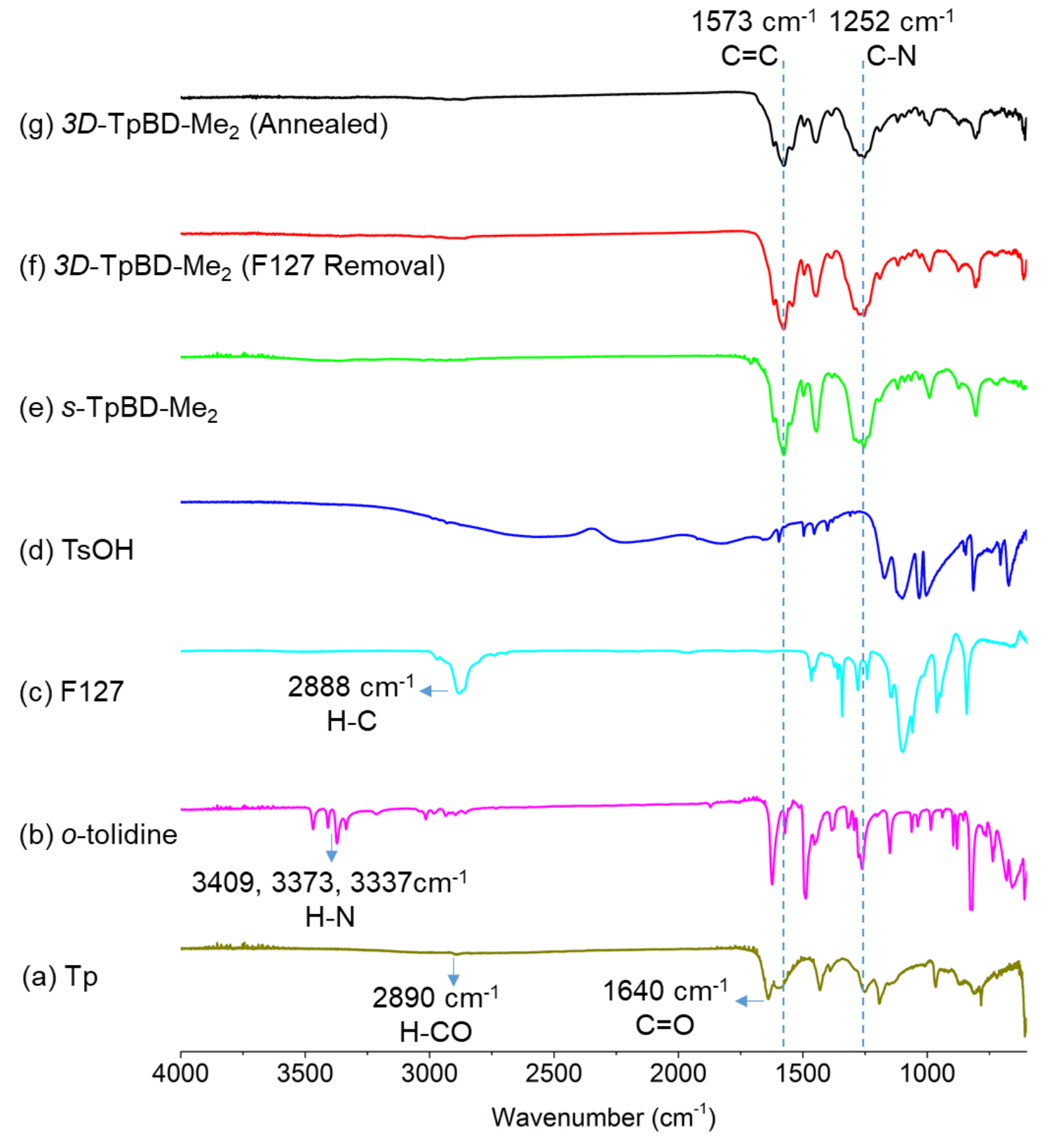

Figure S18. FT-IR spectra of (a) Tp, (b) $o$-tolidine, (c) F127, (d) TsOH, (e) $s$-TpBD-Me2, (f) $3 D$ TpBD-Me2 after F127 removal, (g) 3D-TpBD-Me2 after solvent annealing. 


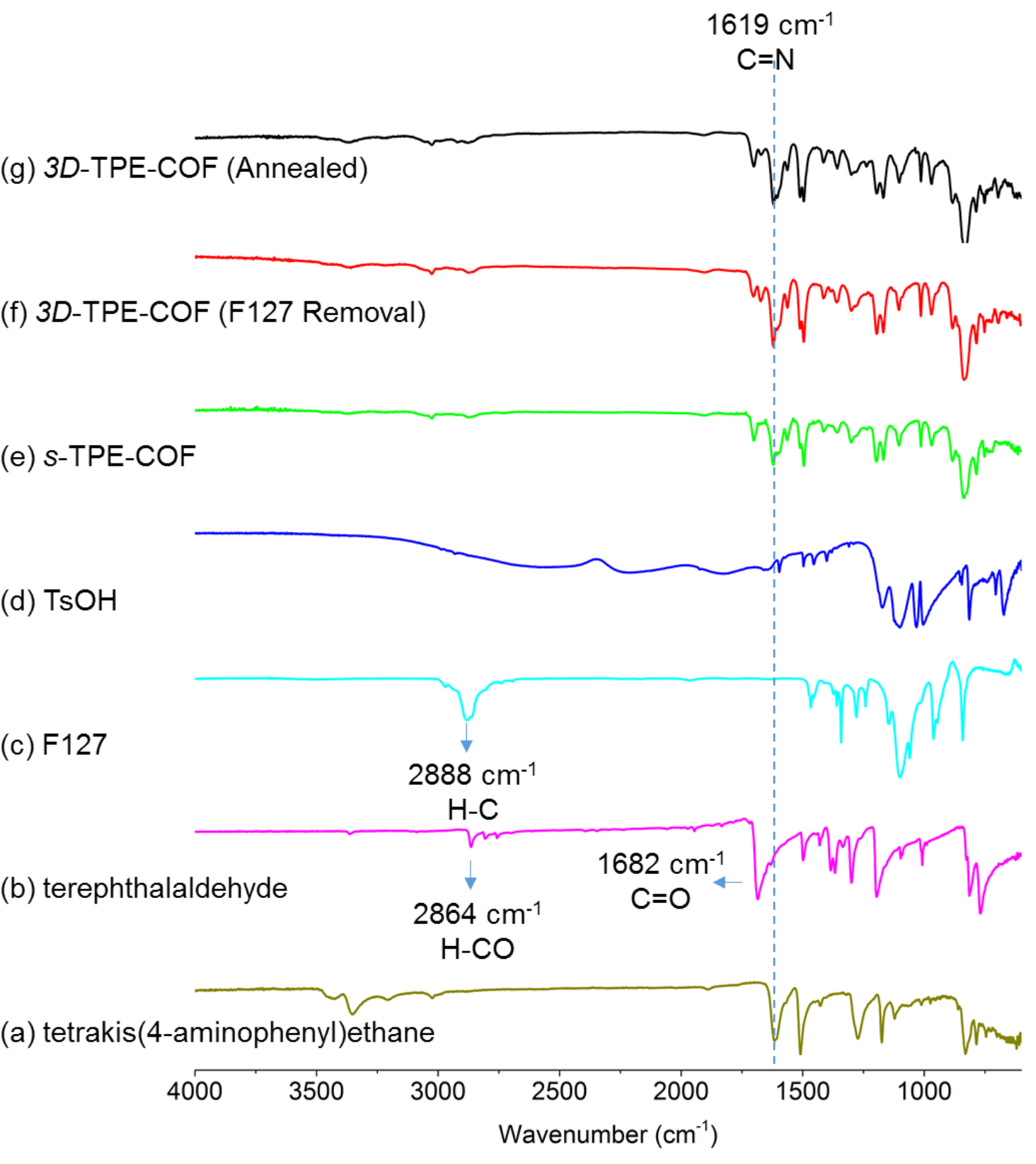

Figure S19. FT-IR spectra of (a) tetrakis(4-aminophenyl)ethene, (b) terephthalaldehyde, (c) F127, (d) TsOH, (e) $\boldsymbol{s}$-TPE-COF, (f) 3D-TPE-COF after F127 removal, and (g) 3D-TPE-COF after solvent annealing. 


\section{S5. Rheological Studies and 3D Printing}

General information. To evaluate the rheological properties of the prepared hydrogel for 3D printing, the elastic $\left(\mathrm{G}^{\prime}\right)$ and loss $\left(\mathrm{G}^{\prime \prime}\right)$ moduli and self-healing behaviors were investigated. The rheological measurements were performed on a stress-controlled rheometer (TA instrument, DHR2) with a 20-mm diameter parallel plate geometry and a measuring gap of $1 \mathrm{~mm}$.

In order to measure the critical gelation temperature of Pluronic F127 hydrogels (30 w/v\%) in the presence of various amount of $\mathrm{TsOH}$, three samples of $\mathrm{F} 127$ hydrogel with $0 \mathrm{M}, 0.6 \mathrm{M}$, and $1.0 \mathrm{M}$ $\mathrm{TsOH}$ were prepared for temperature-dependent rheological measurements. The elastic and loss moduli of the hydrogel were monitored at an angular frequency of $1 \mathrm{rad} / \mathrm{s}$ at different temperatures. During this time-dependent measurement, the temperature was increased from $25^{\circ} \mathrm{C}$ to $90{ }^{\circ} \mathrm{C}$ with a heating speed of $5{ }^{\circ} \mathrm{C} / \mathrm{min}$. An addition of $120 \mathrm{~s}$ equilibrium time was added before each test.

Study of the F127/S1 interactions. In order to investigate the interactions between F127 and imine/ $\beta$-ketoenamine polymers, model compound $\mathbf{S 1}$ was employed as a soluble molecular segment of the TpPa-1 for UV-Vis studies. Experimentally, various amounts of F127 (0 wt\%, 10 $\mathrm{wt} \%$, and $20 \mathrm{wt} \%$ ) were added to a saturated $\mathrm{S1}_{2} \mathrm{O} / \mathrm{CH}_{3} \mathrm{OH}(\mathrm{v} / \mathrm{v}=1 / 1,3 \mathrm{~mL})$ solution for UVVis measurements. In the presence of F127, the shoulder peak at 465 and $335 \mathrm{~nm}$ was diminished as a result of F127-induced $\mathbf{S 1}$ de-aggregation.

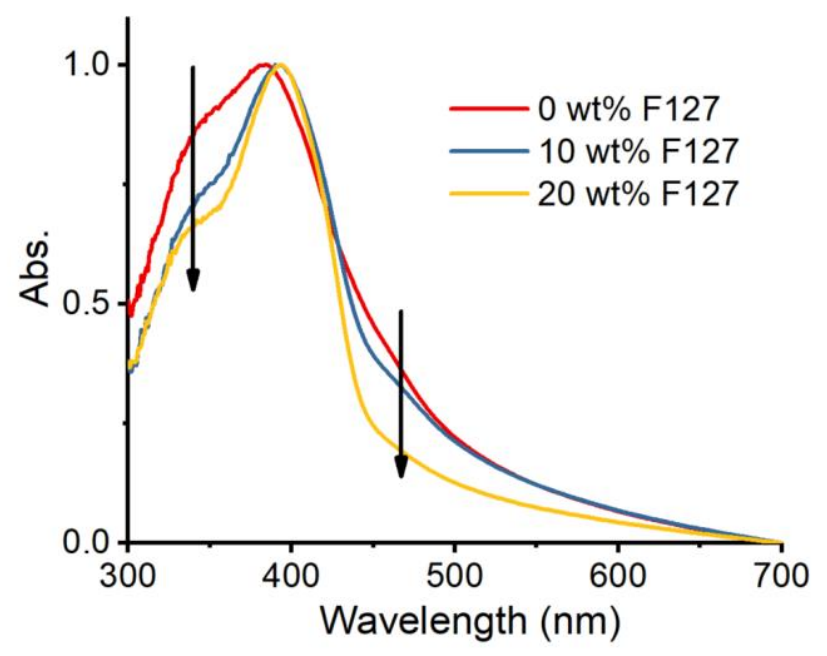

Figure S20. Normalized UV-Vis spectra of $\mathbf{S 1}$ in $\mathrm{H}_{2} \mathrm{O} / \mathrm{CH}_{3} \mathrm{OH}(\mathrm{v} / \mathrm{v}=1 / 1)$ with various amount of F127 (0 wt $\%, 10 \mathrm{wt} \%$, and $20 \mathrm{wt} \%)$. 


\section{Rheological measurements of the 3D-printable imine polymer/F127 co-assembled hydrogels.}

To evaluate the 3D printability of COF precursor inks, oscillation strain sweep and dynamic step strain amplitude tests were performed at room temperature.

Direct-ink-write 3D Printing. 3D printing experiments were performed on an extrusion-based 3D printer (Tabletop, nScrypt) equipped with Nordson EFD precision smoothflower tapered tips. The freshly prepared hydrogels were loaded into Nordson EFD syringe barrels $(3 \mathrm{~mL})$ and installed onto the 3D printer. Three types of printing paths were generated by P-CAD software, which includes lattice cube, pyramid, and house. The printing pressure was controlled between 30 and 50 psi based on the viscosity and critical stress of different hydrogels. Printing speed was varied between 20 and $40 \mathrm{~mm} / \mathrm{s}$ to allow smooth extrusion of inks from the printing nozzle.

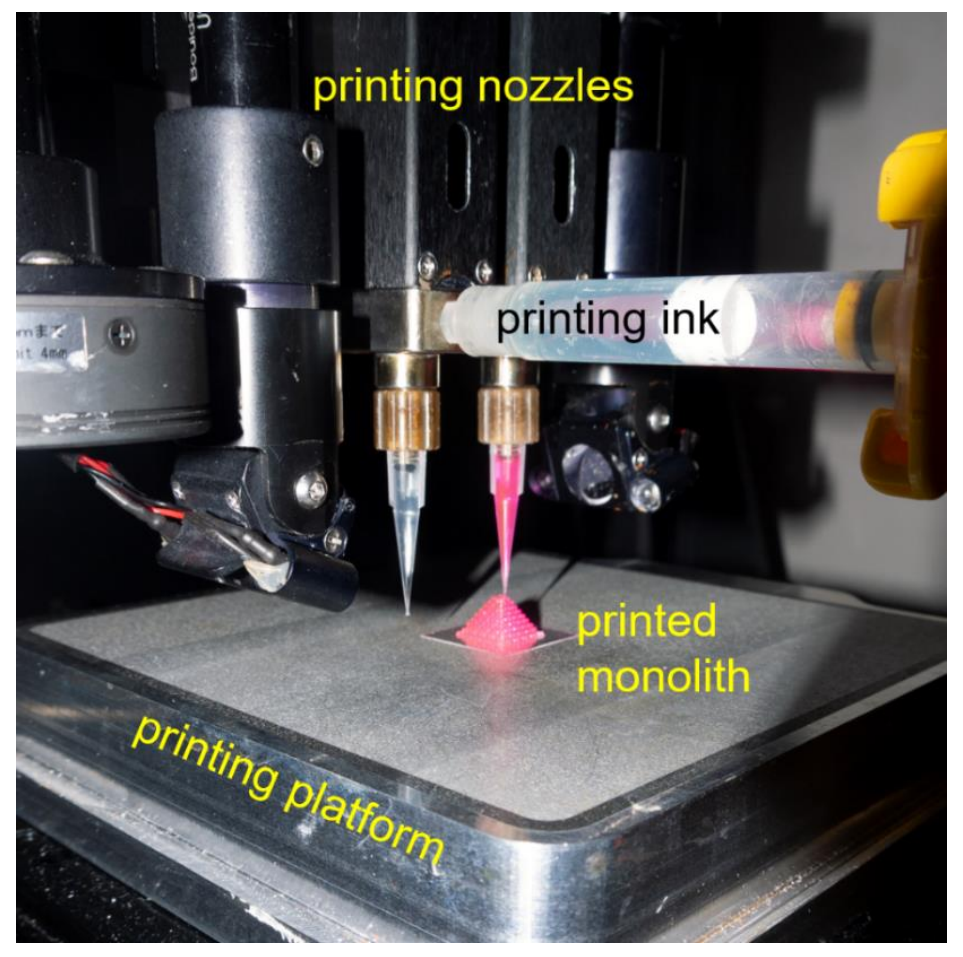

Figure S21. The 3D printing platform employed in this investigation.

Single component 3D printing: lattice pyramids $(12.0 \times 12.0 \times 7.2 \mathrm{~mm})$ consisting of four repetitive layers were $3 \mathrm{D}$ printed with good structural integrity on glass slides.

Dual-component 3D printing using: G1, G2, and G3 were loaded into separate syringe barrels and installed onto different printing heads of the $3 \mathrm{D}$ printer. The heterogeneous structures were fabricated by printing the bottom section using $\mathbf{G 1}$ and top section using $\mathbf{G 2}$ or $\mathbf{G 3}$. 

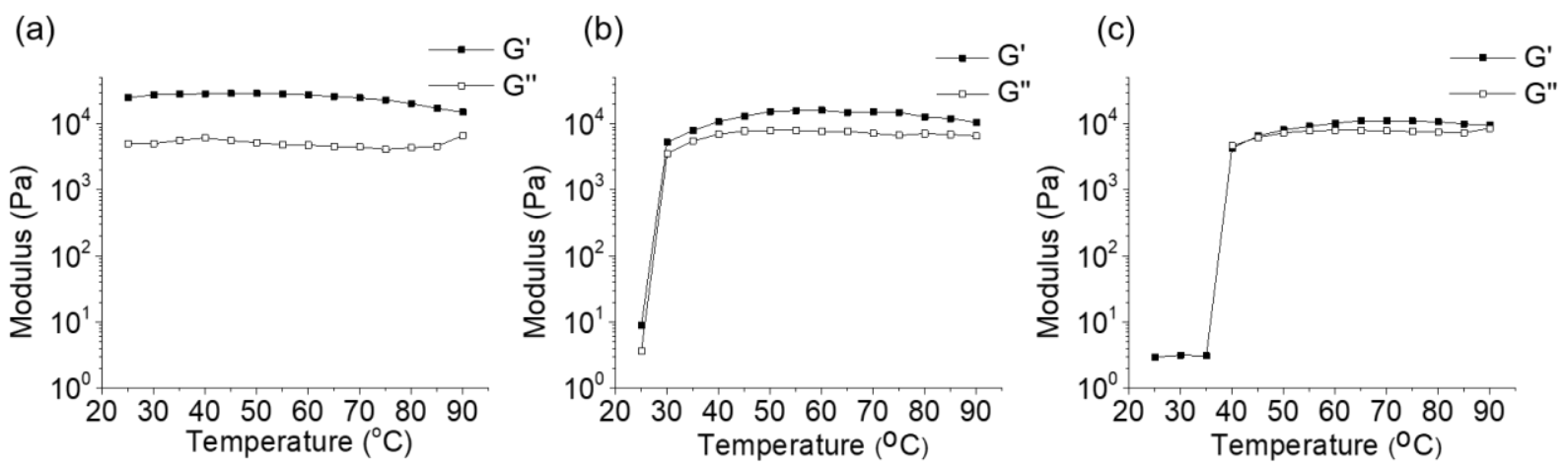

Figure S22. Time-dependent elastic $\left(\mathrm{G}^{\prime}\right)$ and loss moduli $\left(\mathrm{G}^{\prime \prime}\right)$ of $\mathrm{F} 127$ hydrogel $(30 \mathrm{w} / \mathrm{v} \%)$ in the presence of TsOH at (a) $0 \mathrm{M}$, (b) $0.6 \mathrm{M}$, and (c) $1.0 \mathrm{M}$. Compared with the F127-only hydrogel, the critical gelation temperature of these hydrogels in the presence of $\mathrm{TsOH}$ were increased to 25 and $35^{\circ} \mathrm{C}$, respectively.

(a)

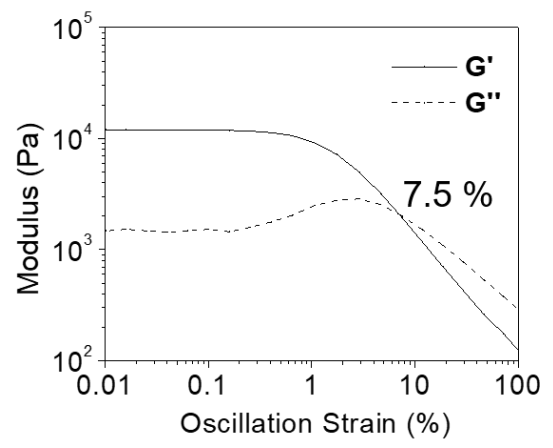

(b)

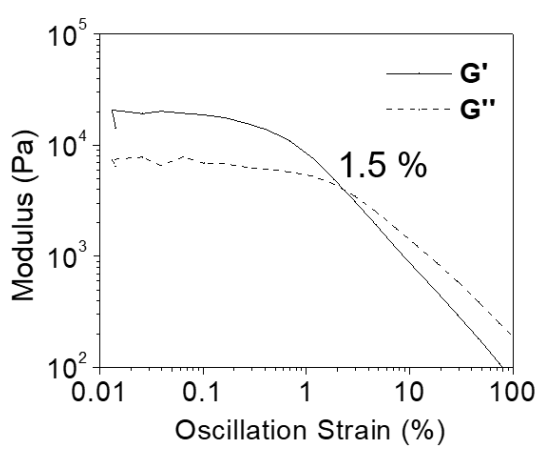

(c)

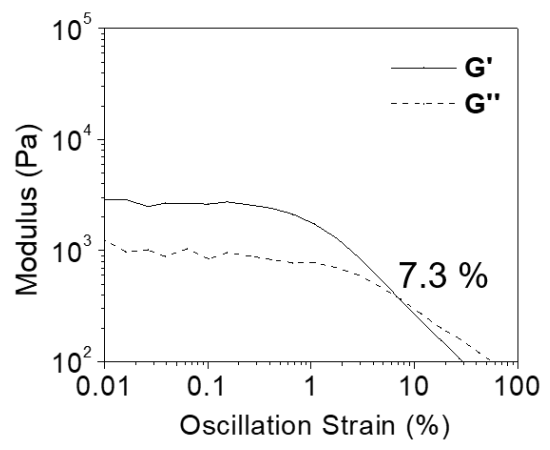

Figure S23. Oscillation strain sweep profiles of the prepared (a) G1, (b) G2, and (c) G3 hydrogels, respectively. The $G^{\prime}$ and $G^{\prime \prime}$ of the prepared inks were recorded with the oscillation strains increased from $0.01 \%$ to $100 \%$ and an angular frequency of $10 \mathrm{rad} / \mathrm{s}$. G1, G2, and G3 possess yield strains (where $\mathrm{G}^{\prime}=\mathrm{G}^{\prime \prime}$ ) of $7.5 \%, 1.5 \%, 7.3 \%$, respectively. 
(a)

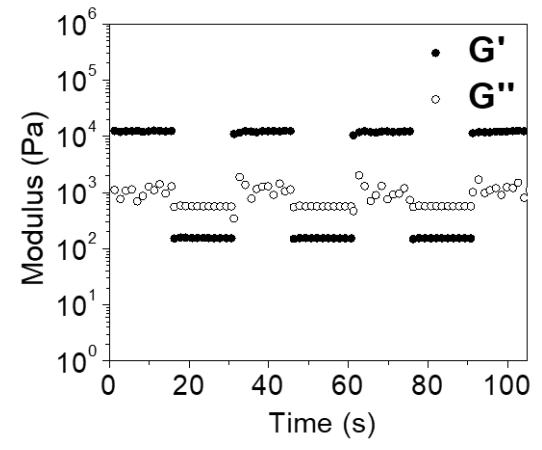

(b)

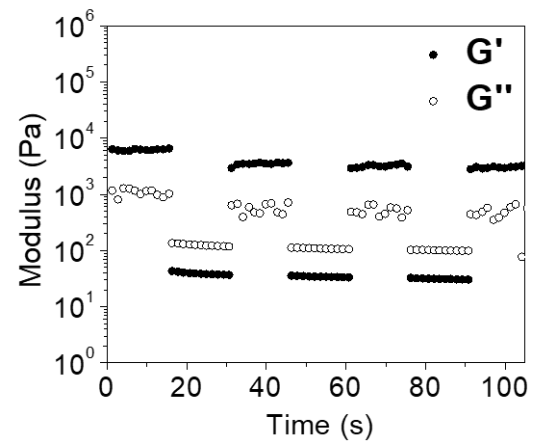

(c)

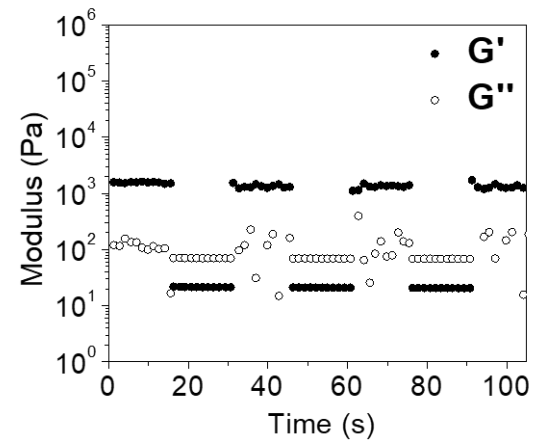

Figure S24. Step-strain sweep profiles of the prepared (a) G1, (b) G2, and (c) G3 hydrogels. The $\mathrm{G}^{\prime}$ and $\mathrm{G}^{\prime \prime}$ were recorded with a strain of $0.1 \%$ and $100 \%$ alternatively at an angular frequency of $10 \mathrm{rad} / \mathrm{s}$. The period of each step is $15 \mathrm{~s}$ and no additional equilibrium time set in between.
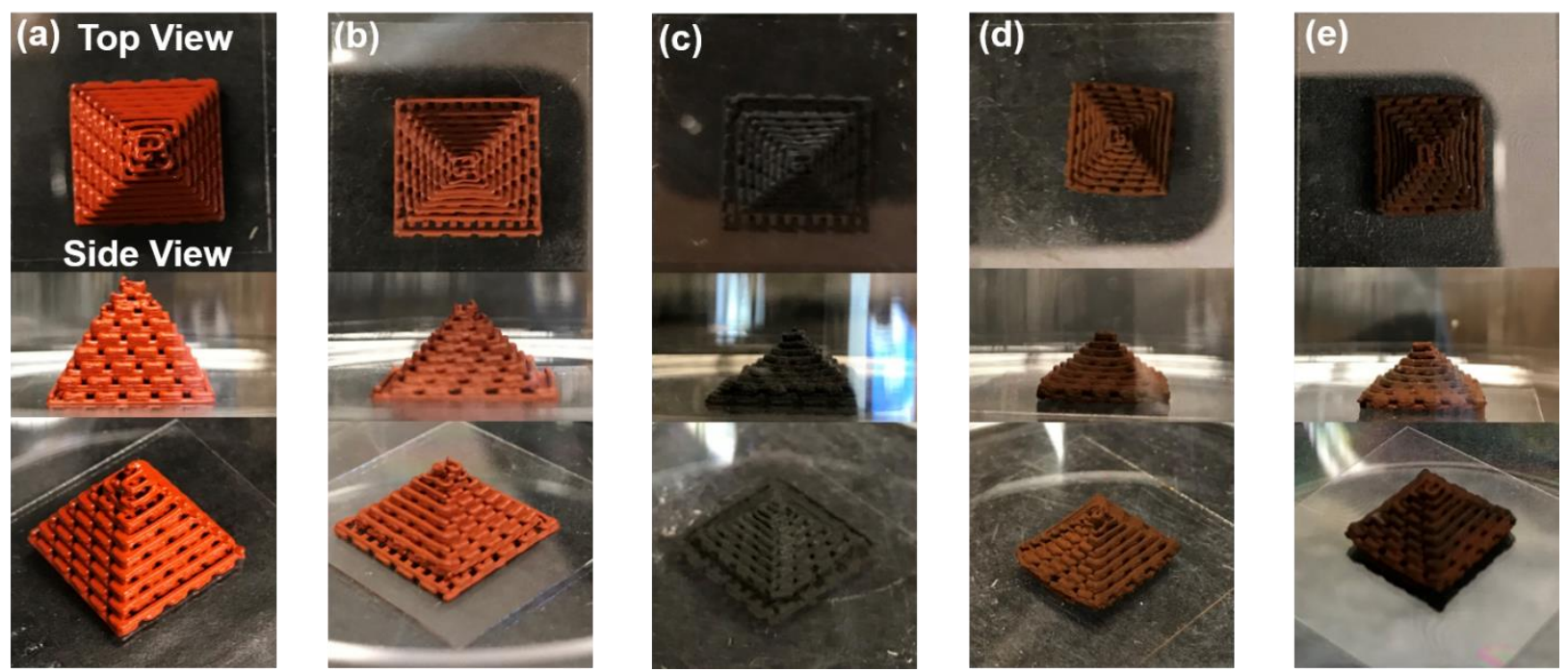

Figure S25. Images of a 3D-printed pyramid composed of TpPa-1 precursors and F127 ink at different stages: (a) as-printed; (b) after drying; (c) after heating at $90{ }^{\circ} \mathrm{C}$; (d) after $\mathrm{F} 127$ template removal; (e) after solvent annealing. 

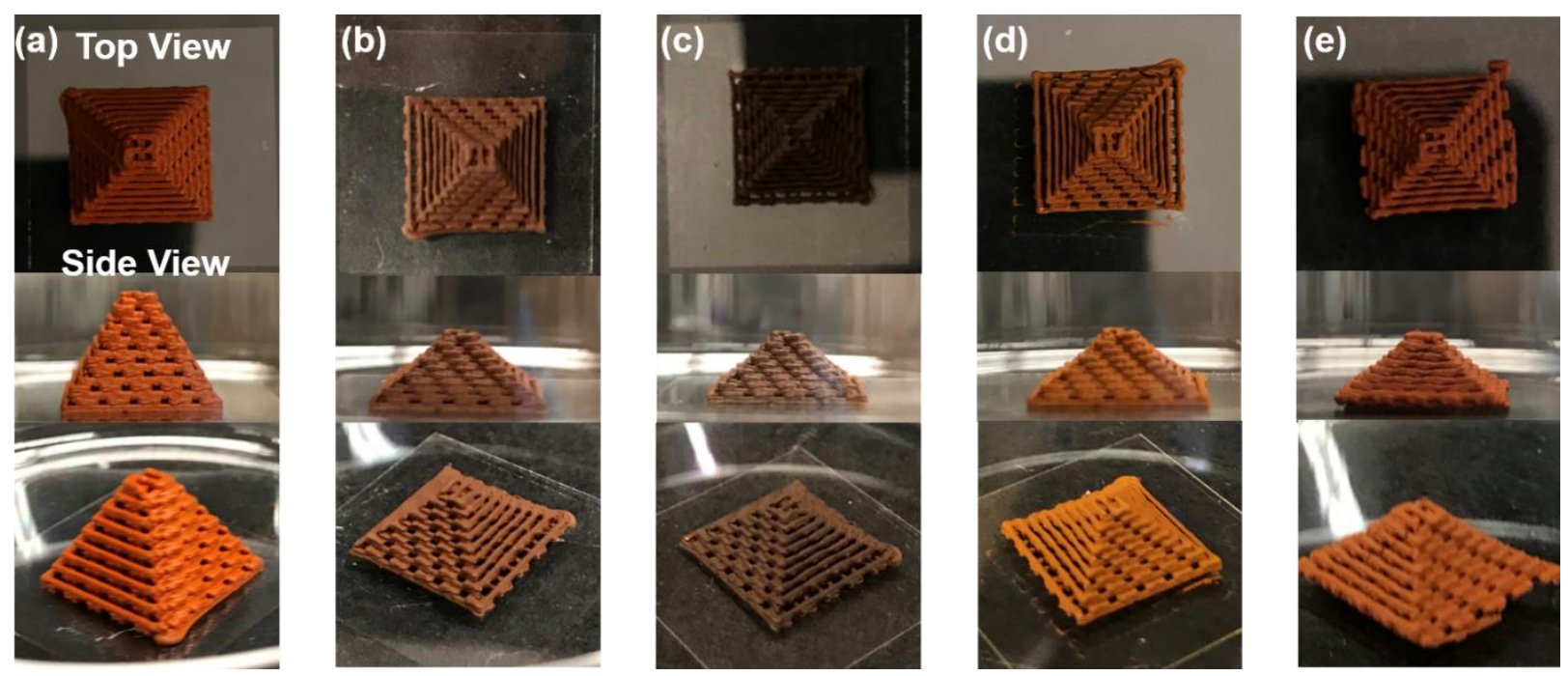

Figure S26. Images of a 3D-printed pyramid composed of TpBD-Me2 precursors and F127 ink at different stages: (a) as-printed; (b) after drying; (c) after heating at $90{ }^{\circ} \mathrm{C}$; (d) after F127 template removal; (e) after solvent annealing.
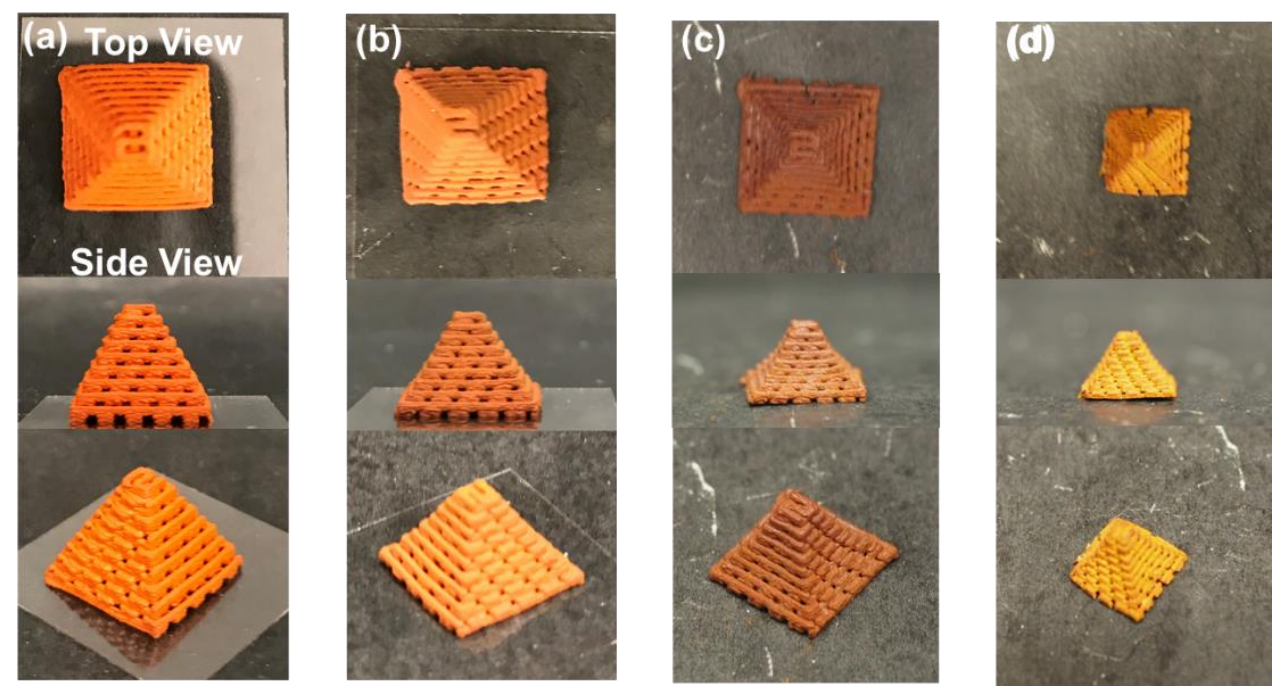

Figure S27. Images of a 3D-printed pyramid composed of TPE-COF precursors and F127 ink at different stages: (a) as-printed; (b) after drying; (c) after heating at $90{ }^{\circ} \mathrm{C}$; (d) after solvent annealing and F127 template removal. 


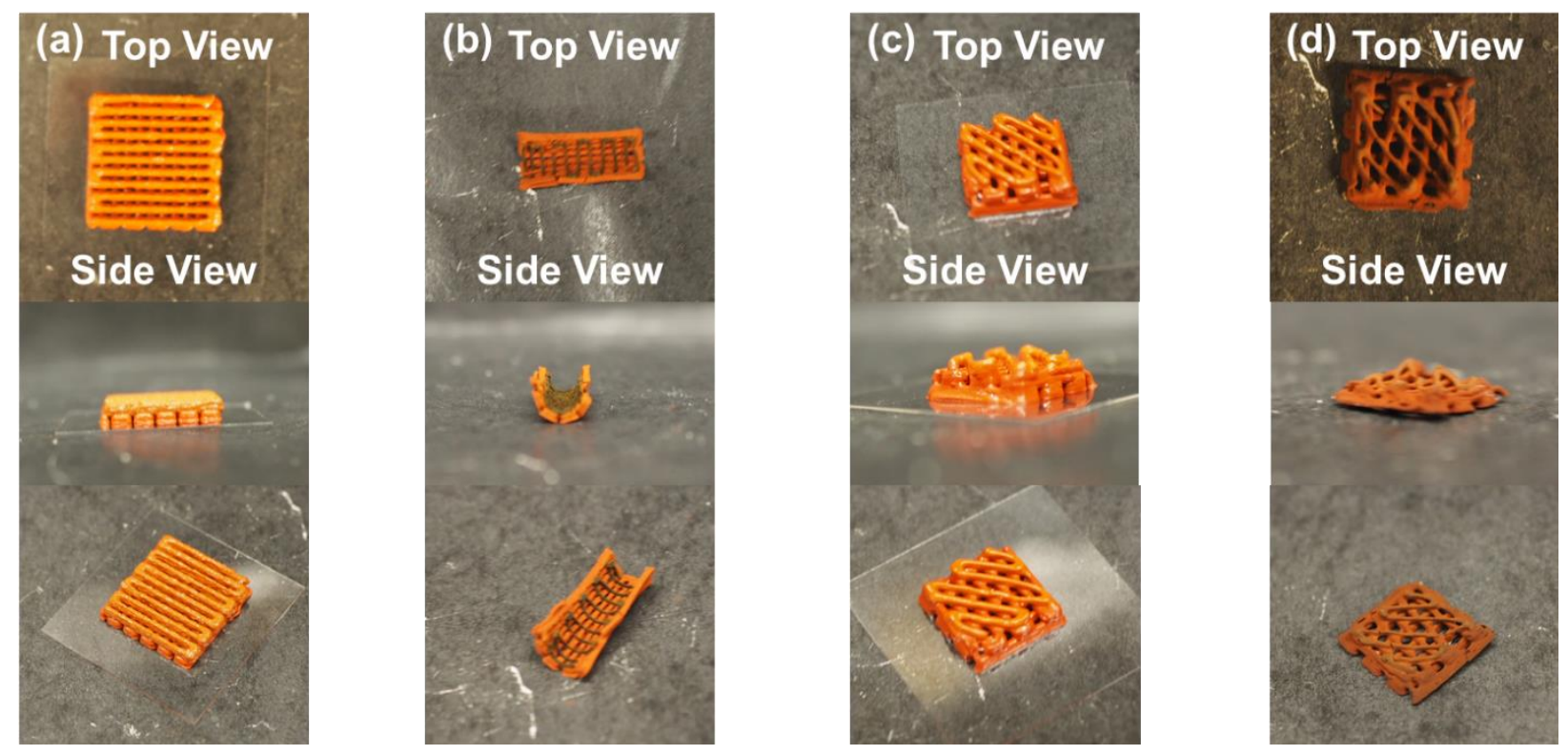

Figure S28. Images of 3D-printed hetero-COF monoliths. (a) An as-printed 3D-printed [3DTpPa-1/ TPE-COF] hetero-monolith; (b) a 3D-printed [3D-TpPa-1/ TPE-COF] hetero-monolith after solvent annealing; (c) an as-printed 3D-printed [3D-TpPa-1/ TpBD-Me2] hetero-monolith; (d) a 3D-printed [3D-TpPa-1/ TpBD-Me2] hetero-monolith after solvent annealing.

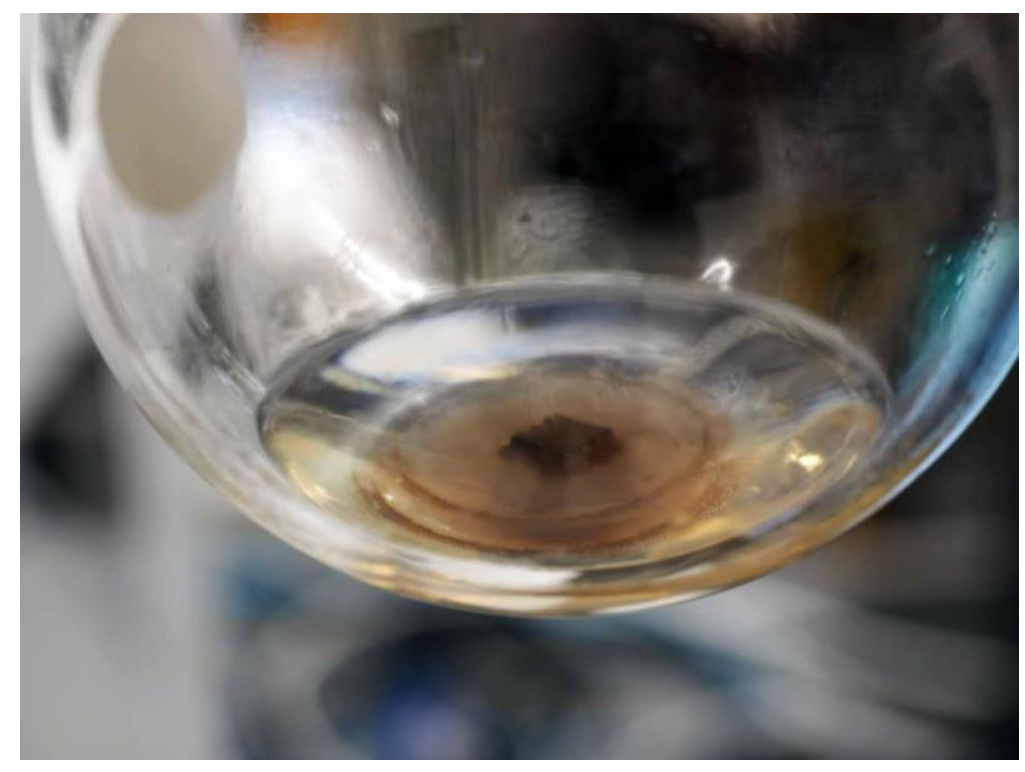

Figure S29. Image of the solvent annealing setup for the amorphous-to-crystalline transformation. 
S6. Morphology Analysis

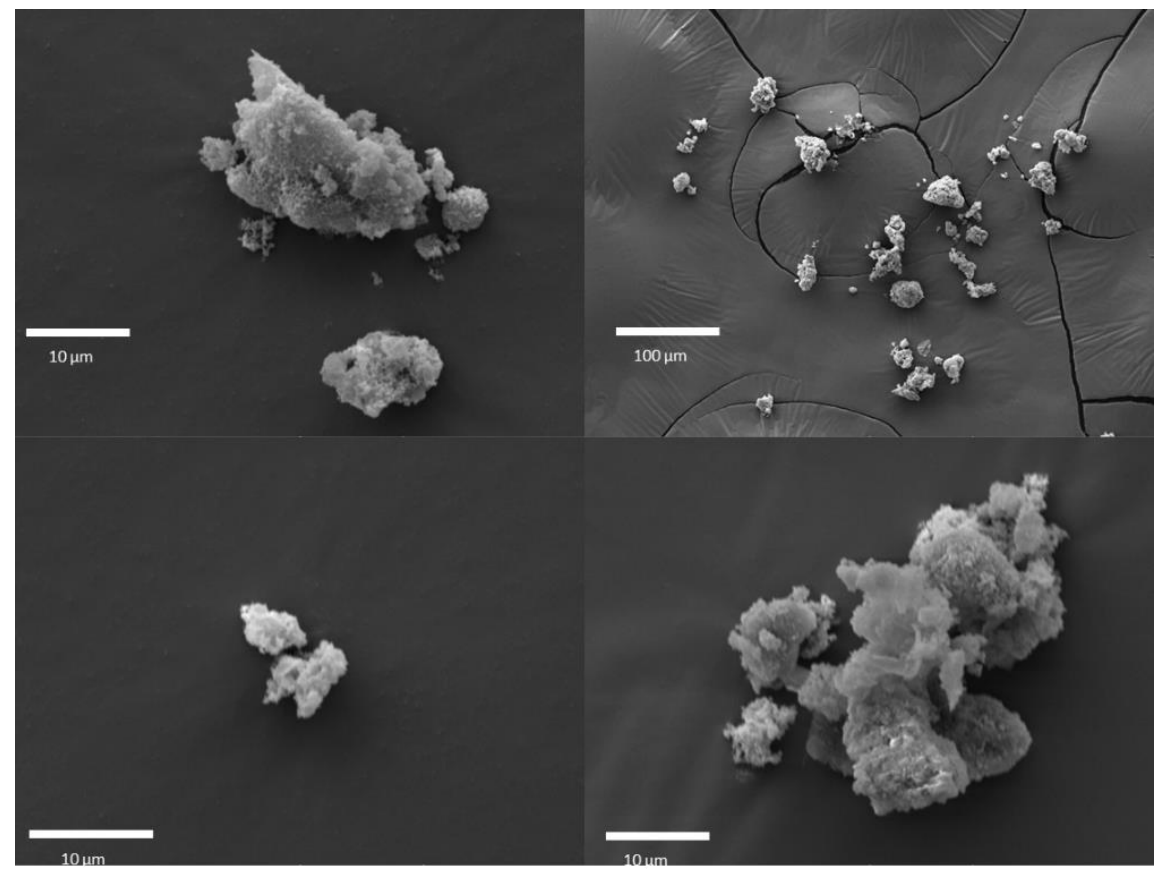

Figure S30. SEM images of $s$-TpPa-1 powder.

(a)
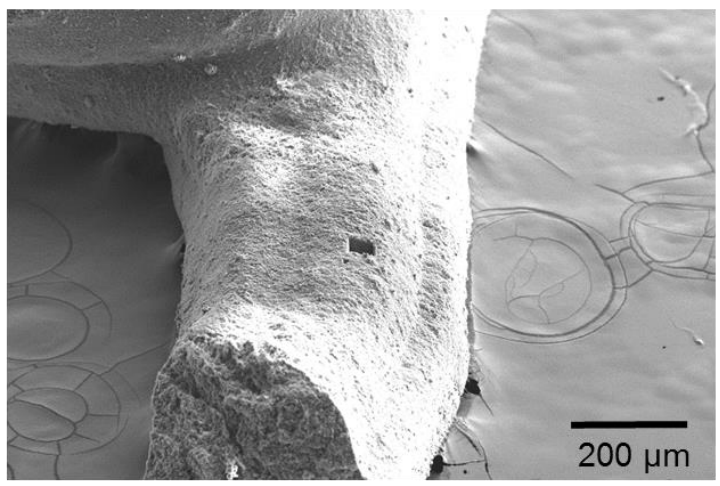

(c)

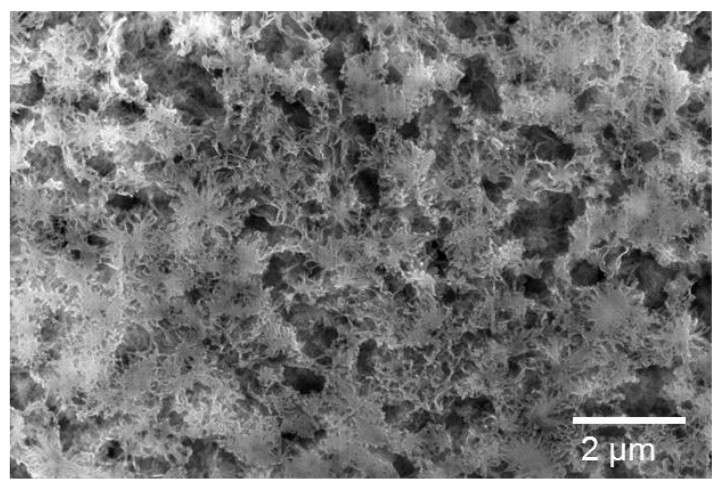

(b)

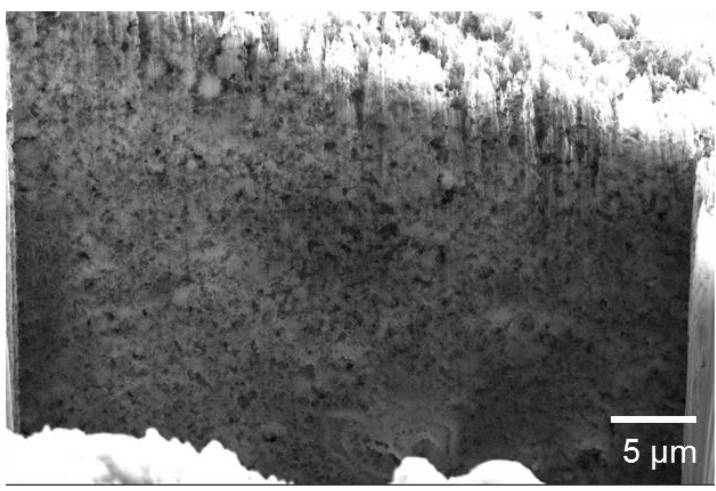

(d)

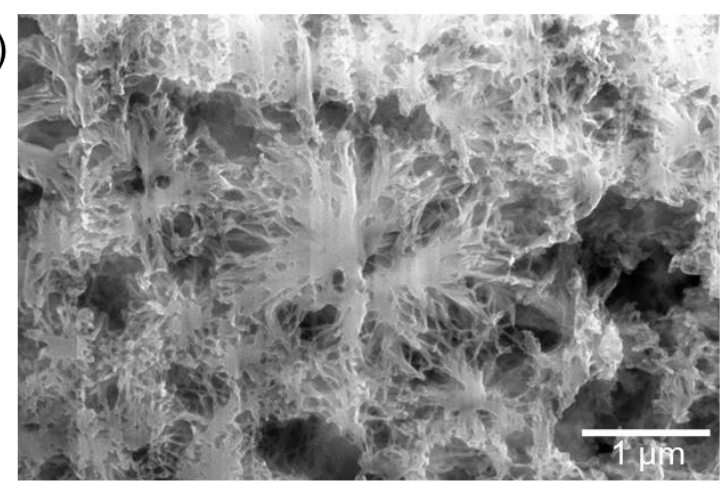

Figure S31. SEM images of a 3D-TpPa-1 monolith after solvent annealing. The cross-sectioned sample of the 3D-TpPa-1 monolith was prepared by $\mathrm{Ga}^{+}$ion beam etching on an FEI dual beam Scios Low Vacuum SEM / FIB. 
(c)

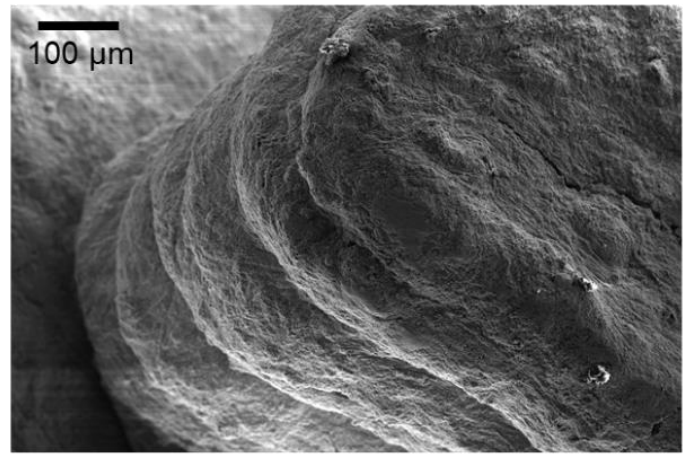

(e)

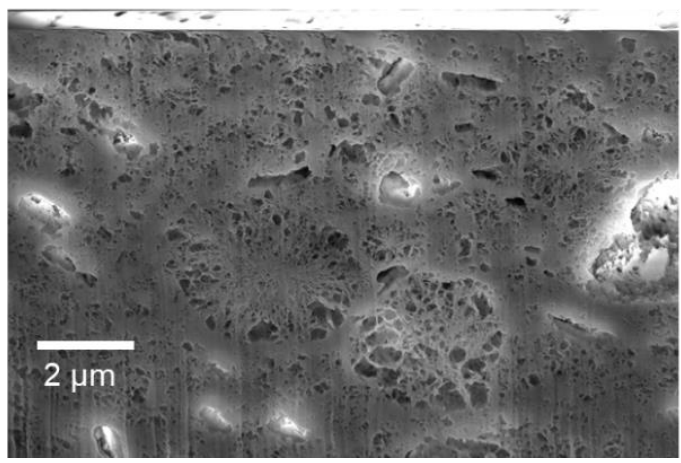

(d)

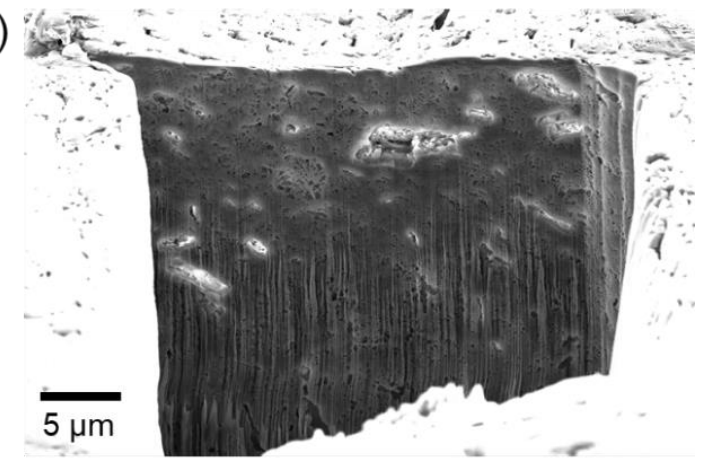

(f)

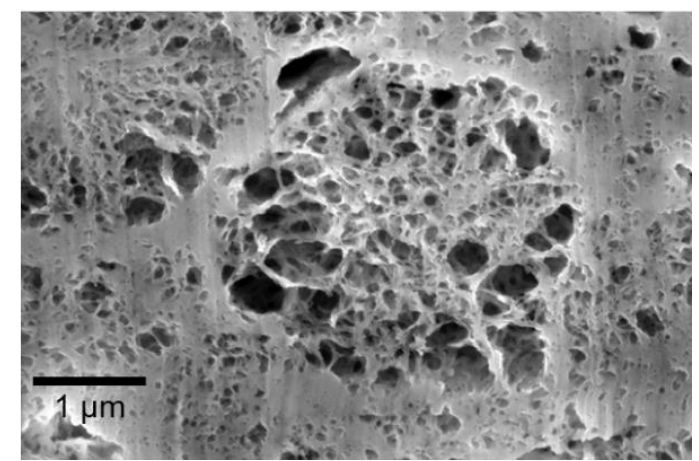

Figure S32. SEM images of a 3D-TpBD-Me2 monolith after solvent annealing. The 3D-TpBDMe2 monolith was cross-sectioned by $\mathrm{Ga}^{+}$ion beam and observed with the electron beam on an FEI dual beam Scios Low Vacuum SEM/ FIB

(a)

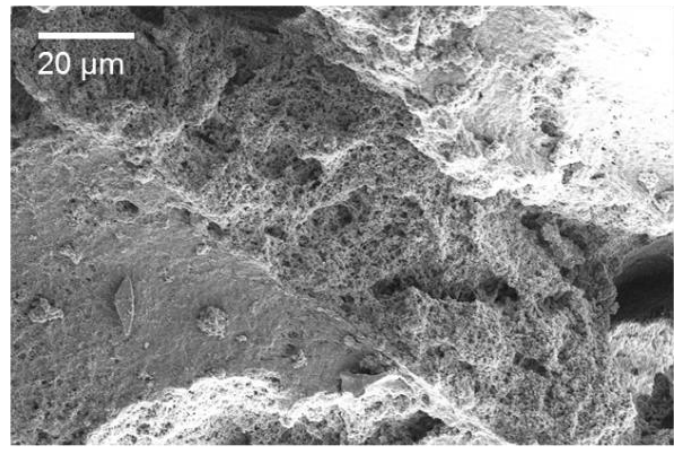

(c)

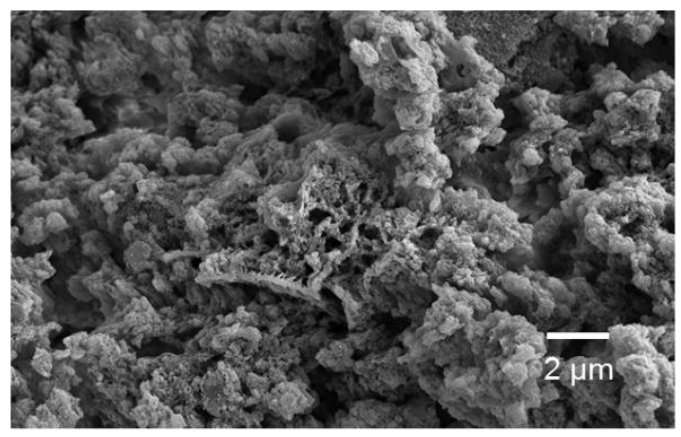

(b)

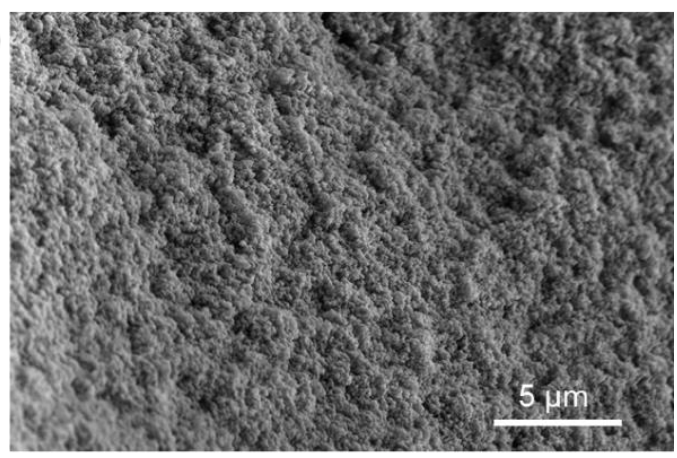

(d)

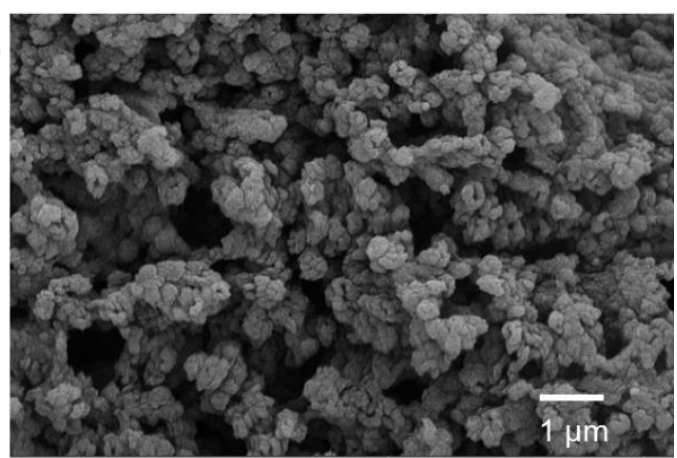

Figure S33. SEM images of 3D-TPE-COF monolith after solvent annealing, which was physically broken to expose the interior structure. 
(a)

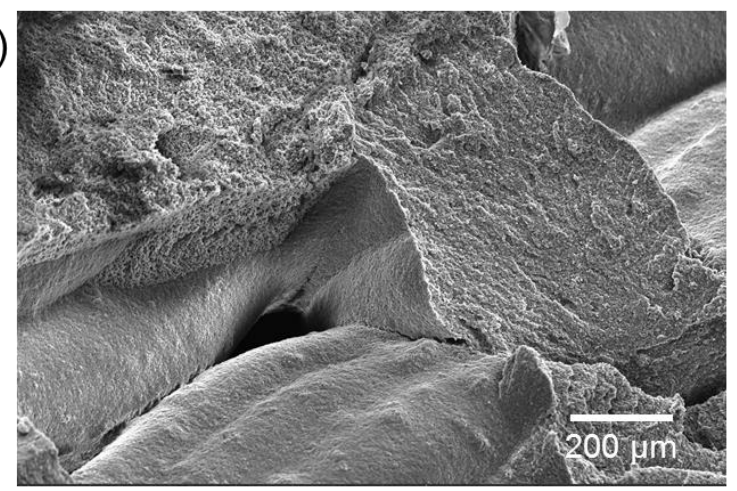

(c)

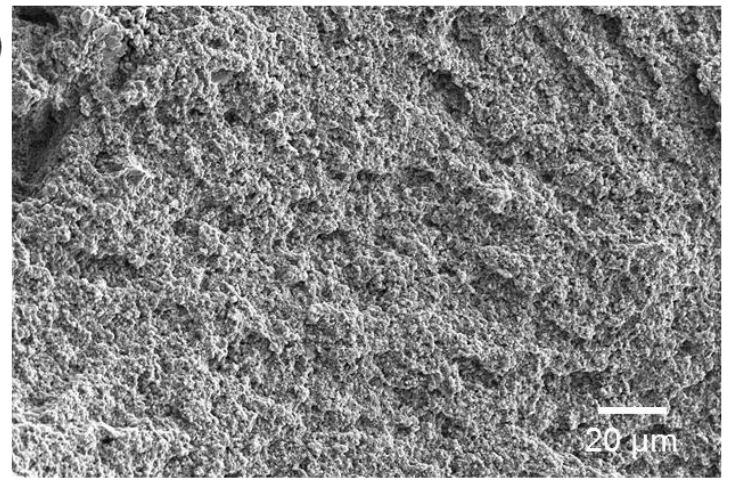

(e)

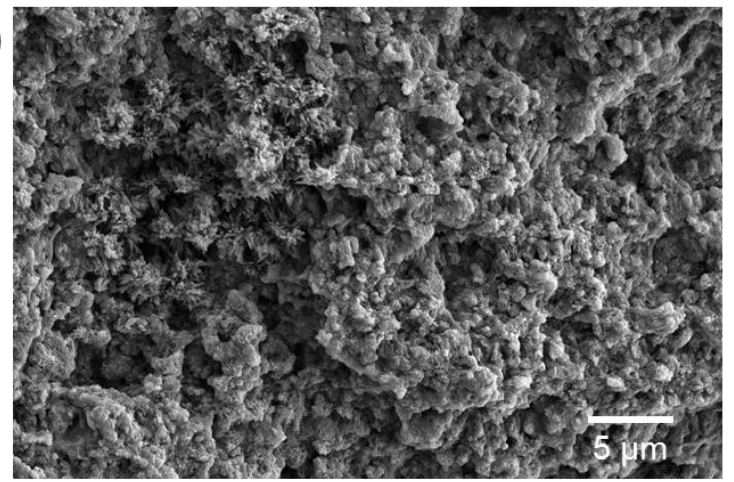

(b)

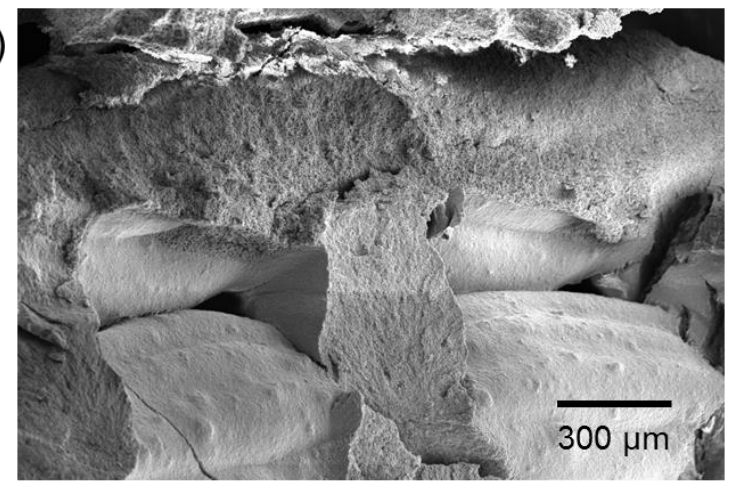

(d)

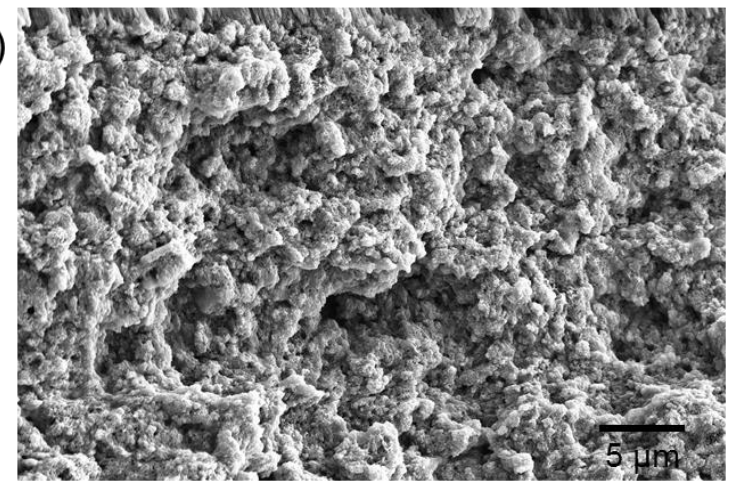

(f)

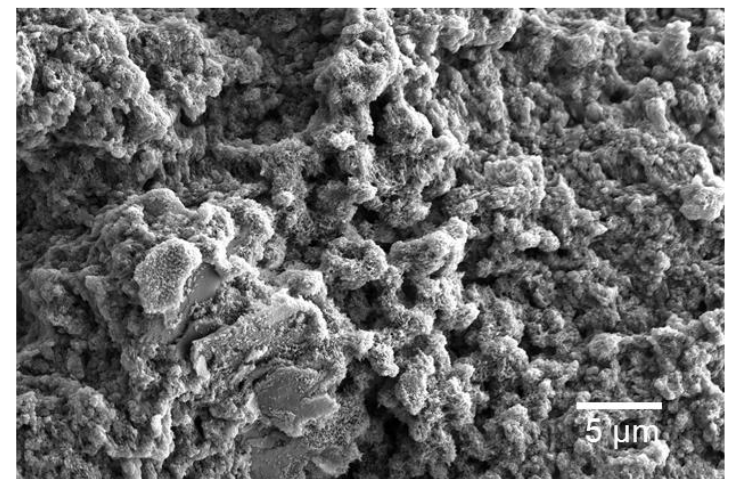

Figure S34. SEM images of a 3D-printed [3D-TpPa-1/TpBD-Me2] hetero-monolith, which was physically broken to expose the interface between two COFs. Images of (a-d) the interface of $3 D$ TpPa-1/TpBD-Me2, (e) 3D-TpPa-1 section in the hetero-monolith, and (f) $3 D$-TpBD-Me2 section in the hetero-monolith. 
S7. Porosity Analysis

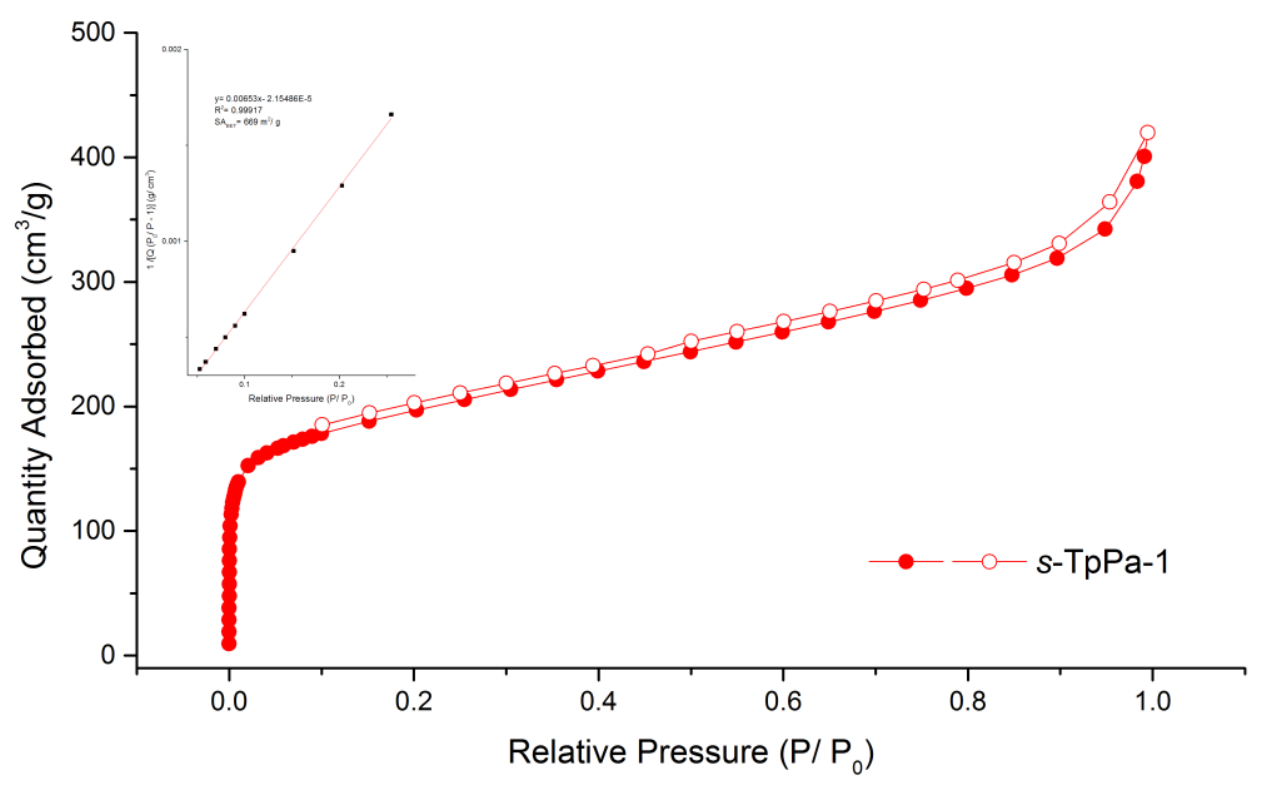

Figure S35. $\mathrm{N}_{2}$ sorption isotherm of $\boldsymbol{s}$-TpPa-1 measured at $77 \mathrm{~K}$ (BET surface area $=669 \mathrm{~m}^{2} / \mathrm{g}$ ).

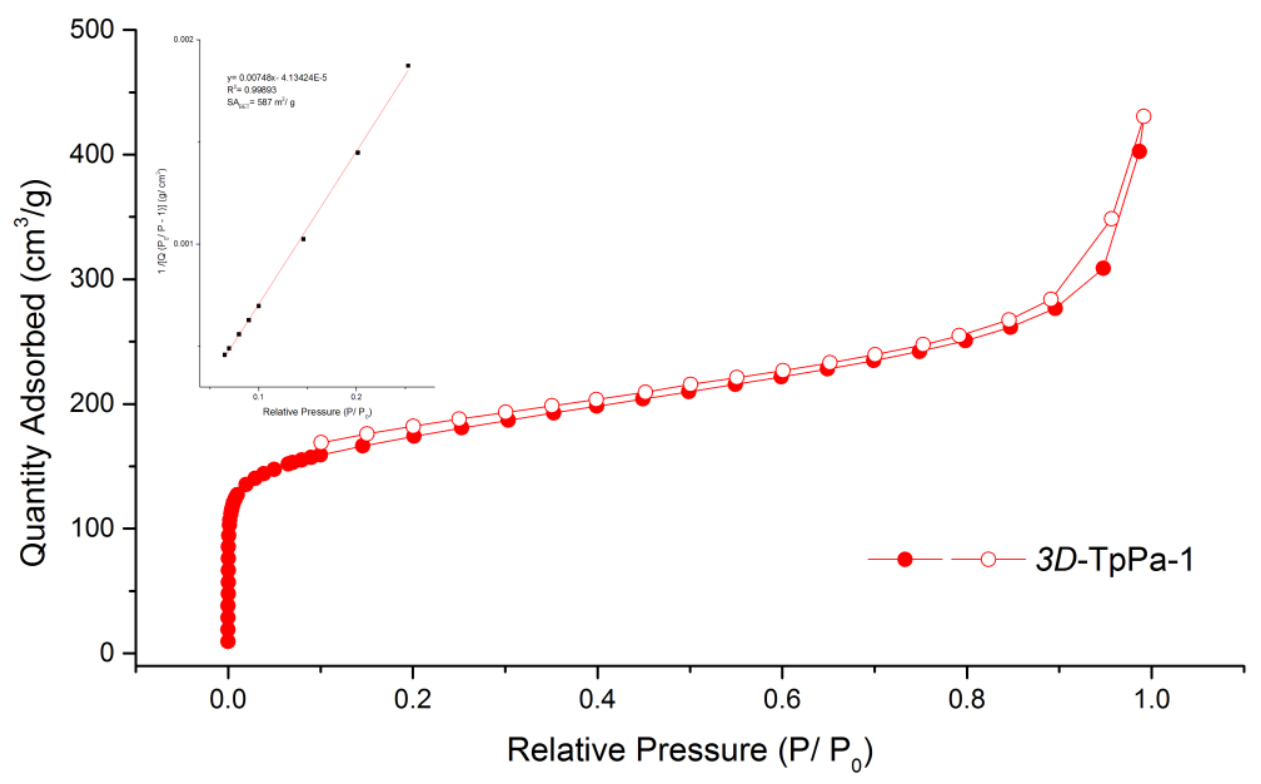

Figure S36. $\mathrm{N}_{2}$ sorption isotherm of 3D-TpPa-1 measured at $77 \mathrm{~K}$ (BET surface area $=587 \mathrm{~m}^{2} / \mathrm{g}$ ). 


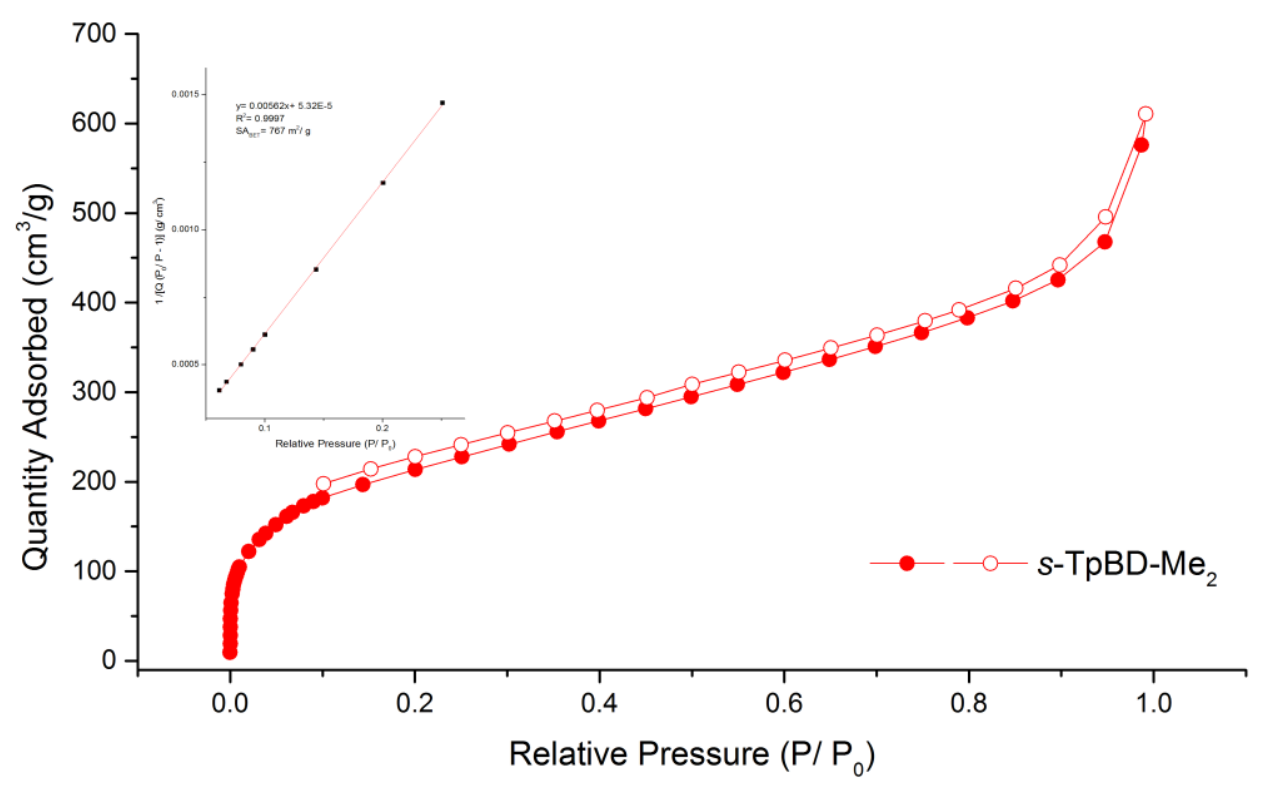

Figure S37. $\mathrm{N}_{2}$ sorption isotherm of $\boldsymbol{s}$-TpBD-Me2 measured at $77 \mathrm{~K}$. (BET Surface area $=767$ $\left.\mathrm{m}^{2} / \mathrm{g}\right)$.

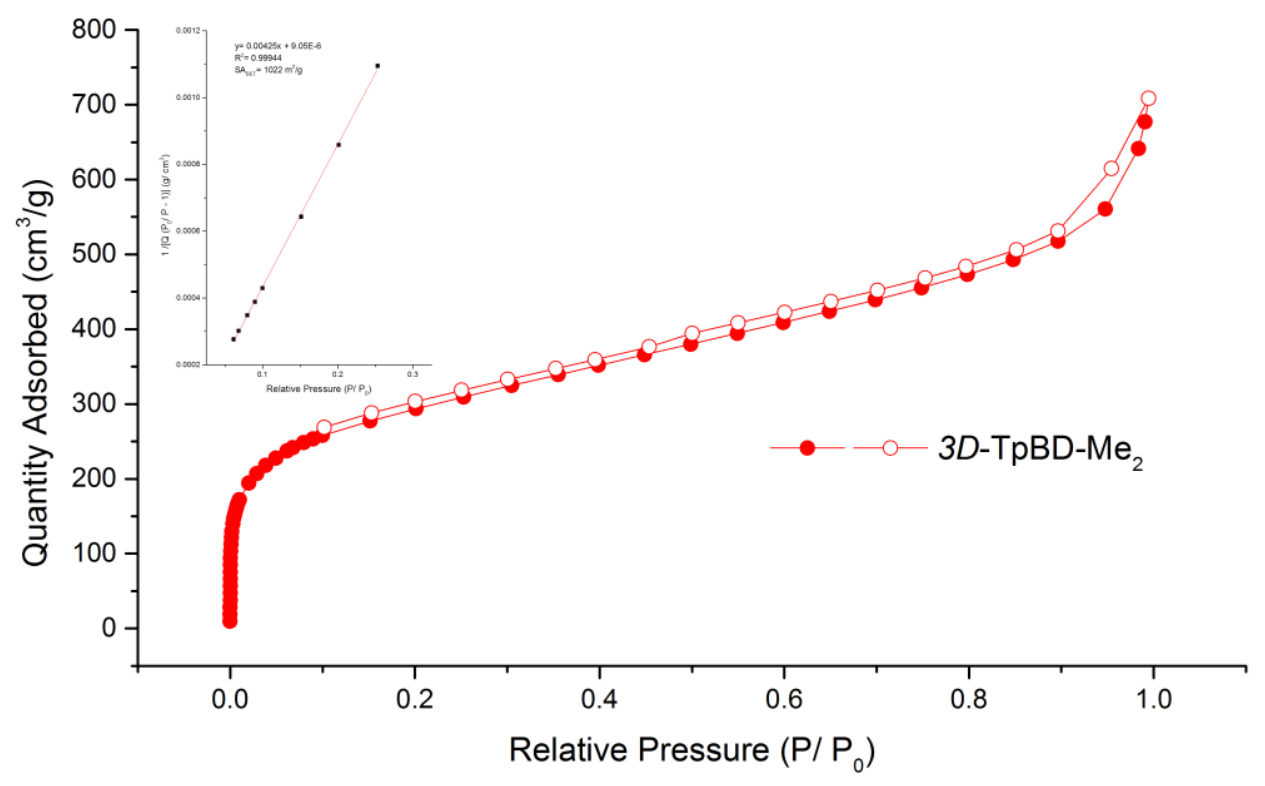

Figure S38. $\mathrm{N}_{2}$ sorption isotherm of $\mathbf{3 D}$-TpBD-Me2 measured at $77 \mathrm{~K}$. (BET Surface area $=1022$ $\left.\mathrm{m}^{2} / \mathrm{g}\right)$. 


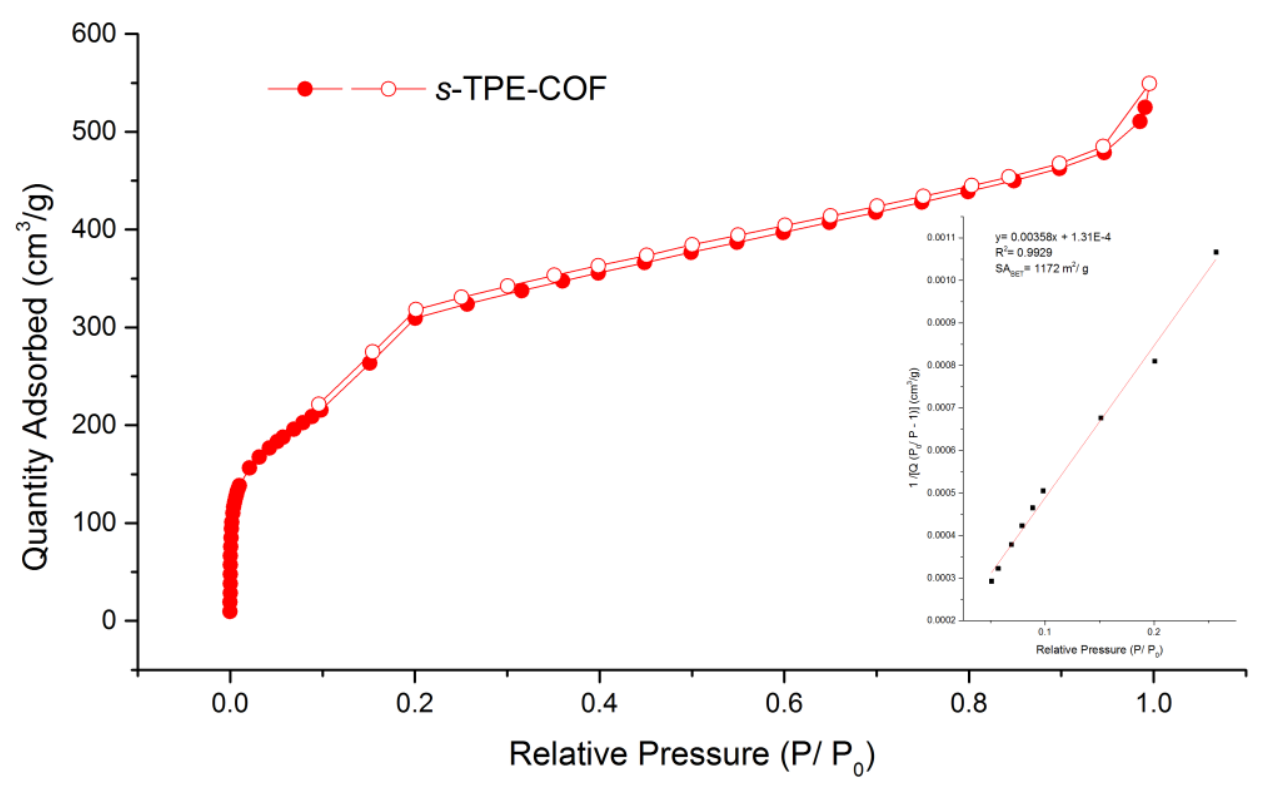

Figure S39. $\mathbf{N}_{2}$ sorption isotherm of $\boldsymbol{s}$-TPE-COF measured at $77 \mathrm{~K}$. (BET Surface area $=1172$ $\left.\mathrm{m}^{2} / \mathrm{g}\right)$.

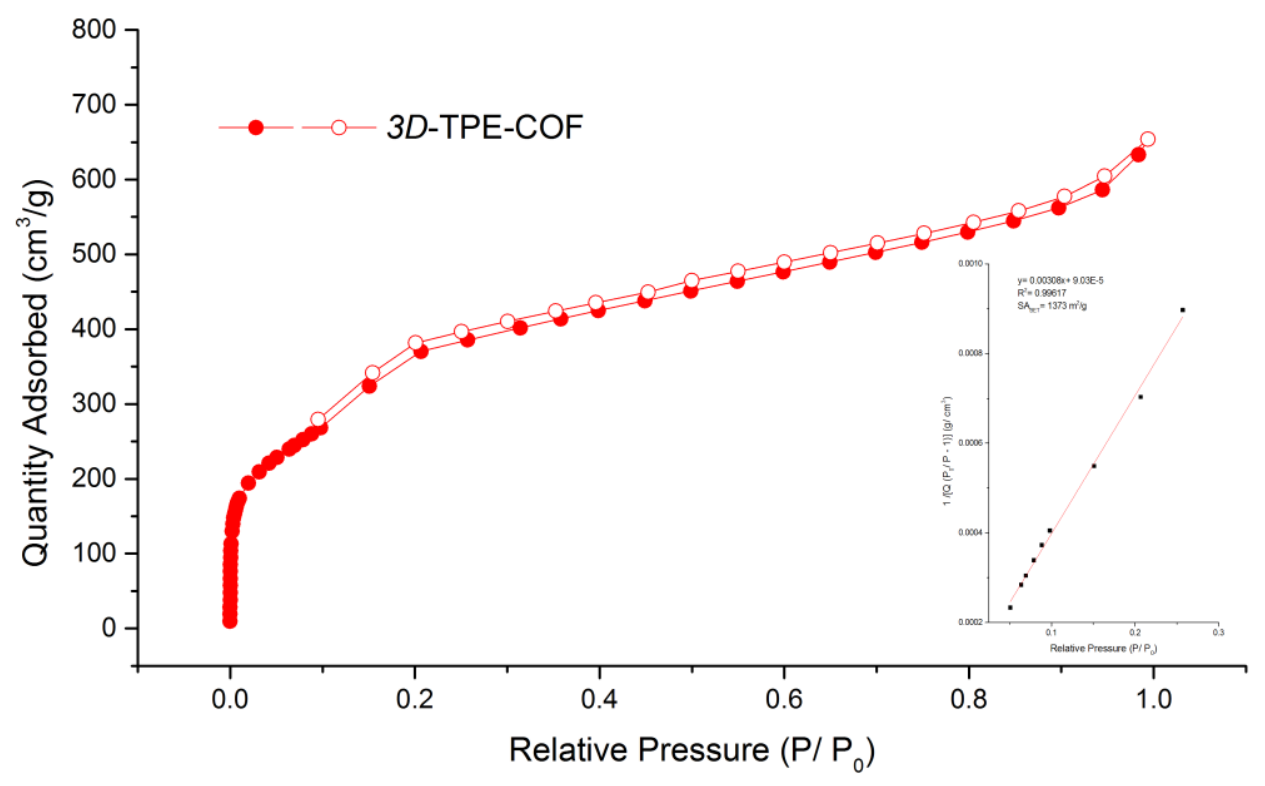

Figure S40. $\mathrm{N}_{2}$ sorption isotherm of 3D-TPE-COF measured at $77 \mathrm{~K}$. (BET Surface area $=1373$ $\left.\mathrm{m}^{2} / \mathrm{g}\right)$. 
S6.2 Pore size distributions

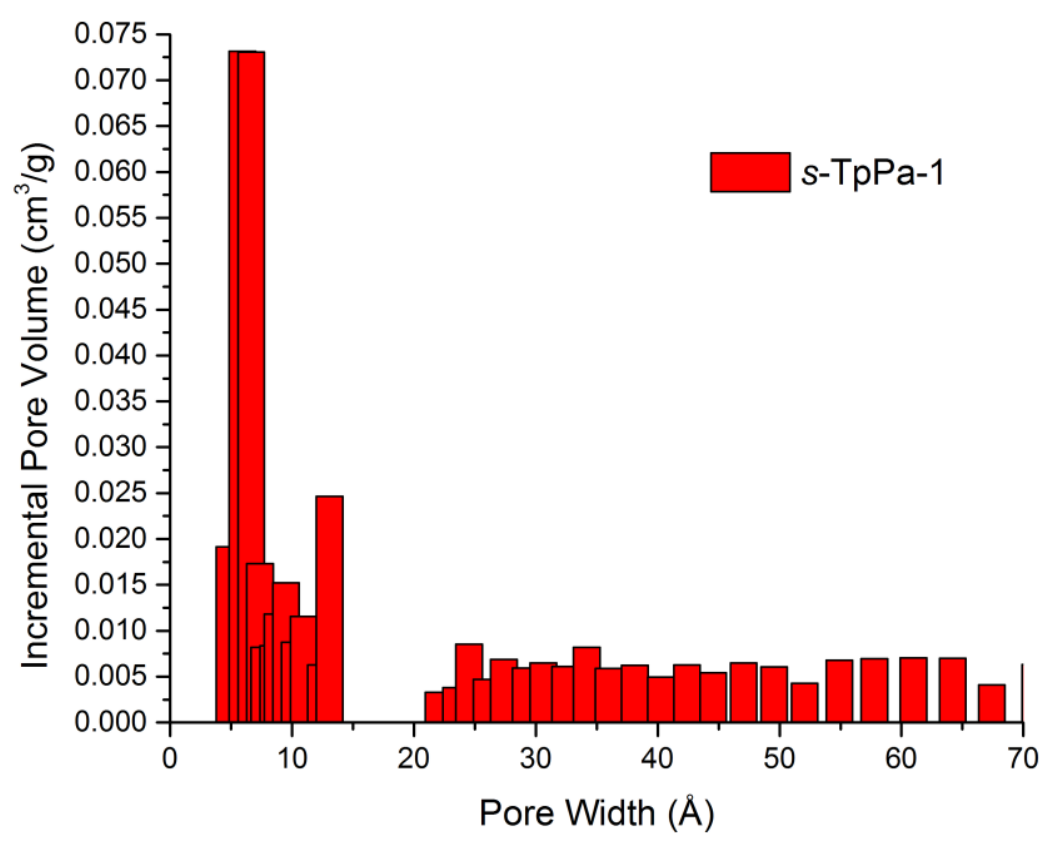

Figure S41. Pore size distribution of $s$-TpPa-1.

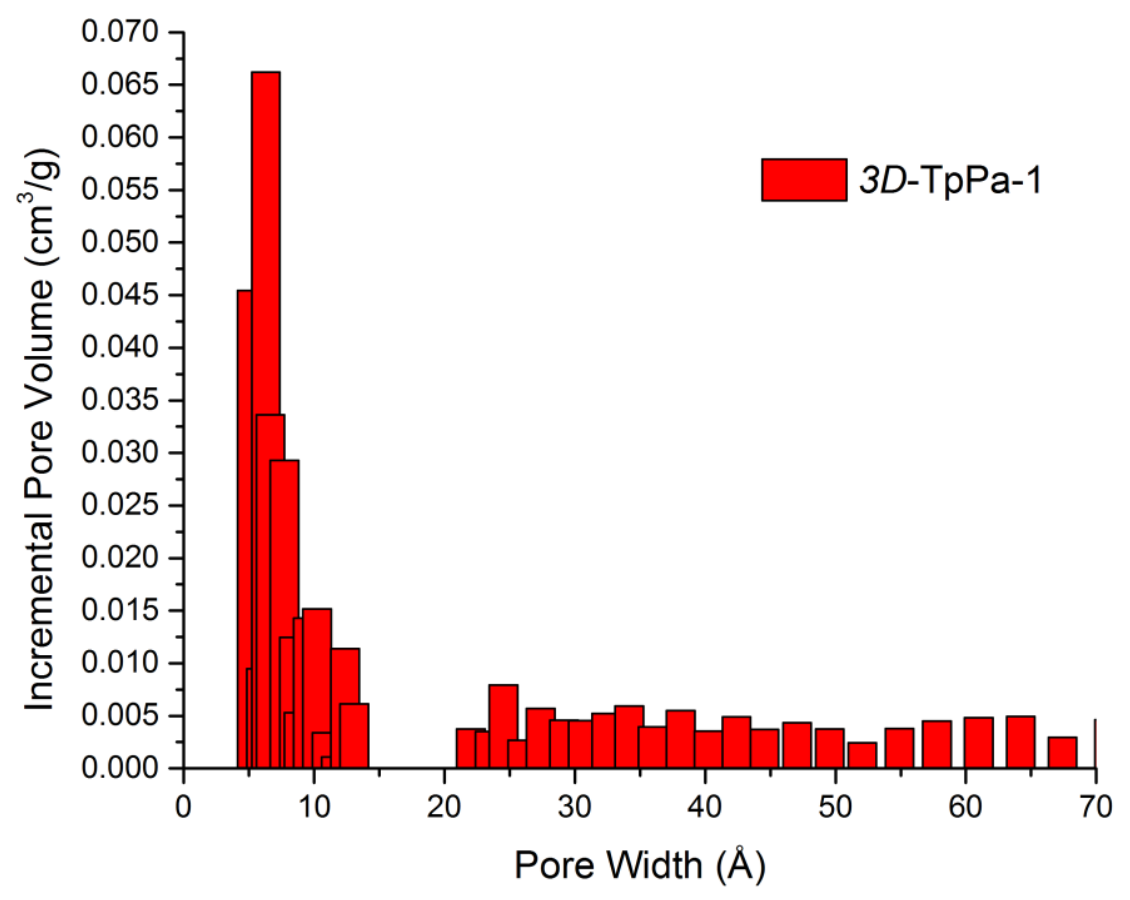

Figure S42. Pore size distribution of 3D-TpPa-1. 


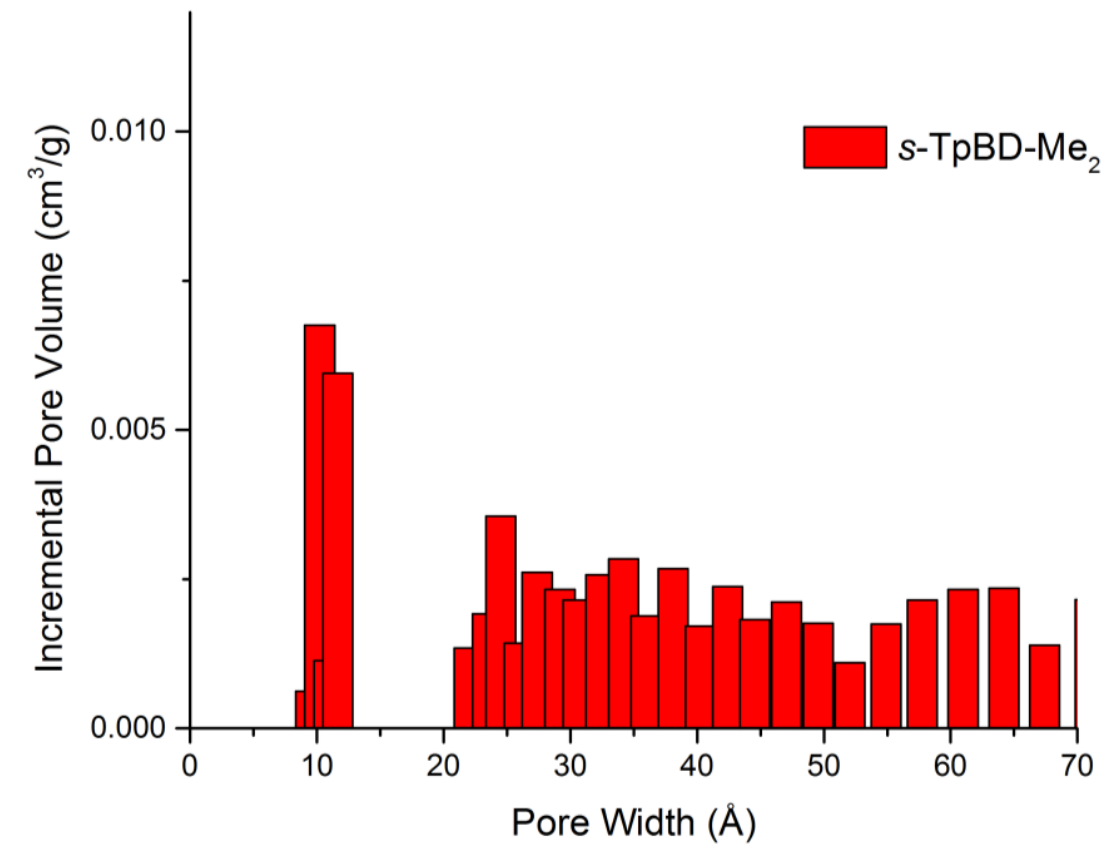

Figure S43. Pore size distribution of $s$-TpBD-Me2.

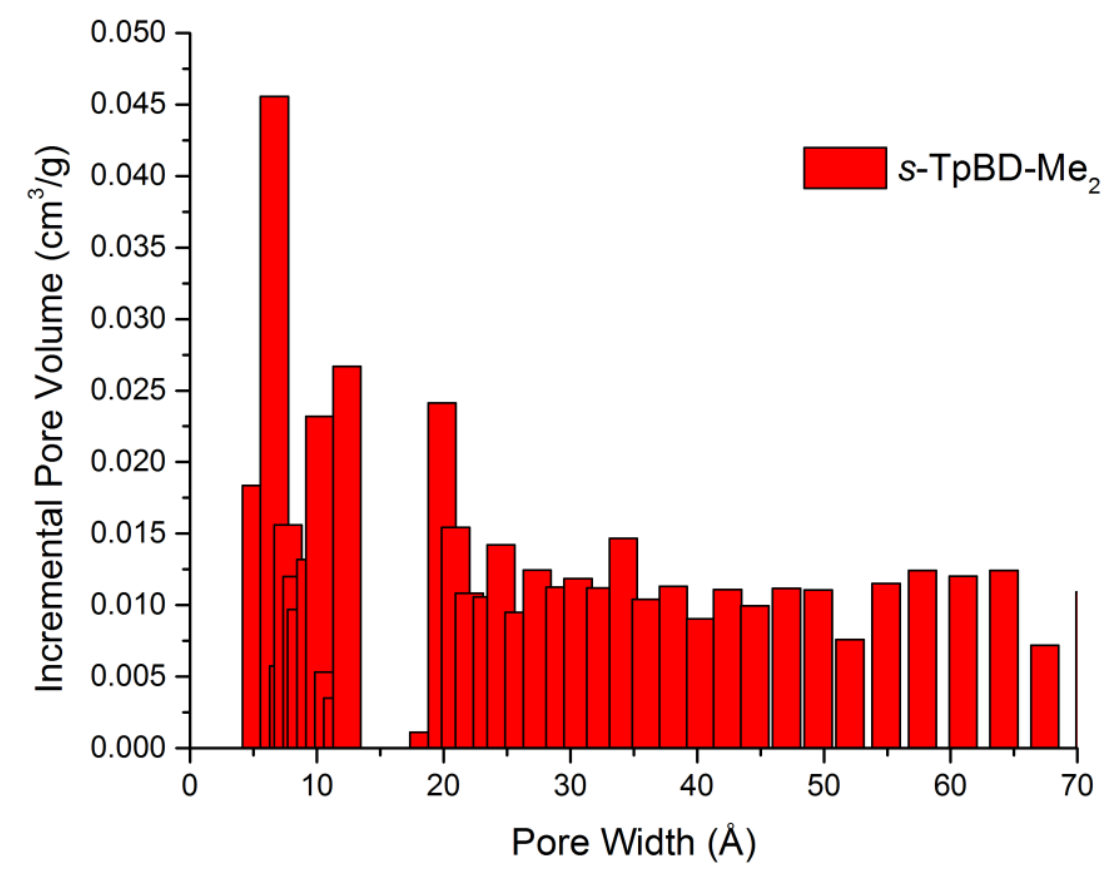

Figure S44. Pore size distribution of 3D-TpBD-Me2 after solvent annealing. 


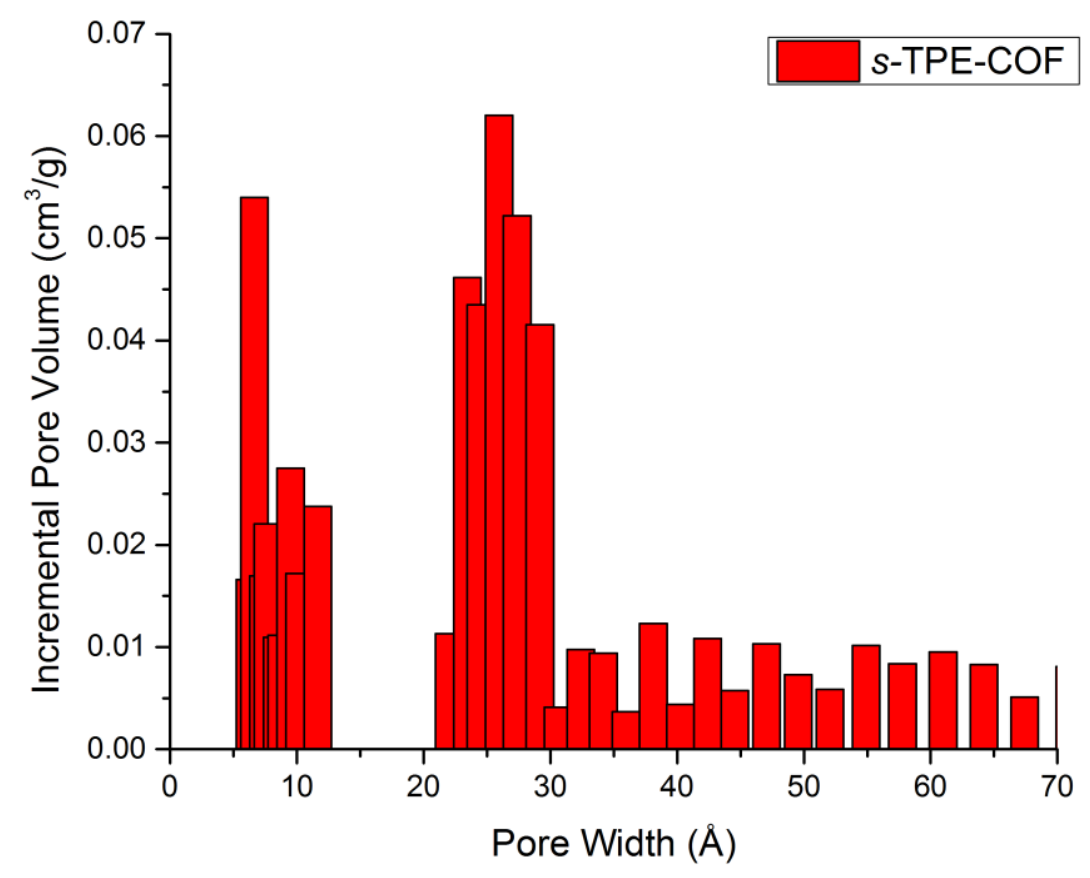

Figure S45. Pore size distribution of $s$-TPE-COF.

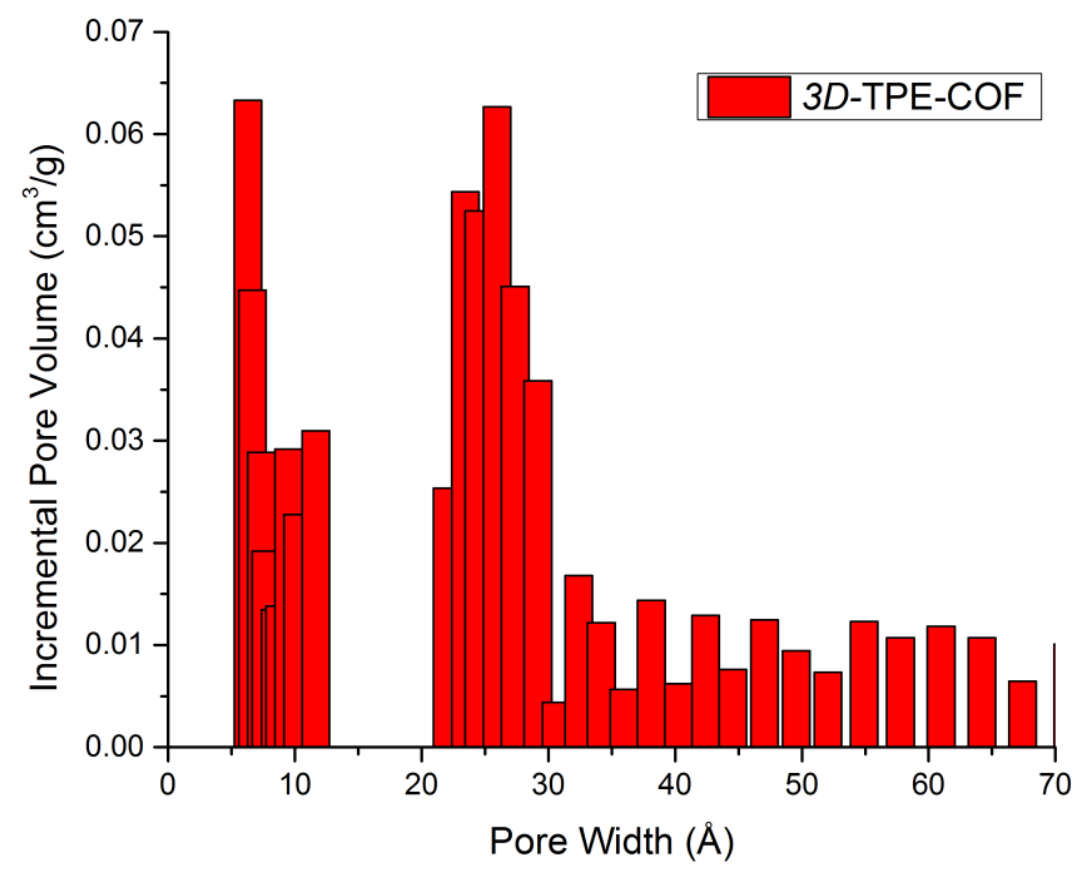

Figure S46. Pore size distribution of 3D-TPE-COF . 
S8. Solid-state NMR Spectra

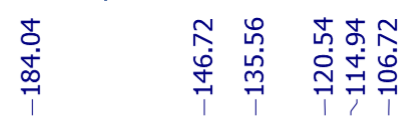

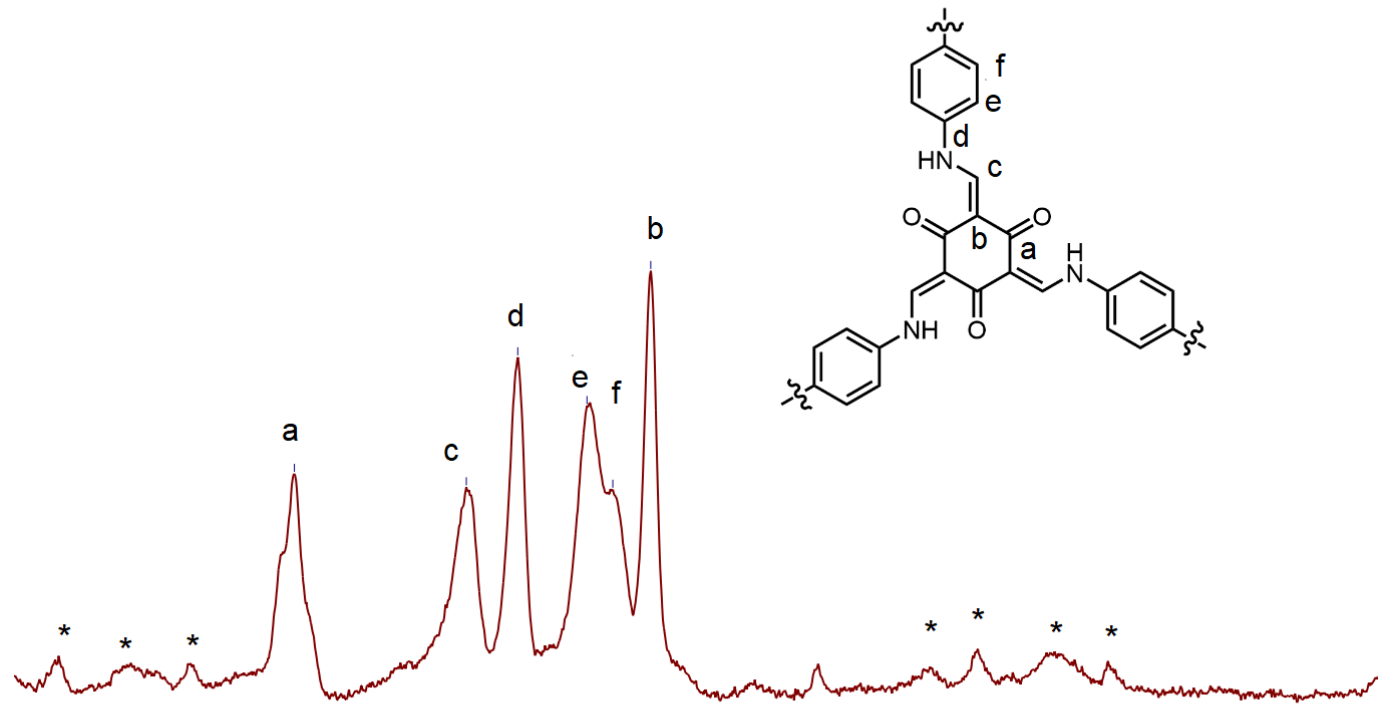

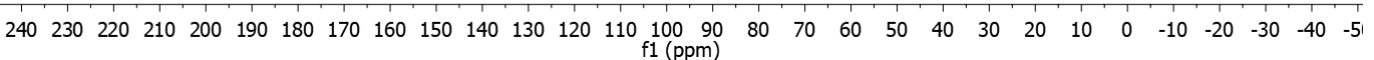

Figure S47. The solid-state ${ }^{13}$ CPMAS NMR spectrum of 3D-TpPa-1. The spin sidebands were marked with a $*$ symbol.

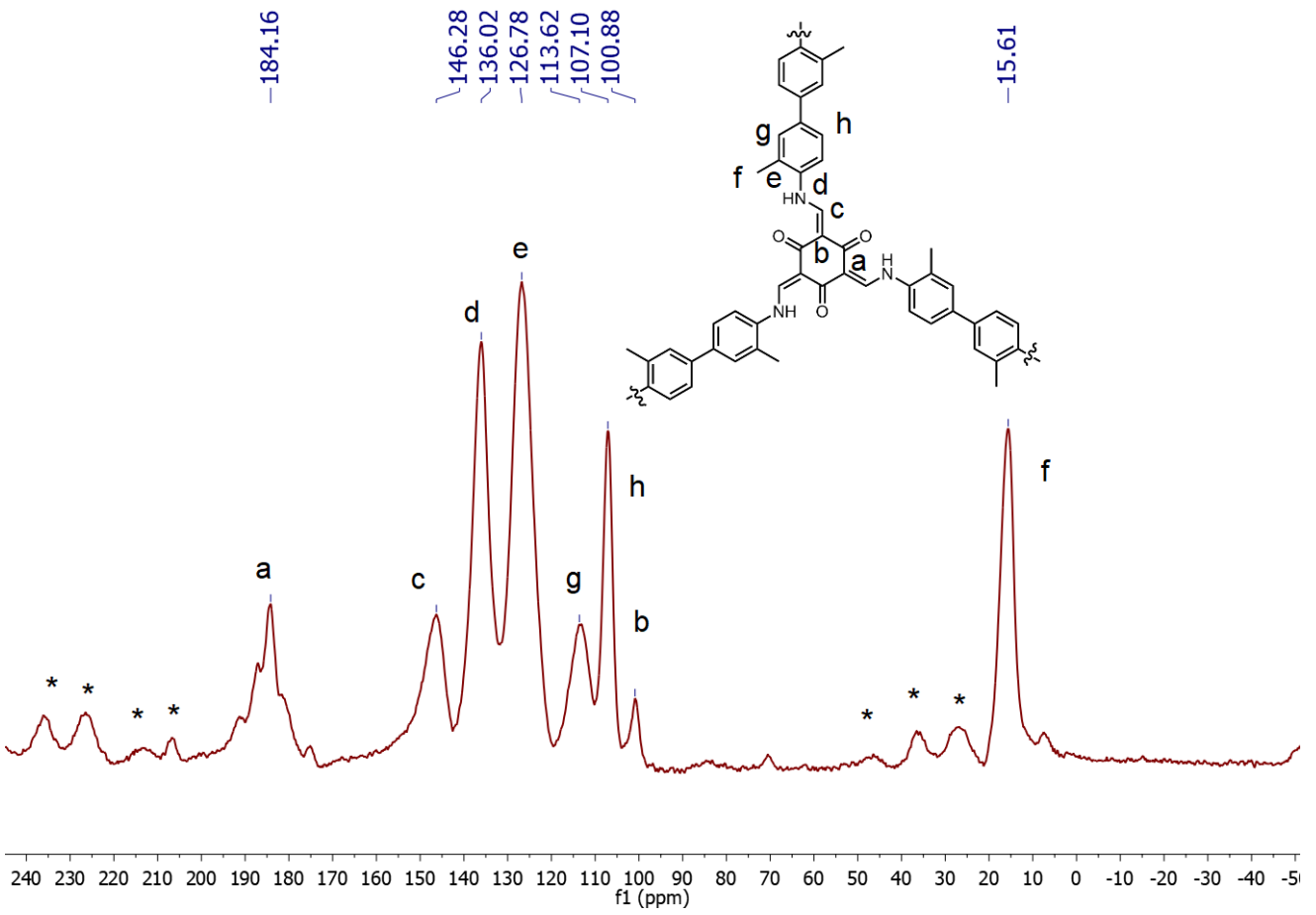

Figure S48. The solid-state ${ }^{13}$ CPMAS NMR spectrum of 3D-TpBD-Me2. The spin sidebands were marked with a $*$ symbol. 


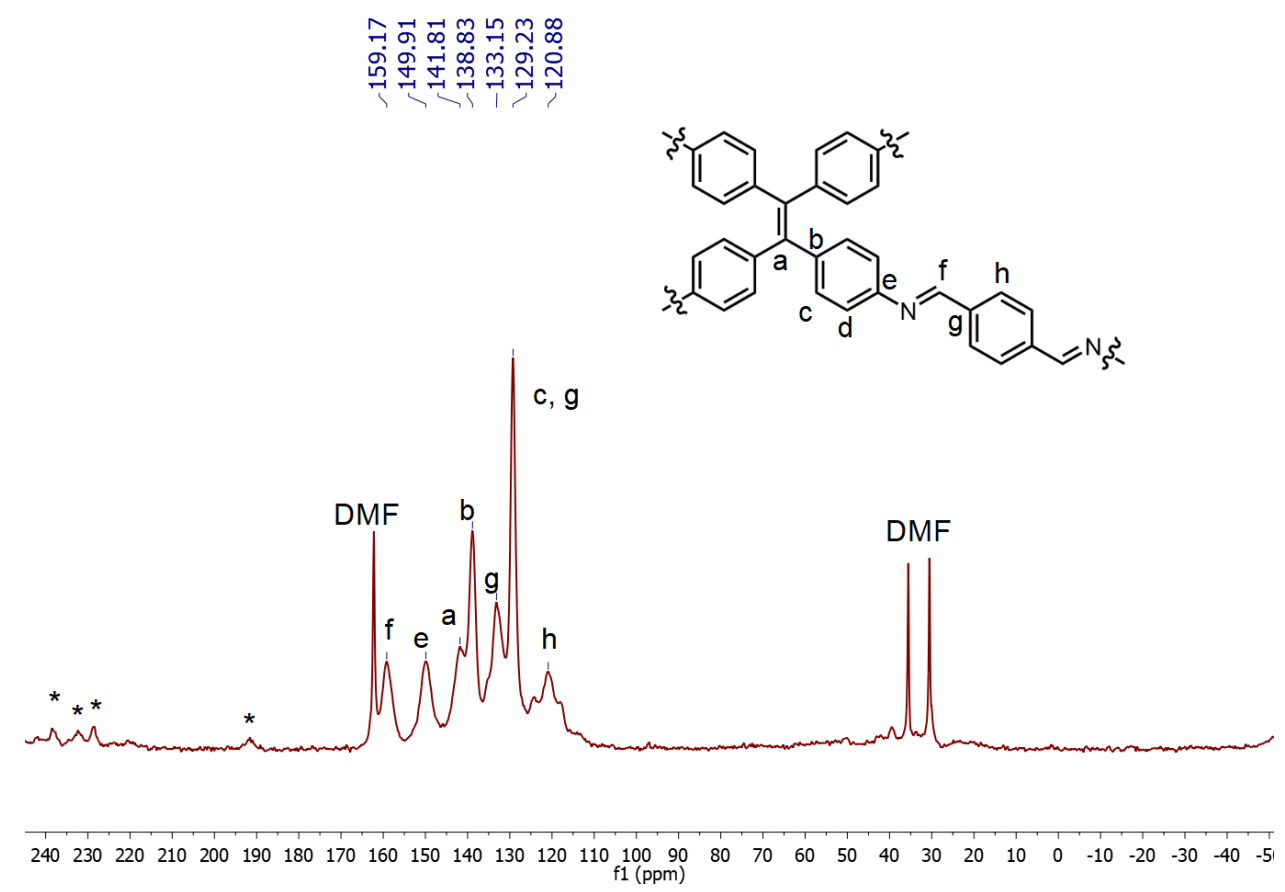

Figure S49. The solid-state ${ }^{13}$ CPMAS NMR spectrum of $3 \boldsymbol{D}$-TPE-COF. The spin sidebands were marked with a $*$ symbol.

(d)

no residual F127 signal

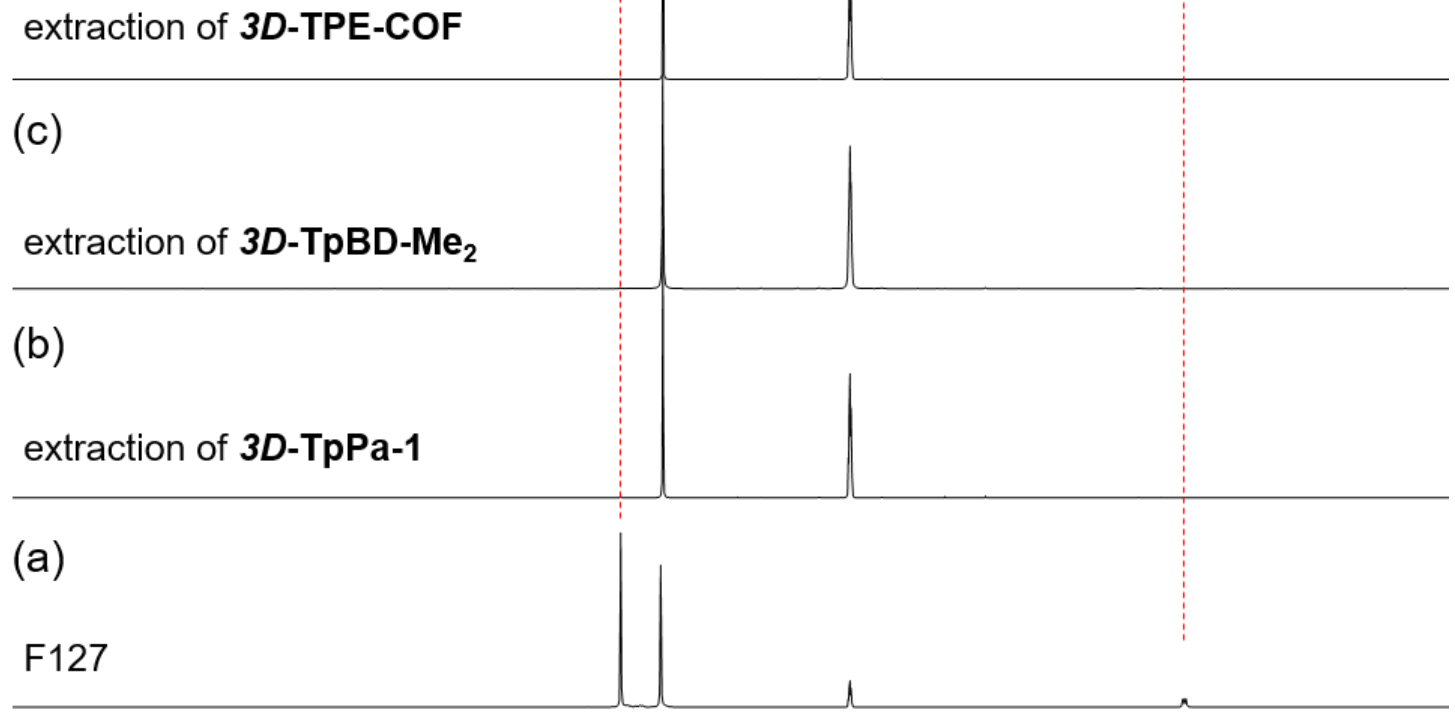

\begin{tabular}{|c|c|c|c|c|c|c|c|c|c|c|c|c|}
\hline 6.0 & 5.5 & 5.0 & 4.5 & 4.0 & 3.5 & $\begin{array}{c}3.0 \\
(\mathrm{ppm})\end{array}$ & 2.5 & 2.0 & 1.5 & 1.0 & 0.5 & 0.0 \\
\hline
\end{tabular}

Figure S50. ${ }^{1} \mathrm{H}$ NMR spectra $\left(500 \mathrm{MHz}, 298 \mathrm{~K}\right.$, DMSO- $\left.d_{6}\right)$ of (a) F127, and (b-d) the extractions of the 3D-printed monoliths. 3D-TpPa-1, 3D-TpBD-Me2, and 3D-TPE-COF were soaked in hot $\left(80{ }^{\circ} \mathrm{C}\right) \mathrm{DMSO}-d_{6}$ for $12 \mathrm{~h}$ before the ${ }^{1} \mathrm{H}$ NMR experiment. No F127 could be extracted from the monolith, indicating a complete removal of F127. 
(S1) Ding, Z.-D.; Wang, Y.-X.; Xi, S.-F.; Li, Y.; Li, Z.; Ren, X.; Gu, Z.-G. A Hexagonal Covalent Porphyrin Framework as an Efficient Support for Gold Nanoparticles toward Catalytic Reduction of 4-Nitrophenol. Chem. Eur. J. 2016, 22, 17029-17036.

(S2) Kandambeth, S.; Mallick, A.; Lukose, B.; Mane, M. V.; Heine, T.; Banerjee, R. Construction of Crystalline 2D Covalent Organic Frameworks with Remarkable Chemical (Acid/Base) Stability via a Combined Reversible and Irreversible Route. J. Am. Chem. Soc. 2012, 134, 19524-19527.

(S3) Chandra, S.; Kandambeth, S.; Biswal, B. P.; Lukose, B.; Kunjir, S. M.; Chaudhary, M.; Babarao, R.; Heine, T.; Banerjee, R. Chemically Stable Multilayered Covalent Organic Nanosheets from Covalent Organic Frameworks via Mechanical Delamination. J. Am. Chem. Soc. 2013, 135, 17853-17861.

(S4) Waller, P. J.; Lyle, S. J.; Osborn Popp, T. M.; Diercks, C. S.; Reimer, J. A.; Yaghi, O. M. Chemical Conversion of Linkages in Covalent Organic Frameworks. J. Am. Chem. Soc. 2016, 138, 15519-15522.

(S5) Al Kayal, T.; Panetta, D.; Canciani, B.; Losi, P.; Tripodi, M.; Burchielli, S.; Ottoni, P.; Salvadori, P. A.; Soldani, G. Evaluation of the Effect of a Gamma Irradiated DBM-Pluronic F127 Composite on Bone Regeneration in Wistar Rat. PLOS ONE 2015, 10, e0125110. 